UNIVERSIDADE DE SÃO PAULO

ESCOLA DE ENGENHARIA DE SÃO CARLOS

DEPARTAMENTO DE HIDRÁULICA E SANEAMENTO

CENTRO DE RECURSOS HÍDRICOS E ECOLOGIA APLICADA

\title{
CARACTERIZAÇÃO AMBIENTAL DA MICROBACIA DO CÓRREGO DA BARRINHA (PIRASSUNUNGA - SP), UTILIZANDO GEOPROCESSAMENTO E O SISTEMA TOPOGRÁFICO LOCAL
}

Engenheiro Agrimensor: REGINALDO MACEDÔNIO DA SILVA Email: macedoniors@yahoo.com

Dissertação apresentada à Escola de Engenharia de São Carlos da Universidade de São Paulo, como parte dos requisitos para obtenção do Título de Mestre em Ciências da Engenharia Ambiental.

Orientadora: Profa. Dra. Maria Lúcia Calijuri

São Carlos

2000 


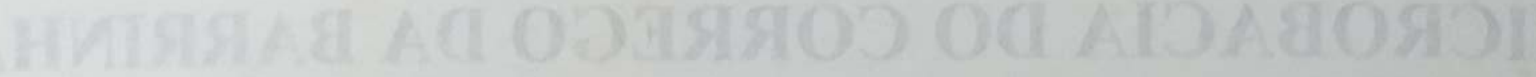 OQVAXIHTU, (92- ADVUИU2ZAЯI9) AMATRE O J OThAMA229009403D UADOI ODIMASDOQOT}

Ficha catalográfica preparada pela Seção de Tratamento da Informação do Serviço de Biblioteca - EESC/USP

$\mathrm{S} 586 \mathrm{C}$

Silva, Reginaldo Macedônio da

Caracterização ambiental da microbacia do Córrego da Barrinha (Pirassununga - SP), utilizando geoprocessamento e o sistema topográfico local / Reginaldo Macedônio da Silva. -- São Carlos, 2000.

Dissertação (Mestrado) -- Escola de Engenharia de São Carlos-Universidade de São Paulo, 2000.

Area: Ciências da Engenharia Ambiental.

orientador: Profa. Dra. Maria Lúcia Calijuri.

1. Sistema de informações geográficas. 2. GPS.

5. Microbacia. 4. Sistema topográfico local.

5. Caracterizaçăo ambiental. I. Título. 


\section{FOLHA DE APROVACÃO}

Candidato: Engenheiro REGINALDO MACEDÔNIO DA SILVA

Dissertação defendida e aprovada em 17-07-2000 pela Comissão Julgadora:

Mavia Suni Oalina

Profa. Titular MAARIA LÚCIA CALIJURI (Orientadora)

(Universidade Federal de Viçosa - UFV)

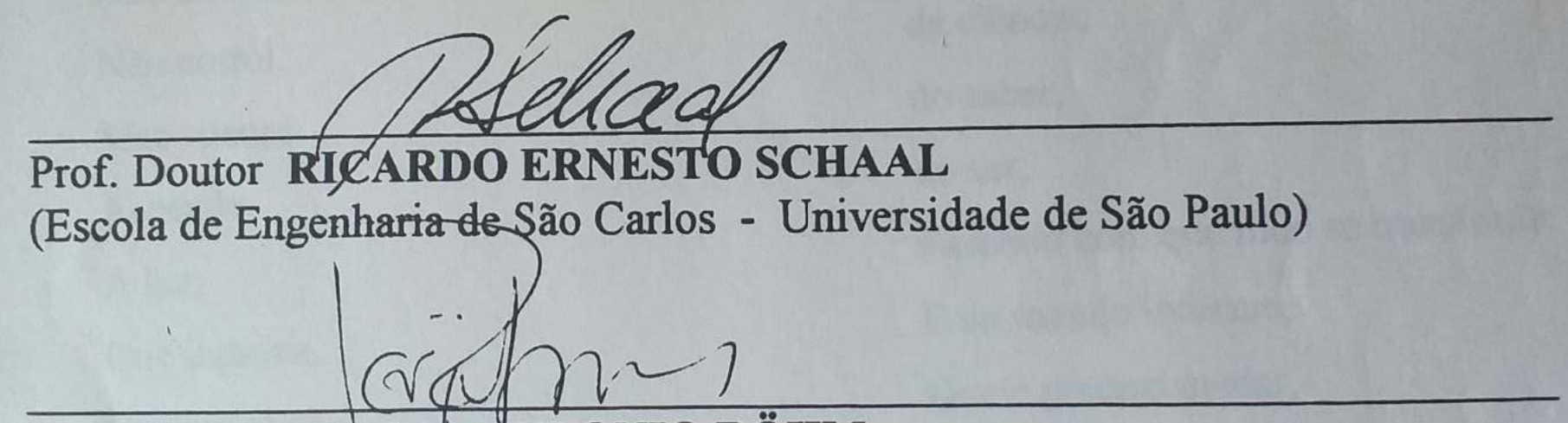

Prof. Doutor SERGIO ANTONIO RÖHM

(Universidade Federal de São Carlos - UFSCar)
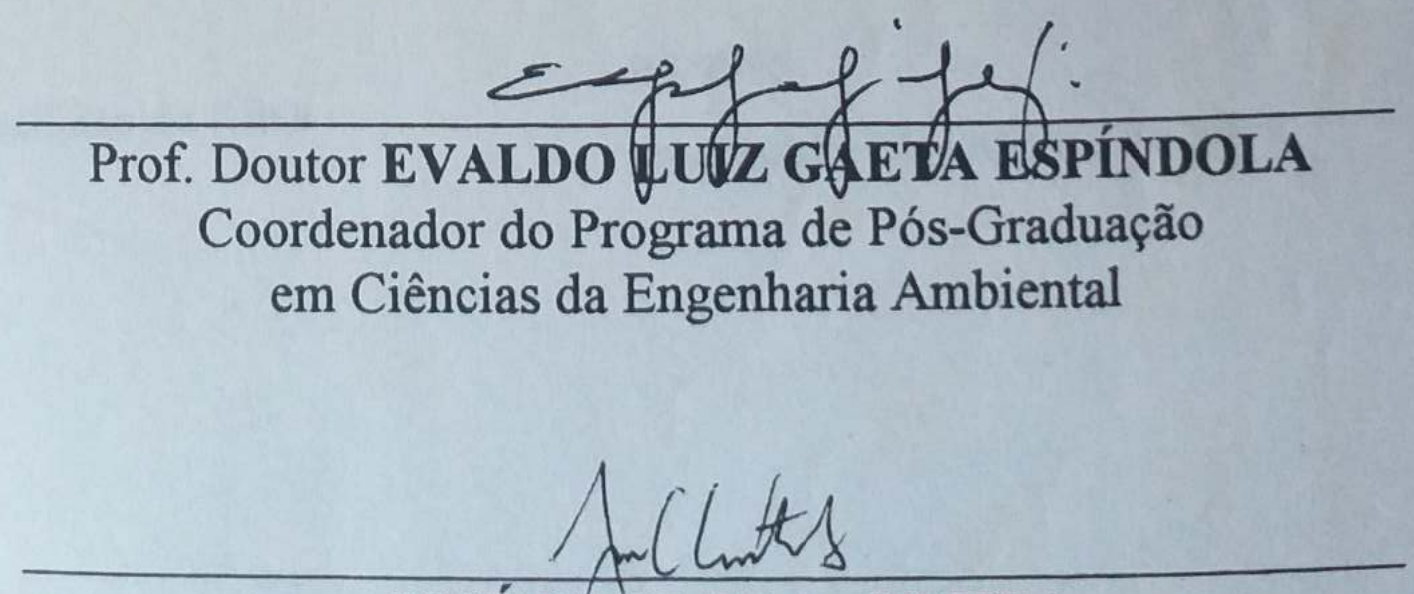

JOSÉ CARLOS A. CINTRA

Presidente da Comissão de Pós-Graduação da EESC 
A minha mãe, pela compreensão e apoio em todas as decisões da minha vida e por me ensinar muito mais do que qualquer livro e à minha irmã que está distante, morando em Portugal. 


\section{AGRADECIMENTOS}

A Deus, por ter me dado muita saúde e força para superar as dificuldades que tive ao longo deste período e pela oportunidade de dar mais um passo nos degraus do conhecimento e da vida.

À minha mãe Josefa Isabel da Silva, pela sua compreensão e apoio nas decisões da minha vida, pois mesmo não tendo oportunidade de ter estudado, me ensinou muito mais do que qualquer livro e mostrou-me com sua sabedoria, paciência e humildade os ensinamentos que a vida lhe deu.

À minha irmã Regineide Pereira da Silva, pelo respeito e união desta família que morou na periferia de São Paulo e que acreditaram em mim, através da educação, onde consegui provar que ser pobre não é sinônimo de "burrice", e em cada obstáculo superado uma nova força para vencer barreiras mais difíceis.

As pessoas Ciclene, Valdirene, Tony, Eva, Rosana, Rosinha e Mara, que me ajudaram quando fui internado no hospital e todos aqueles que me visitaram nesses dias em que estive enfermo.

A família Pantaneira, Valdirene, Tony e Paulino, que me aceitaram como novo morador num momento decisivo da minha vida, pela grande amizade e espírito de luta para conclusão desta dissertação.

Aos Amigos Clóvis, Eva, Ricardo, Raquel, Iracema, Juliana, Maurício Veronez, Cleidilene, Gaspar, Márcia Eller, André Bufon, João Vila, Myrian e Victor pelas dúvidas que tiraram sobre meu trabalho, pelo respeito e amizade.

À minha orientadora Prof ${ }^{\mathrm{a}}$. Dr ${ }^{\mathrm{a}}$. Maria Lúcia Calijuri pela amizade e por acreditar no meu trabalho, dando apoio nas modificações desta dissertação, aprimorando a qualidade e aperfeiçoando o conhecimento. 


\section{AGRADECIMENTOS}

Ao CEPTA/IBAMA pela possibilidade de fazer uma dissertação que não ficasse na prateleira e que servirá de apoio no conhecimento do local onde se encontra.

À CAPES pela bolsa concedida, pois sem este apoio não seria possível a realização deste trabalho devido às minhas condições financeiras.

À todas as pessoas que trabalham no CRHEA (Centro de Recursos Hídricos e Ecologia Aplicada), pelo respeito e amizade e a Claudete pela paciência e dedicação em seu trabalho.

Aos Amigos do laboratório de SIG pelas discussões sobre geoprocessamento e pelo respeito e amizade.

Aos Professores Evaldo Espíndola e Maria do Carmo pela dedicação na Coordenação da Área de Ciências da Engenharia Ambiental e pelo respeito e amizade.

Aos Amigos de Viçosa-MG da turma de 93 do curso de Engenharia de Agrimensura, que mesmo distante me apoiaram na luta para conclusão deste Mestrado, pois o respeito e a amizade prevalecem quando os amigos são verdadeiros.

Aos Amigos Júlio Cézar Alves, Sandro Silveira, Alessandra Lara, Daniela, Marcos Soares e Gustavo Borges pelo respeito e amizade.

À todas as pessoas que contribuíram direta ou indiretamente para realização deste trabalho e mesmo que o nome não esteja aqui, jamais serão esquecidos. 


\section{VITÓRIA}

Nas veias do meu corpo

Flui o sangue

Que me alimenta

E sustenta

A esperança

De lutar

E provar

Para todos

Que a miséria

Não desanima

Não destrói

Não corrói

Mas apenas

Ascende

A luz

Que ilumina

Os caminhos

Da Vitória.

$03 / 1993$

Reginaldo Macedônio da Silva

\section{NADA PERMANECE O MESMO}

Eu já não sou o mesmo

Você já não é o mesmo

As palavras já não são as mesmas

A caneta com que escrevo já não é a mesma

A hora já não é a mesma

As pessoas já não são as mesmas

O tempo já não é o mesmo

Porque tudo é movimento

Assim como este momento

Que no detrimento

da consciência,

da ciência,

do saber,

do ser

Fazendo com que tudo se transforme

$\mathrm{E}$ ao mundo informe

Que é preciso mudar

Para que possamos avançar

E o futuro conquistar.

\section{5/1993}

Reginaldo Macedônio da Silva 


\section{RESUMO}

SILVA, R M. (2000) - Caracterização Ambiental da Microbacia do Córrego da Barrinha (Pirassununga - SP), Utilizando Geoprocessamento e o Sistema Topográfico Local. São Carlos, 120p. Dissertação (Mestrado) - Escola de Engenharia de São Carlos, Universidade de São Paulo.

O objetivo do trabalho foi sistematizar informações e criar uma caracterização ambiental da microbacia do Córrego da Barrinha, utilizando geoprocessamento e adotando como sistema de referência o Sistema Topográfico Local. A área de estudo está localizada na região do CEPTA/IBAMA em Pirassununga, abrangendo um total de aproximadamente 860 hectares. Utilizou-se como layers para a caracterização ambiental, informações sobre Geologia, Hidrografia, Uso e Ocupação do Solo e Curvas de Nível. Os dados cartográficos foram digitalizados em mesa digitalizadora, sendo utilizados pontos de controle levantados com GPS geodésico para georreferenciar o mapa aerofotogramétrico restituído. Essas coordenadas foram convertidas posteriormente para um Sistema Topográfico Local. A manipulação dos dados digitalizados foi executada no Sistema de Informações Geográficas (SIG), IDRISI, onde se fez as análises espaciais, sobrepondo as informações. Dessas análises obtiveram-se como resultado quatro mapas temáticos de integração dos dados. Pôde-se observar nos mapas temáticos que a região tem predomínio de atividade agrícola com $46,5 \%$ da área total, e nas áreas de faixa de mata ciliar tem maior abrangência, como atividade antrópica, as culturas temporárias (algodão, soja e milho). Uma outra atividade degradante na região é a mineração de saibro e areia, que ocorre próximo da mata ciliar. A região tem como características em sua maior parte um relevo plano, com $65,2 \%$ do total e uma variação de 0 a $3 \%$, predominando na região um solo arenoso, com formação geológica composta pela Formação Pirassununga. No mapa temático de criticidade observou-se que as regiões de maiores criticidades estão localizadas ao longo do leito do Córrego da Barrinha. Finalmente pôde-se analisar os problemas de degradação ambiental da microbacia, levantar as características ambientais predominante na área de estudo, usando como ferramenta de estudo o SIG, e o georreferenciamento em um Sistema Topográfico Local.

Palavras Chaves: Sistema de Informações Geográficas, GPS, Microbacia, Sistema Topográfico Local, Caracterização Ambiental 
ABSTRACT

SILVA, R M. (2000) - Environment Characterization of the Barrinha Stream Microbasin (Pirassununga, SP), Using Geoprocessing and the Local Topographic System. São Carlos, 120p. Master Dissertation - Engineering School of São Carlos, University of São Paulo.

Main objectives were to systematize information and to propose an environmental characterization of the Barrinha Stream microbasin, using geoprocessing and local topographical system as the reference system. The nearly 860 ha study site is located in the CEPTA/IBAMA area at Pirassununga, São Paulo State. Information on geology, hidrography, soil use and occupation, and level curves were used as layers for the environmental characterization. Cartographic data were processed in digitizing table, geodesic GPS control points were used for georeferencing the restored aerial photogrammetric map. Such coordinates were converted into a local topographical system. Manipulation of digitized data was carried out by the Geographical Information System (GIS), IDRISI, where spatial analyses were made by information overlapping. Four data integration thematic maps were obtained. Prevalence of agricultural activity (46,5\% of the total area), and large inclusion of temporary cultures (cotton, soy and corn) along the gallery forest were observed as main antrophic activities. Another degrading activity in the area was represented by "saibro" and sand mining, occurring near by the gallery forest. The major part of the area $(65,2 \%)$ has a plane relief, and a variation from 0 to $3 \%$, prevailing sandy soil, with geologic formation composed by the "Formação Pirassununga". Critic thematic map showed that the most critical areas are located along the Barrinha Stream bed. Finally, the use of GIS, and geoprocessing information in a local topographical system allowed the evaluation of the environmental degradation problems of the microbasin, and the survey of the dominant environmental characteristics in the study area.

Key words: Geographic Information System, GPS, Microbasin, Local Topographic System, Environmental Characterization. 


\section{LISTA DE FIGURAS}

Figura 01 - Rio Mogi-Guaçú - Barragem em Cachoeira de Emas..............................2

Figura 02 - Portão de Entrada do Cepta - Ibama.......................................................2

Figura 03 - Etapas da Gestão Ambiental.............................................................25

Figura 04 - Arquitetura de Sistemas de Informação Geográfica...............................32

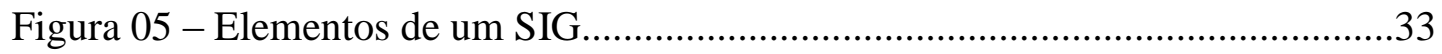

Figura 06 - Modelos de Representação do SIG........................................................35

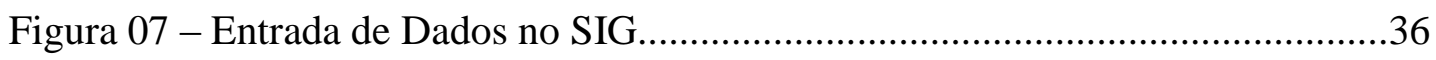

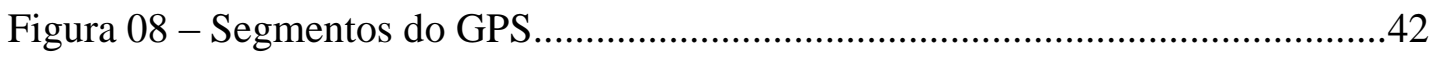

Figura 09 - Segmento Espacial - Constelação GPS.................................................43

Figura 10 - Segmento de Controle Terrestre...........................................................44

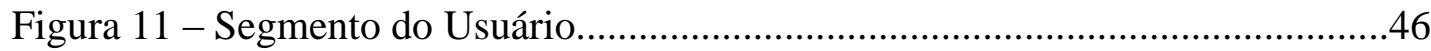

Figura 12 - Região Central de Pirassununga.............................................................47

Figura 13 - Localização da Área de Estudo...........................................................49

Figura 14 - Vista Interna da Lagoa do Cepta (IBAMA) em Pirassununga.................50

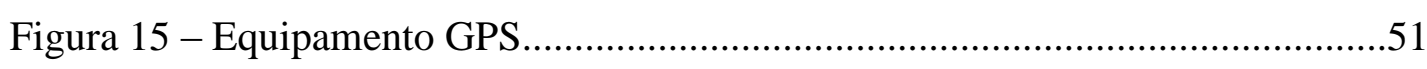

Figura 16 - Elementos do Sistema Topográfico Local..........................................54

Figura 17 - Origem do Sistema Topográfico Local e Distância Máxima a Esta

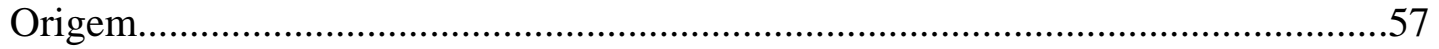

Figura 18 - Informações Retiradas do Mapa Aerofotogramétrico Restituído.............59

Figura 19 - Informações Retiradas do Mapa Geológico...........................................60

Figura 20 - Ponto Pref1 - Um dos Pontos de Controle do Mapa Aerofotogramétrico Restituído.

Figura 21 - Cepta1 (Ponto GPS Utilizado como Ponto de Origem do Sistema

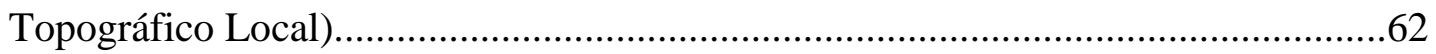

Figura 22 - Pontos de Controle do Mapa Geológico...................................................63 
Figura 23 - Diagrama de Integração das Informações.........................................72

Figura 24 - Mapa de Buffers de Distância da Hidrografia.........................................73

Figura 25 - Mapa de Uso e Ocupação do Solo Atualizado........................................74

Figura 26 - Mapa de Uso e Ocupação do Solo Desatualizado.....................................75

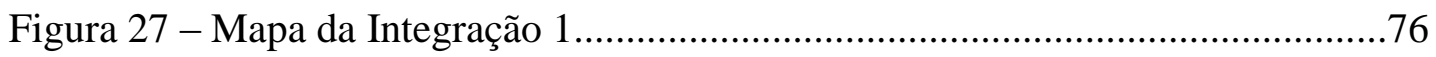

Figura 28 - Porcentagem das Áreas do Mapa da Integração 1.................................77

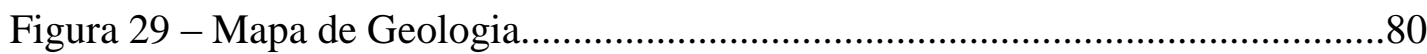

Figura 30 - Porcentagem dos Tipos de Formação Geológica....................................81

Figura 31 - Porcentagem das Áreas do Mapa de Uso e Ocupação do Solo

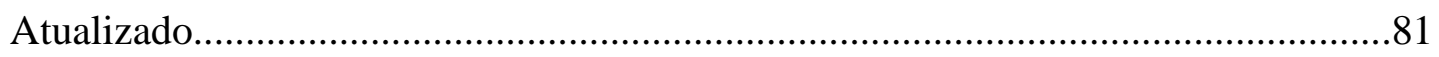

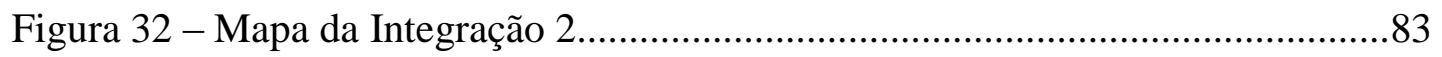

Figura 33 - Porcentagem das Áreas do Mapa da Integração 2................................8 84

Figura 34 - Plantação de Algodão em Solo Arenoso Próximo da Nascente...............85

Figura 35 - Latossolo Roxo Próximo Do Rio Mogi Guaçú........................................87

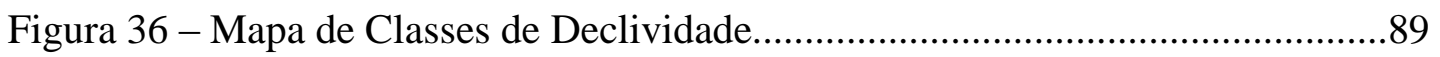

Figura 37 - Mapa do Modelo de Sombreamento.....................................................90

Figura 38 - Porcentagem por Classe de Declividade.............................................91

Figura 39 - Mapa da Integração 3 .....................................................................92

Figura 40 - Porcentagem das Áreas do Mapa da Integração 3 ..................................93

Figura 41 - Modelo Digital de Terreno com as Classes de Declividade....................95

Figura 42 - Modelo Digital de Terreno Gerado no Surfer........................................96

Figura 43 - Porcentagem das Áreas do Mapa da Integração 4..................................99

Figura 44 - Mapa da Integração 4.......................................................................100

Figura 45 - Pontos Utilizados para Avaliação........................................................103

Figura 46 - Foto da Localização do Ponto 2 ............................................................104 
TABELA 1 - Número de Áreas Protegidas na América do Sul..................................12

TABELA 2 - Unidades de Conservação no Brasil e suas Respectivas Áreas............15

TABELA 3 - Classificação Internacional de Unidades de Conservação.....................16

TABELA 4 - Matriz de Objetivos da Gestão e Categorias de Unidades de

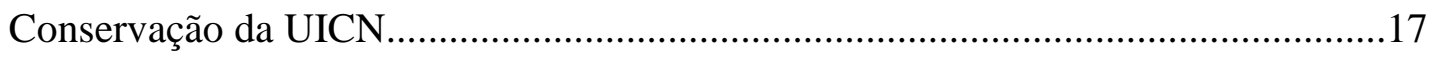

TABELA 5 - Áreas de Proteção Ambiental no Estado de São Paulo - Propostas de

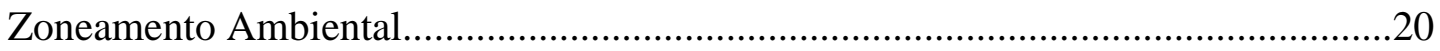

TABELA 6 - Pontos de Controle........................................................................61

TABELA 7 - Coordenadas Convertidas para o Sistema Topográfico Local..............62

TABELA 8 - Coordenadas Convertidas de Córrego Alegre para SAD69.................63

TABELA 9 - Coordenadas Convertidas para o Sistema Topográfico Local.............64

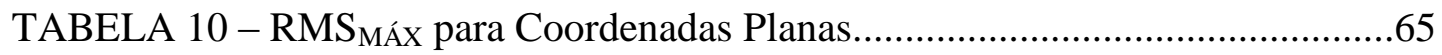

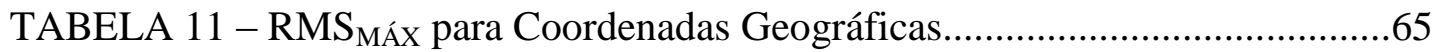

TABELA 12 - Topologia dos Mapas Digitalizados..................................................66

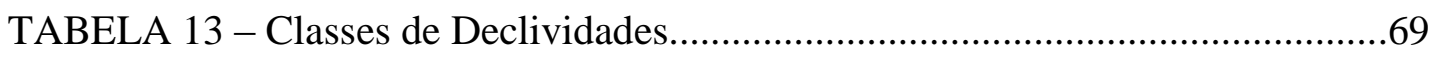

TABELA 14 - Faixas Marginal de Reserva Permanente..........................................69

TABELA 15 - Atividades Antrópicas na Faixa de Mata Ciliar.................................78

TABELA 16 - Critério Adotado para o Uso e Ocupação do Solo Atualizado............82

TABELA 17 - Resultado das Classes do Mapa da Integração 2...............................82

TABELA 18 - Agrupamento das Classes de Uso e Ocupação do Solo Atualizado...97

TABELA 19 - Peso das Classes de Uso e Ocupação do Solo Atualizado e

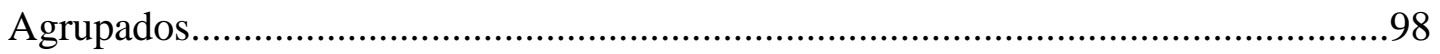

TABELA 20 - Peso do Mapa de Classes de Declividade..........................................98

TABELA 21 - Coordenadas Levantadas em Campo e seus Respectivos Erros.......102 


\begin{tabular}{|c|c|}
\hline AFA & - Academia da Força Aérea \\
\hline $\mathrm{AM}$ & - Amplitude Modulada \\
\hline APA & - Área de Proteção Ambiental \\
\hline ARIE & - Área de Relevante Interesse Ecológico \\
\hline AS & - Anti Spoofing \\
\hline $\mathrm{C} / \mathrm{A}$ & - Coarse Acquisition code \\
\hline CEPTA & - Centro Nacional de Pesquisa de Peixes Tropicais \\
\hline CONAMA & - Conselho Nacional do Meio Ambiente \\
\hline DPI & - Dots Per Inch \\
\hline ESEC & - Estação Ecológica \\
\hline EUA & - Estados Unidos da América \\
\hline FLONA & - Floresta Nacional \\
\hline FM & - Freqüência Modulada \\
\hline GPS & - Global Positioning System \\
\hline GUI & - Graphical User Interface \\
\hline \multirow[t]{2}{*}{ IBAMA } & - Instituto Brasileiro do Meio Ambiente e dos Recursos \\
\hline & Naturais Renováveis \\
\hline IBGE & - Instituto Brasileiro de Geografia e Estatística \\
\hline IGC & - Instituto Geográfico e Cartográfico \\
\hline NAVSTAR & - Navigation System with Time and Ranging \\
\hline NBR & - Norma Brasileira Registrada \\
\hline ONGs & - Organizações Não Governamentais \\
\hline OSW & - Open Survey World \\
\hline $\mathrm{P}$ & - Precise Code \\
\hline PPS & - Precise Positioning Service \\
\hline
\end{tabular}




$\begin{array}{ll}\text { RBMC } & \text { - Rede Brasileira de Monitoramento Contínuo } \\ \text { RE } & \text { - Reserva Ecológica } \\ \text { REBIO } & \text { - Reserva Biológica } \\ \text { RESEX } & \text { - Reserva Extrativista. } \\ \text { RMS } & \text { - Root Mean Square Error } \\ \text { SA } & \text { - Selective Availability } \\ \text { SAD69 } & \text { - South American Datum 1969 } \\ \text { SGB } & \text { - Sistema Geodésico Brasileiro } \\ \text { SGDB } & \text { - Sistema de Gestão de Bases de Dados Relacional } \\ \text { SIGs } & \text { - Sistemas de Informações Geográficas } \\ \text { SIRGAS } & \text { - Sistema de Referência Geocêntrico para a América Latina } \\ \text { SMA } & \text { - Secretaria do Meio Ambiente } \\ \text { SPS } & \text { - Standard Positioning Service } \\ \text { UCs } & \text { - Unidades de Conservação } \\ \text { UICN } & \text { - União Internacional Para a Conservação da Natureza e dos } \\ & \text { - Recursos Naturais } \\ \text { USP } & \text { - Universidade de São Paulo } \\ \text { UTM } & \text { - Universe Transverse Mercator } \\ \text { WGS84 } & \text { - World Geodesic System 1984 } \\ \text { ZEE } & \text { ZPVS }\end{array}$




\section{LISTA DE SÍMBOLOS}

\begin{tabular}{|c|c|}
\hline$X$ & - Abscissa Cartesiana Geodésica \\
\hline $\mathrm{Y}$ & - Ordenada Cartesiana Geodésica \\
\hline $\mathrm{Z}$ & - Altura Cartesiana Geodésica \\
\hline $\mathrm{f}_{0}$ & - Freqüência Fundamental \\
\hline Mhz & - Megahertzs \\
\hline $\mathrm{Km}$ & - Quilômetro \\
\hline OA, & $\begin{array}{l}\text { - É a Projeção Ortogonal de OA sobre o Plano Topográfico } \\
\text { Local }\end{array}$ \\
\hline OB ${ }^{\prime,}$ & $\begin{array}{l}\text { - É a Projeção Ortogonal de OB sobre o Plano Topográfico } \\
\text { Local }\end{array}$ \\
\hline A"'A" & $\begin{array}{l}\text { - É o Erro Devido à Desconsideração da Curvatura Terrestre } \\
\text { de OA }\end{array}$ \\
\hline $\mathrm{B}^{\prime, '} \mathrm{~B}$, & $\begin{array}{l}\text { - É o Erro Devido à Desconsideração da Curvatura Terrestre } \\
\text { de OB }\end{array}$ \\
\hline OA" & $\begin{array}{l}\text { - É a Representação do Arco OA sobre o Plano Topográfico } \\
\text { Local }\end{array}$ \\
\hline OB” & $\begin{array}{l}\text { - É a Representação do Arco OB sobre o Plano Topográfico } \\
\text { Local }\end{array}$ \\
\hline $\mathrm{AB}$ & $\begin{array}{l}\text { - É a Projeção Gnomônica ou Central de uma Distância (ab) } \\
\text { Medida no Terreno, sobre a Superfície do Nível Médio do } \\
\text { Terreno, Correspondendo à Distância Horizontal entre "a" e } \\
\text { "b” }\end{array}$ \\
\hline$A^{\prime} B^{\prime}$ & $\begin{array}{l}\text { - É a Projeção Gnomônica ou Central de AB sobre a } \\
\text { Superfície da Esfera de Adaptação de Gauss (superfície de } \\
\text { nível zero) }\end{array}$ \\
\hline
\end{tabular}




\begin{tabular}{|c|c|}
\hline$A^{\prime \prime} B^{\prime \prime}$ & $\begin{array}{l}\text { - É a Projeção (representação) em Verdadeira Grandeza de AB } \\
\text { sobre o Plano Topográfico Local }\end{array}$ \\
\hline$H_{\mathrm{t}}$ & - Altitude Ortométrica \\
\hline$X$ & - Abscissa Plano-Retangular \\
\hline$Y$ & - Ordenada Plano-Retangular \\
\hline$c$ & - Corresponde ao Fator de Elevação, Adimensional \\
\hline$H_{\mathrm{t}}$ & - Corresponde à Altitude Ortométrica média do terreno \\
\hline$R_{\mathrm{m}}$ & $\begin{array}{l}\text { - Corresponde ao Raio Médio Terrestre igual a } \sqrt{M \cdot N} \text {, } \\
\text { adotado como raio da esfera de adaptação de Gauss }\end{array}$ \\
\hline$M$ & $\begin{array}{l}\text { - Corresponde ao Raio de Curvatura da Elipse Meridiana do } \\
\text { Elipsóide de Referência na Origem do Sistema Topográfico } \\
\text { Local }\end{array}$ \\
\hline $\mathrm{a}$ & - Semi Eixo Maior do Elipsóide \\
\hline$e^{2}$ & - Quadrado da Primeira Excentricidade do Elipsóide \\
\hline$\phi 1$ & - Latitude Geodésica do Ponto 1 \\
\hline$N$ & - Corresponde ao Raio de Curvatura da Elipse Normal à Elipse \\
\hline & Meridiana na Origem do Sistema Topográfico Local \\
\hline$\phi$ & - Latitude Geodésica de um ponto qualquer \\
\hline$\lambda$ & - Longitude Geodésica de um ponto qualquer \\
\hline $\mathrm{h}$ & - Altitude Ortométrica de um ponto qualquer \\
\hline $\mathrm{X}_{\mathrm{O}}$ & - Abscissa de Origem do Sistema Topográfico Local \\
\hline $\mathrm{Y}_{0}$ & - Ordenada de Origem do Sistema Topográfico Local \\
\hline ha & - Hectare \\
\hline
\end{tabular}




\section{SUMÁRIO}

LISTA DE FIGURAS.............................................................................................

LISTA DE TABELAS............................................................................................ii

LISTA DE ABREVIATURAS E SIGLAS............................................................iv

LISTA DE SÍMBOLOS..............................................................................................vi

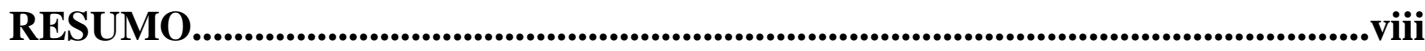

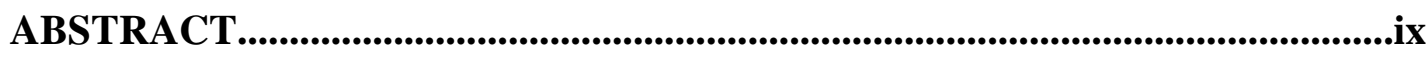

1 - INTRODUÇÃ

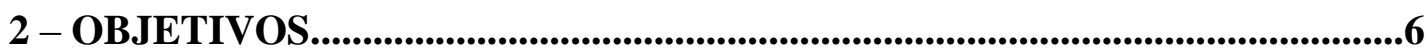

3 - REVISÃO BIBLIOGRÁFICA.........................................................................7

3.1 - Política Nacional do Meio Ambiente............................................................

3.1.1 - Objetivos da Política Nacional do Meio Ambiente...................................8

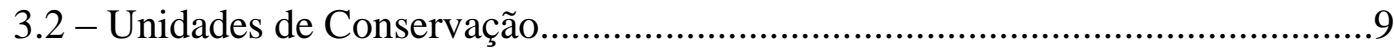

3.2.1 - Objetivos das Unidades de Conservação.................................................10

3.2.2 - Classificação Internacional das Áreas Naturais

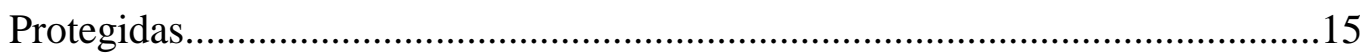

3.3 - Áreas de Proteção Ambiental..................................................................18

3.3.1 - Objetivo, Leis e Decretos de Criação....................................................18

3.3.2 - Áreas de Proteção Ambiental no Estado de São

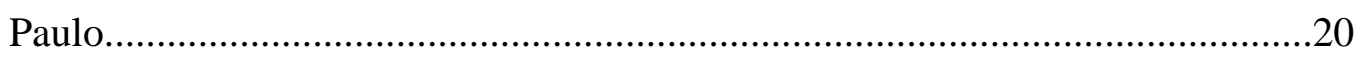

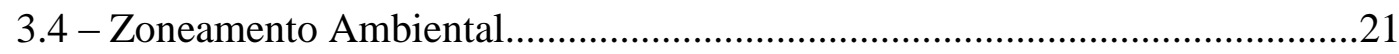

3.5 - Gestão Ambiental.......................................................................................24

3.5.1 - Instrumentos De Gestão Ambiental.........................................................27 
3.7 - Sistemas de Informações Geográficas - Aplicações em Planejamento e

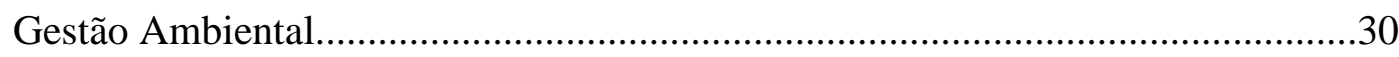

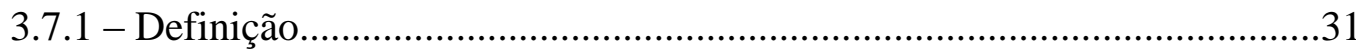

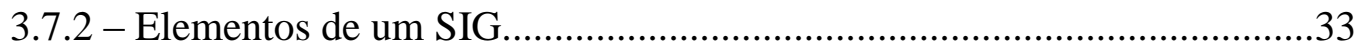

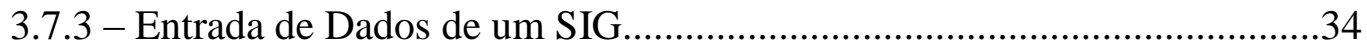

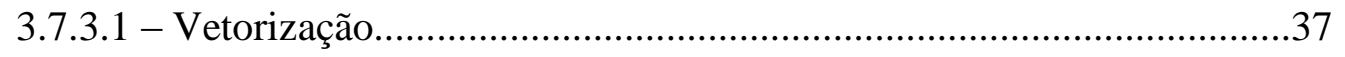

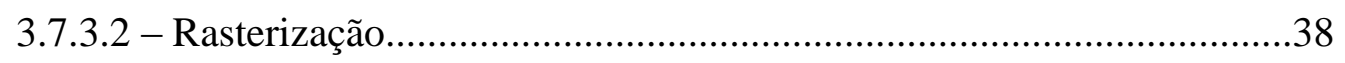

3.8 - O Uso de GPS (Global Positioning System) para Georreferenciamento de

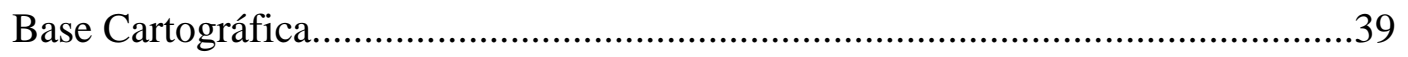

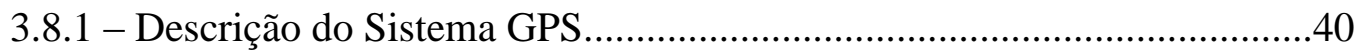

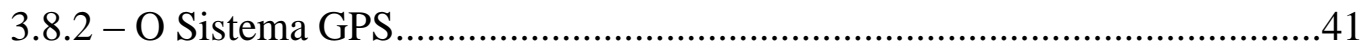

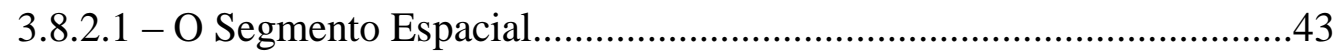

3.8.2.2 - O Segmento de Controle Terrestre .................................................44

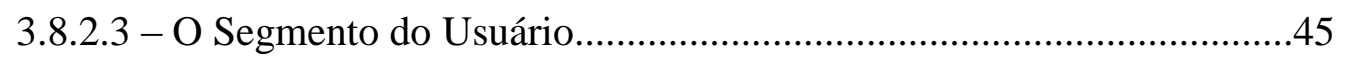

4 - MATERIAIS E MÉTODOS.....................................................................47

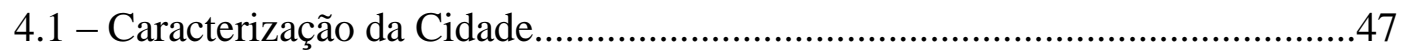

4.2 - Caracterização da Área de Estudo...............................................................48

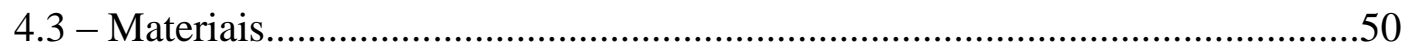

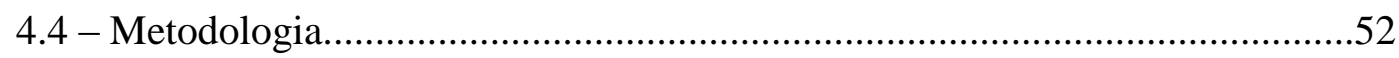

4.4.1 - O Sistema Topográfico Local...........................................................54

4.4.1.1 - Plano de Representação, Origem, Eixos e

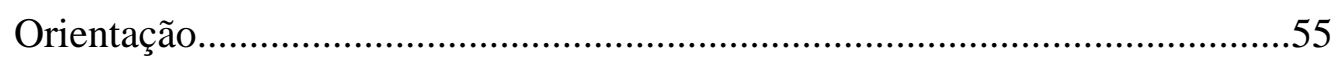

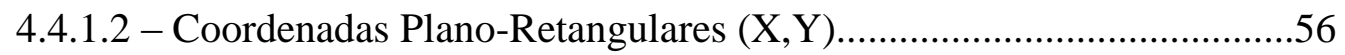

4.4.1.3 - Fator de Elevação..........................................................................57

4.4.2 - Organização das Informações Digitalizadas............................................59

4.4.2.1 - Preparação das Coordenadas dos Pontos de

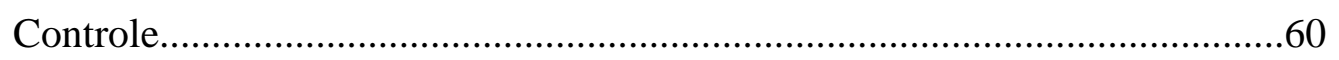

4.4.2.2 - $\quad$ Registrando a $\quad$ Mesa Digitalizadora no

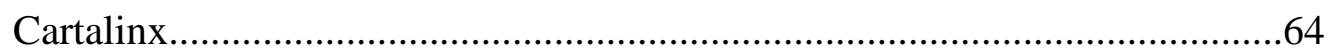


4.4.2.3 - Edição das Informações Digitalizadas

4.4.2.4 - Entrada dos Dados no Idrisi For Windows. .68

5 - RESULTADOS E DISCUSSÃO. 72

5.1 - Integração das Informações Digitalizadas. .72

5.1.1 - Análise da Integração 1 (Buffers de Distância X Uso e Ocupação do Solo) .73

5.1.2 - Análise da Integração 2 (Uso e Ocupação do Solo X

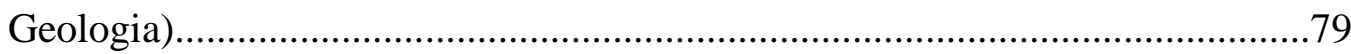

5.1.3 - Análise da Integração 3 (Geologia X Classes de

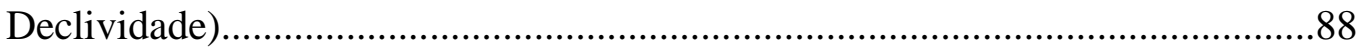

5.1.4 - Análise da Integração 4 (Classes de Declividade X Uso e Ocupação do Solo. .97

5.2 - Avaliação do Sistema Topográfico Local 102

6 - CONCLUSÕES. 106

7 - RECOMENDAÇÕES. 109

8 - REFERÊNCIAS BIBLIOGRÁFICAS. .110

9 - ANEXOS. .118 


\section{1 - INTRODUÇÃO}

O Município de Pirassununga, no Estado de São Paulo, possui uma área de cerrado e pequenas manchas de mata atlântica, ainda intactas. Este município tem um grande potencial desenvolvimentista, caracterizado pelas suas indústrias, comércios e agropecuária fortes e pelo seu potencial educacional, pois existem algumas faculdades, como o Campus da USP e a Faculdade de Engenharia de Agrimensura, além da AFA (Academia da Força Aérea).

O município está bem localizado, encontrando-se no eixo de duas grandes cidades, Ribeirão Preto e Campinas. A cidade de Pirassununga não se livrou do problema da maioria das cidades do Estado de São Paulo, cujo desmatamento e a exploração agrícola, através de grandes plantações de cana cresceram em todo o estado. Este problema tem acabado com as poucas áreas "verdes" ainda existentes, e consequentemente, tem destruído as áreas de mananciais, degradando a qualidade e quantidade de água em regiões de grande potencial ecoturístico.

Pirassununga possui áreas ecoturísticas como a Cachoeira de Emas (figura 01), conhecida pela diversidade de peixes e pela Piracema, que ocorre neste local, e outras cachoeiras que podem ser encontradas próximas ao município de Analândia. 


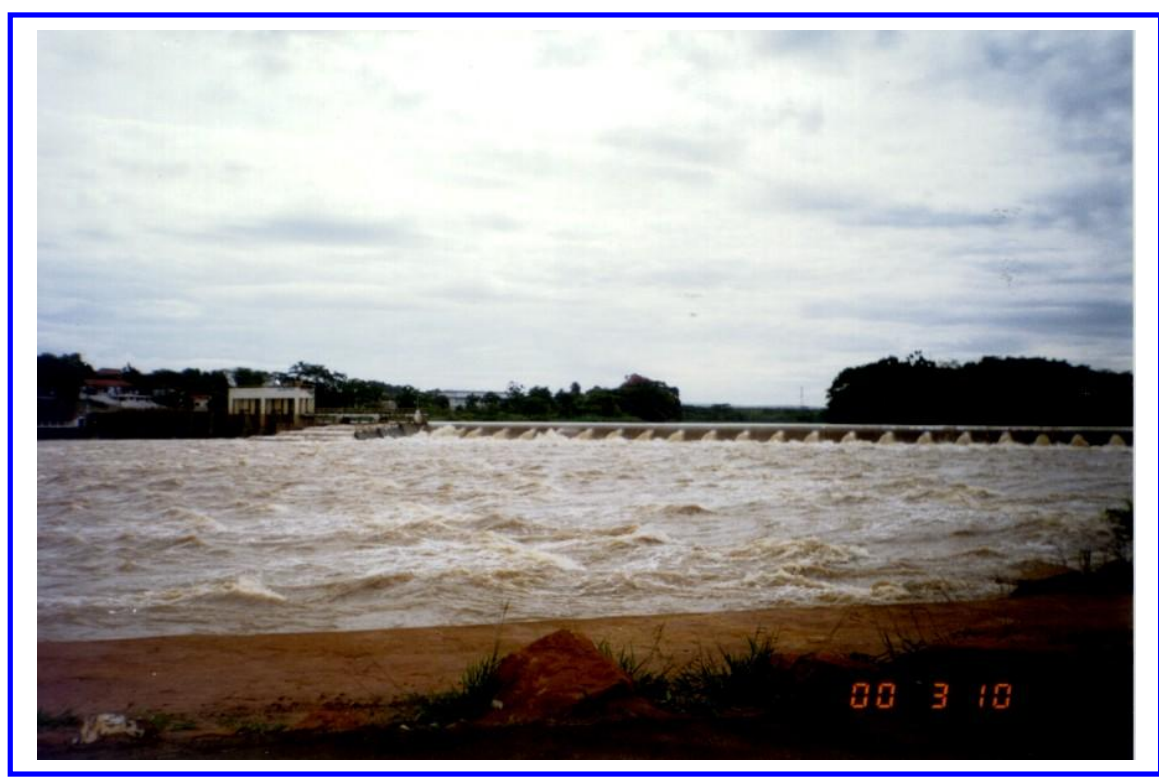

FIGURA 01 - RIO MOGI-GUAÇÚ - BARRAGEM EM CACHOEIRA DE EMAS

Próximo da região da Cachoeira de Emas localiza-se o CEPTA (Centro Nacional de Pesquisa de Peixes Tropicais - figura 02), pertencente ao IBAMA (Instituto Brasileiro do Meio Ambiente e dos Recursos Naturais Renováveis), que contribui para o desenvolvimento e preservação das espécies de peixes encontradas na região. Neste local encontra-se uma pequena faixa da mata atlântica, abrilhantando a área e servindo como um pequeno ecossistema para algumas espécies de plantas e animais e do outro lado localiza-se a AFA onde existe uma grande área de cerrado.

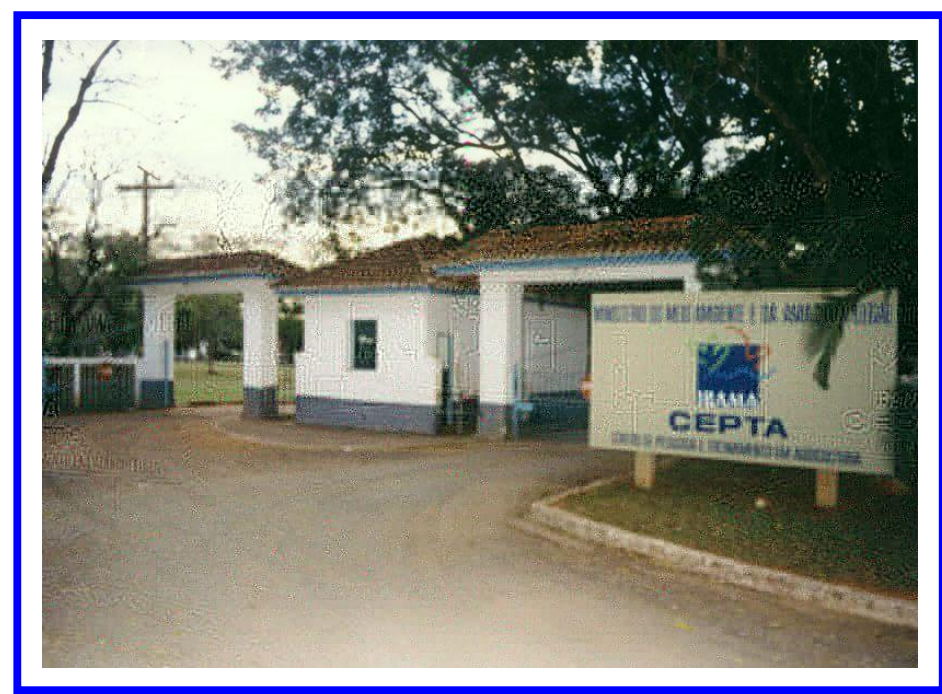

FIGURA 02 - PORTÃO DE ENTRADA DO CEPTA - IBAMA 
Para que haja uma manutenção das pequenas manchas de vegetação ainda existentes e dos afluentes, é preciso utilizar ferramentas que propiciem sua conservação.

Uma dessas ferramentas é a criação de Áreas de Proteção Ambiental (APA's), porém, para que seja criado a APA é necessário que seja feito uma Caracterização Ambiental da área para delimitar suas características e futuramente propor um Zoneamento Ambiental da área, conforme um dos instrumentos da Política Nacional do Meio Ambiente, estabelecida na lei 6938/81.

Tendo como prioridade por parte do poder público a promoção do zoneamento ambiental em todo o Brasil, com o intuito de controlar os processos de produção do espaço e priorizar a conservação ambiental, é necessário que a sociedade de uma forma geral participe, através de instituições e universidades para que haja um esforço em conjunto e mude o quadro em que o país atualmente se encontra, utilizando-se novas técnicas para a prática relacionada ao meio ambiente.

Segundo ALVARENGA (1997), tanto a conscientização quanto a prática relativa às questões ambientais são recentes nos países subdesenvolvidos, ou em desenvolvimento. Com a nova legislação ambiental deve-se procurar encontrar aplicações capazes de motivar e mobilizar a sociedade na recuperação, manutenção e melhoria das condições ambientais do país, e também, promover, através deste meio, um crescimento econômico capaz de diminuir os conflitos sociais existentes.

Mas para MERICO (1996), as sociedades subdesenvolvidas estão caminhando para o lado do crescimento econômico, com o objetivo de atingir o estágio de desenvolvidas, mesmo que isto signifique profundas injustiças sociais e irreversíveis alterações ambientais.

A AGENDA 21 (1992), deixa claro que uma política de meio ambiente voltada para a conservação e a proteção dos recursos naturais deve levar em consideração as necessidades daqueles que dependem desses recursos para sua sobrevivência e gerenciar adequadamente o uso desses recursos de forma sustentável. Não sendo assim, tal política poderia ter um impacto adverso tanto sobre o combate à pobreza como sobre as possibilidades de êxito a longo prazo da conservação dos recursos e do meio ambiente. Do mesmo modo, qualquer política de desenvolvimento voltada somente para o aumento da produção de bens e que não 
considere a sustentabilidade dos recursos sobre os quais se baseia a produção, haverá de defrontar-se, mais cedo ou mais tarde, com um declínio da produtividade - o que aumentaria a dificuldade da implantação de programas de combate à pobreza.

De acordo ainda com a AGENDA 21 (1992a) "a disponibilidade de informação científica e tecnológica, o acesso à tecnologia ambientalmente saudável e a transferência dessa tecnologia são requisitos essenciais para o desenvolvimento sustentável de um país. O provimento de informação adequada sobre os aspectos ambientais das tecnologias atuais possui dois componentes interrelacionados: aperfeiçoar a informação sobre as tecnologias atuais e as mais modernas, inclusive sobre seus riscos ambientais e facilitar o acesso às tecnologias ambientalmente saudáveis".

Assim, como está na Declaração de Estocolmo de 1972 onde se afirma que "todos os países devem aceitar a responsabilidade das conseqüências de suas próprias ações sobre o meio ambiente dos demais" (STRANG, 1977), é preciso que tomemos uma decisão de preservar o que ainda nos resta desse nosso meio ambiente.

Precisa haver preocupação na preservação dessas poucas áreas existentes e, conforme a AGENDA 21 (1992), não basta apenas a implantação de APA's. É preciso considerar, também, os problemas sociais da população presente nessas regiões, conscientizando-as de que a preservação pode ser lucrativa, através da exploração ecológica, como educação ambiental ou pela extração racional de recursos das áreas protegidas.

Devemos lembrar que a educação ambiental numa região em que se pretende criar uma APA não pode ficar somente no papel, que segundo CARVALHO (1992) "as muitas concepções de meio ambiente que circulam atualmente promovem uma espécie de Torre de Babel, onde todos estão falando da mesma coisa sem que haja um nível de comunicação efetiva”, e isto dependerá dos responsáveis pela gestão ambiental e das ações que serão tomadas para transformação da realidade.

Segundo GRIGG (1997), a abordagem sistêmica tem sido o caminho para aplicação de metodologias e filosofias de análise e síntese dos problemas e questões organizacionais relacionadas ao ambiente, tratando o mundo em termos de relações e de integrações. 
Segundo YOUNG \& ROCHA (1999) a abordagem sistêmica implica em uma maior utilização de ferramentas computacionais de análise, que sejam capazes de manipular grandes quantidades de dados e gerar novas informações e conhecimentos, a serem usados no processo de gerenciamento e tomada de decisão. Entre as ferramentas de suporte à decisão, o uso de Sistemas de Informações Geográficas (SIGs) é, provavelmente, aquela que mais se adeqüa a este enfoque sistêmico de gerenciamento de recursos naturais, dada as suas características de integração e manipulação de grandes quantidades de dados espaciais e alfanuméricos.

Há uma preocupação, também, relacionado ao gerenciamento dos recursos hídricos da região, pois o problema da água no estado de São Paulo se tornou um fator de grande relevância, sendo criado no estado vários comitês de bacias para gerenciar a situação de cada bacia hidrográfica., que segundo SILVA et al (1998) São Paulo possui 22 unidades de gerenciamento de recursos hídricos criados na Lei 9034 de 27 de dezembro de 1994.

Assim, este trabalho visa contribuir não só na proposta de zoneamento ambiental da microbacia Córrego da Barrinha, mas também dar apoio ao Comitê de Bacia do Mogi Guaçú com as informações geradas.

Neste trabalho, serão utilizadas ferramentas geotecnológicas como o SIG para a Caracterização Ambiental da Microbacia do Córrego da Barrinha, na região do CEPTA-IBAMA, que possui grande importância ecológica para o município de Pirassununga. 


\section{2 - OBJETIVOS}

\section{OBJETIVO GERAL}

$\mathrm{O}$ presente trabalho tem como objetivo sistematizar as informações ambientais e criar uma Caracterização Ambiental da Microbacia do Córrego da Barrinha, gerando subsídios para que seja feito uma proposta de Zoneamento Ambiental, para que assim, futuramente seja implantada uma Área de Proteção Ambiental na cidade de Pirassununga, na região onde encontra-se o CEPTA (Centro Nacional de Pesquisa de Peixes Tropicais) do IBAMA.

\section{OBJETIVOS ESPECÍFICOS}

$\Rightarrow$ Avaliar o Sistema Topográfico Local como uma nova proposta para estudos ambientais, em áreas que se enquadrem dentro das características deste sistema de referência.

$\Rightarrow$ Elaborar mapas temáticos como Mapa de Classes de Declividades e Mapas de Integração com os layers de Geologia, Uso e Ocupação do Solo Atualizado, Hidrografia e Curvas de Nível, como uma forma de abordagem sistêmica da área de estudo.

$\Rightarrow$ Fornecer subsídios para o Comitê de Bacias do Rio Mogi Guaçú para tomada de decisão. 


\section{3 - REVISÃO BIBLIOGRÁFICA}

\section{1 - POLÍTICA NACIONAL DO MEIO AMBIENTE}

A Lei $\mathrm{n}^{\mathrm{o}}$ 6.938/81 estabelece a Política Nacional do Meio Ambiente que tem por objetivo a preservação, melhoria e recuperação da qualidade ambiental, propícia à vida, visando assegurar, ao País, condições de desenvolvimento sócio-econômico, interesses da segurança nacional e proteção da dignidade da vida humana, atendidos os seguintes princípios:

“I - ação governamental na manutenção do equilíbrio ecológico, considerando o meio ambiente como um patrimônio público a ser necessariamente assegurado e protegido, tendo em vista o uso coletivo;

II - racionalização do uso do solo, do subsolo, da água e do ar, e largura;

III - planejamento e fiscalização do uso dos recursos ambientais;

IV - proteção dos ecossistemas, com a preservação de áreas representativas;

$\mathrm{V}$ - controle e zoneamento das atividades potencial ou efetivamente poluidoras;

VI - incentivos ao estudo e à pesquisa de tecnologias orientadas para o uso nacional e à proteção dos recursos ambientais;

VII - recuperação de áreas degradadas;

IX - proteção de áreas ameaçadas de degradação;

$X$ - educação ambiental a todos os níveis de ensino, inclusive a educação da comunidade, objetivando capacitá-la para participação ativa na defesa do meio ambiente."

O Decreto $\mathrm{n}^{\mathrm{o}}$ 99.274/90 que regulamenta a Lei $\mathrm{n}^{\mathrm{o}}$ 6.902/81 e a Lei $\mathrm{n}^{\mathrm{o}}$ 6.938/81 diz que, na execução da Política Nacional do Meio Ambiente, cumpre proteger as áreas representativas de ecossistemas mediante a implantação de Unidades de Conservação e Preservação Ecológica e incentivar o estudo e a pesquisa 
de tecnológicas para o uso racional e a proteção dos recursos ambientais, utilizando para isso os planos e programas regionais ou setoriais de desenvolvimento.

\subsection{1 - OBJETIVOS DA POLÍTICA NACIONAL DO MEIO AMBIENTE}

O artigo $4^{\circ}$ da Lei $n^{0}$ 6.938/81, estabelece como objetivos da Política Nacional do Meio Ambiente que visará:

"I - à compatibilização do desenvolvimento econômico - social com a preservação da qualidade do meio ambiente e do equilíbrio ecológico;

II - à definição de áreas prioritárias de ação governamental relativa à qualidade e ao equilíbrio ecológico, atendendo aos interesses da União, dos Estados, do Distrito Federal, dos Territórios e dos Municípios;

III - ao estabelecimento de critérios e padrões da qualidade ambiental e de normas relativas ao uso e manejo de recursos ambientais;

IV - ao desenvolvimento de pesquisas e de tecnologias nacionais orientadas para o uso racional de recursos ambientais;

V - à difusão de tecnologias de manejo do meio ambiente, à divulgação de dados e informações ambientais e à formação de uma consciência pública sobre a necessidade de preservação da qualidade ambiental e do equilíbrio ecológico.

VI - à preservação e restauração dos recursos ambientais com vistas à sua utilização racional e disponibilidade permanente, concorrendo para manutenção do equilíbrio ecológico propício à vida;

VII - à imposição, ao poluidor e ao predador, da obrigação de recuperar e/ou indenizar os danos causados e, ao usuário, da contribuição pela utilização de recursos ambientais com fins econômicos."

Pode-se analisar que no inciso $\mathrm{V}$, tem-se como objetivo, uma preocupação com a difusão de tecnologias e informações ambientais, para formação de uma consciência pública, e isto é muito importante para se atingir "objetivos" de trabalhos relacionados ao meio ambiente. Mas isto irá depender da ação e do comportamento das pessoas responsáveis, dentro de cada entidade pública (Instituições de Pesquisas, Fundações e do próprio Governo) que possui informações ambientais, pois para CARVALHO (1992) a ação "é a expressão mais nobre da condição humana" e o 
"comportamento substitui a ação como principal forma de relação humana", isto poderá prejudicar a formação de uma consciência ambiental se houver um comportamento reducionista destas pessoas, inibindo a produção de novas informações ambientais.

\section{2 - UNIDADES DE CONSERVAÇÃO}

As Unidades de Conservação (UCs) são porções delimitadas do território nacional, especialmente protegidas por lei, por conterem elementos naturais de importância ecológica e/ou ambiental. Em geral, ao se definir uma área a ser protegida, são observadas suas características naturais e estabelecidos os principais objetivos de conservação, além do grau de restrição à intervenção antrópica.

A área a ser protegida será enquadrada de acordo com as categorias de Unidades de Conservação previstos por lei. As principais categorias são:

$\checkmark$ Parque Nacional;

$\checkmark$ Estação Ecológica;

$\checkmark$ Reserva Biológica;

$\checkmark$ Reserva Ecológica;

$\checkmark$ Reserva Extrativista;

$\checkmark$ Área de Proteção Ambiental; e

$\checkmark$ Área de Relevante Interesse Ecológico.

O conceito moderno de conservação (União Internacional para a Conservação da Natureza - UICN, 1986 apud SCHIAVETTI, 1997)- a manutenção e utilização de uma gama de recursos - é a combinação de dois princípios, a necessidade de planejar o uso e de se ter medidas preventivas para evitar a exaustão dos recursos, objetivos que podem ser atribuídos às Áreas Silvestres.

A conservação se define da seguinte maneira (UICN, 1994): “a gestão da utilização da biosfera pelo ser humano, de tal sorte que produza o maior benefício sustentado para as gerações atuais, mas que mantenha sua potencialidade para satisfazer às necessidades e às aspirações das gerações futuras”.

Portanto, a conservação só será um fator relevante se compreender a preservação, a manutenção, a utilização sustentada, a restauração e a melhoria do 
ambiente natural. Sendo assim, em UICN (1984) a conservação como o desenvolvimento, destina-se aos homens, enquanto o desenvolvimento procura alcançar as finalidades do homem, mediante a utilização da biosfera, a conservação procura obtê-las por meio da manutenção da referida utilização.

Com essa filosofia pode-se observar que em UICN (1984) a conservação compreende a manutenção e a continuidade, e, por isso, constitui uma resposta racional à própria natureza dos recursos vivos (renovabilidade e destrutibilidade), assim como um imperativo ético, que se manifesta na convicção de que "não herdamos a Terra de nossos pais, mas a tomamos emprestada de nossos filhos".

Sujeitas a regime jurídico especial, para a Secretaria do Meio Ambiente do Estado de São Paulo - SMA (1998), a sua criação está prevista na Constituição Federal de 1988 (capítulo VI, artigo 225, parágrafo primeiro), que determina ao poder público a incumbência de "definir, em todas as Unidades da Federação, espaços territoriais e seus componentes a serem protegidos, sendo a alteração e supressão permitidas somente por meio de lei, vedada qualquer utilização que comprometa a integridade dos atributos que justifiquem sua proteção".

Já na Constituição do Estado de São Paulo de 1989, em seu Capítulo do Meio Ambiente, de acordo com SMA (1998), destaca igualmente sua importância, além de estabelecer, no artigo 184, que cabe ao Estado, com a cooperação dos municípios, orientar a utilização racional de recursos naturais de forma sustentável, compatível com a preservação do meio ambiente, especialmente quanto à proteção e conservação do solo e da água.

\subsection{1 - OBJETIVOS DAS UNIDADES DE CONSERVAÇÃO}

Até recentemente, o objetivo principal do estabelecimento de UCs ou Áreas Silvestres, era a preservação de determinadas espécies, fenômenos naturais ou processos ecológicos únicos. Agora, a preservação da biodiversidade e suas mudanças têm sido o maior objetivo para seu estabelecimento (MACHLIS \& TICHNELL, 1985 apud SCHIAVETTI, 1997).

Para SMA (1998) entre seus objetivos mais importantes destacam-se: 
“Garantir a manutenção de bancos genéticos, da diversidade de espécies e ecossistemas, ou seja, da biodiversidade, assegurando o processo evolutivo;

Manter os processos ecológicos fundamentais e os equilíbrios indispensáveis à qualidade de vida;

Preservar a vida silvestre, especialmente da biota nativa;

Proteger as espécies raras, endêmicas, vulneráveis ou em perigo de extinção;

Proteger áreas com características extraordinárias, ou que abriguem exemplares raros da biota regional;

Estimular alternativas de atividades que promovam, com o uso sustentável dos recursos naturais, a associação do desenvolvimento econômico com a conservação ambiental, servindo também para proteger modos tradicionais de uso dos recursos naturais e dos ecossistemas, permitindo sua evolução autodeterminada;

Proteger locais de interesse arqueológico, geológico, geomorfológico, paleontológico e espeleológico, entre outros;

Preservar a qualidade das águas, protegendo a sua produção e minimizando os processos não naturais de erosão e sedimentação;

Conservar as belezas cênicas;

Promover atividades de educação ambiental, recreativas e científicas;

Fomentar o uso racional e sustentável das riquezas naturais, por meio de áreas de uso múltiplo;

Assegurar melhor qualidade de vida às populações que vivem dentro das UCs e na circunvizinhança."

Para UICN (1986) apud SCHIAVETTI (1997) as UCs são essenciais para a conservação dos recursos naturais, possuindo um papel central no desenvolvimento econômico regional e para o bem-estar dos habitantes dos centros urbanos.

Para DIEGUES (1993) apud SCHIAVETTI (1997) entre as diversas funções destas áreas pode-se considerar como de grande importância a perpetuação de amostras representativas dos ecossistemas, a manutenção dos processos ecológicos e a conservação do material genético. 
Muitas das UCs criadas nos países sul-americanos são pequenas para cobrir a superfície ideal ou mínima necessária para a conservação da diversidade. Seus limites muitas vezes foram marcados com base na forma das divisões políticas locais, mecanismos de agrimensura ou características topográficas, sem critérios conservacionistas (NAGAMI, 1993).

TABELA 1 - NÚMERO DE ÁREAS PROTEGIDAS NA AMÉRICA DO SUL

\begin{tabular}{|c|c|c|c|}
\hline PAÍ́S & $\begin{array}{c}\text { Total de Áreas } \\
\text { Protegidas }\end{array}$ & $\begin{array}{c}\text { Porcentagem do } \\
\text { Território }\end{array}$ & $\begin{array}{c}\text { Áreas Protegidas } \\
\text { Particulares }\end{array}$ \\
\hline Argentina & 190 & 4,35 & 23 \\
\hline Bolívia & 33 & 10,69 & 4 \\
\hline Brasil & 162 & 2,4 & $\mathrm{n} / \mathrm{d}$ \\
\hline Colômbia & 42 & 8,60 & $\mathrm{n} / \mathrm{d}$ \\
\hline Chile & 79 & 18,18 & $\mathrm{n} / \mathrm{d}$ \\
\hline Equador & 15 & 10,32 & $\mathrm{n} / \mathrm{d}$ \\
\hline Guiana & 1 & 0,10 & $\mathrm{n} / \mathrm{d}$ \\
\hline Guiana Francesa & $\mathrm{n} / \mathrm{d}$ & $\mathrm{n} / \mathrm{d}$ & $\mathrm{n} / \mathrm{d}$ \\
\hline Paraguai & 13 & 3,03 & $\mathrm{n} / \mathrm{d}$ \\
\hline Peru & 46 & 4,49 & $\mathrm{n} / \mathrm{d}$ \\
\hline Suriname & 14 & 4,49 & $\mathrm{n} / \mathrm{d}$ \\
\hline Uruguai & 24 & 0,35 & $\mathrm{n} / \mathrm{d}$ \\
\hline Venezuela & 56 & 15,38 & $\mathbf{3 5}$ \\
\hline Total & $\mathbf{6 6 7}$ & $\mathbf{5 , 5 0}$ & \\
\hline
\end{tabular}

FONTE: Modificado de RIDENOUR (1993) apud SCHIAVETTI (1997).

De acordo com BRASIL (1994), analisando-se em conjunto os objetivos para os quais as Unidades de Conservação foram criadas bem como os usos permitidos e as proibições impostas, torna-se possível catalogá-las nos seguintes grupos:

1 - Unidades nas quais é vedado qualquer tipo de uso bem como alteração na cobertura vegetal. Com isso, as atividades relacionadas à administração dessas Unidades concentram-se principalmente em cercear a ação antrópica e impedir ou combater incêndios. Nesse grupo encontra-se o tipo:

Área de Preservação Permanente - Esta Unidade corresponde na maioria das vezes a uma Reserva Florestal de pequena extensão, voltada à captação dos recursos hídricos locais e corresponde aos trechos com cobertura de florestas e demais formas de vegetação natural situadas ao longo de rios ou de qualquer curso de água; ao redor de lagoas; lagos ou reservatórios de água; no topo de morros, montes, montanhas e serras; nas encostas ou em parte destas, com declividade superior a $45^{\circ}$; nas 
restingas, como fixadoras de dunas ou estabilizadoras de mangues; nas bordas de tabuleiro ou chapadas; em altitudes superiores a $1800 \mathrm{~m}$ nos campos naturais.

2 - Unidades nas quais o uso admissível no seu interior é regulado de modo a compatibilizá-lo com os objetivos da conservação ambiental e com o objetivo a ser protegido. Nestas áreas, a superfície deverá ser mantida intacta, em quase sua totalidade. Isso implica a proibição de qualquer forma de exploração de recursos naturais, neste caso temos:

Áreas de Relevante Interesse Ecológico - Compreende uma área que possui características naturais extraordinárias ou abrigue exemplares raros da biota, exigindo cuidados especiais de proteção por parte do poder público. Esta área deve ter extensão inferior a 5000 ha e a ocupação humana deve ser fraca ou nula por ocasião do ato declaratório;

Estação Ecológica - Corresponde a uma área representativa de um ecossistema brasileiro, estabelecida com o objetivo de permitir estudos comparativos com outras áreas da mesma região e que estejam ocupadas e modificadas pelo homem a fim de obter informações úteis ao planejamento regional e ao uso racional de recursos naturais. Cerca de $90 \%$ da área são resguardados; no restante, caso haja um plano de zoneamento aprovado, poderá ser autorizada a realização de pesquisas ecológicas que não venham a acarretar modificações no ambiente;

Parque - Compõe uma área criada com a finalidade de resguardar atributos excepcionais da natureza, conciliando a proteção integral da flora, da fauna e das belezas naturais, com a utilização para objetivos educacionais, recreativos e científicos;

Reserva Ecológica - Esta área é criada com o objetivo de preservação de ecossistemas brasileiros, destinada a realização de pesquisas básicas e aplicadas de ecologia, à proteção do ambiente natural e ao desenvolvimento da educação conservacionista. $\mathrm{O}$ intuito de preservação desta área é transformá-la em Estação Ecológica, depois da realização dos estudos de zoneamento e determinação dos seus objetivos;

Reserva Biológica - Esta área tem por finalidade a salvaguarda de um ou mais ecossistemas ou ainda proteger as belezas cênicas de depredação humana. Constitui área essencialmente não perturbada por atividades antrópicas, onde só é permitido o 
desenvolvimento de atividades científicas, devidamente autorizadas e controladas para não provocar alterações no meio ambiente físico. São vedadas a utilização do solo, perseguição, caça, apanha ou introdução de espécies da flora e da fauna silvestre ou domésticas.

3 - Unidades nas quais é permitida a exploração racional dos recursos florestais através de manejo, neste caso temos:

Floresta - Esta área foi criada com fins econômicos, técnicos ou sociais, inclusive reservando áreas ainda não florestadas e destinadas a atingir aquele fim. Os principais objetivos de criação são os de assegurar o manejo técnico dos produtos vegetais e animais, garantindo a captação de águas, associadas às ofertas de recreação ao ar livre;

Reserva Florestal - Esta categoria de manejo é transitória. Geralmente trata-se de área extensa, não habitada, de difícil acesso e em estado natural, da qual ainda se carece do conhecimento e tecnologia para o uso racional dos recursos, ou quando as prioridades nacionais em matéria de recursos humanos e financeiros impedem investigações de campo, avaliação e o desenvolvimento delas no momento.

Os valores naturais, sociais e econômicos não se encontram suficientemente identificados a ponto de permitir que a área seja manejada, sob uma categoria específica de áreas silvestres ou para sua conversão em outros usos da terra.

Os objetivos gerais de manejo são proteger os valores do recurso natural para uso futuro e impedir ou reter atividades de desenvolvimento, até que sejam estabelecidos outros objetivos de manejo permanentes ou para outro fim;

Reserva Extrativista - Espaço territorial considerado de interesse ecológico e social. Identifica-se por possuir características naturais ou exemplares da biota que possibilitem a sua exploração auto-sustentável, sem prejuízo da conservação ambiental. Este espaço está destinado às populações extrativistas para a exploração e conservação dos recursos naturais renováveis.

4 - Unidades nas quais é permitida a ocupação humana em todo o seu território, mas os usos do solo e as atividades econômicas são selecionados de modo a conservar ou melhorar as condições ecológicas locais, neste caso temos:

Área de Proteção Ambiental - A criação desse tipo de área objetiva assegurar o bem estar das populações humanas e conservar ou melhorar as condições ecológicas. 
Compreende ambientes com diferentes graus de ocupação humana. A legislação pertinente à criação estabelece que as terras permanecem em mãos de seus proprietários.

TABELA 2 - UNIDADES DE CONSERVAÇÃO NO BRASIL E SUAS RESPECTIVAS ÁREAS.

\begin{tabular}{|l|c|c|c|}
\hline \multicolumn{1}{|c|}{ UNIDADES DE CONSERVAÇÃO } & NÚMERO & $\begin{array}{c}\text { ÁREA } \\
\text { TOTAL (ha) }\end{array}$ & $\begin{array}{c}\text { \% EM RELAÇÃO A } \\
\text { ÁREA TERRITORIAL }\end{array}$ \\
\hline Parques Nacionais & 35 & 9.751 .180 & 1,1408 \\
\hline Reservas Biológicas & 25 & 3.040 .269 & 0,3556 \\
\hline Estações Ecológicas & 30 & 2.366 .876 & 0,2769 \\
\hline Reservas Ecológicas & 7 & 558.866 & 0,0653 \\
\hline Reservas Extrativistas & 9 & 2.200 .755 & 0,2574 \\
\hline Florestas Nacionais & 39 & 12.594 .334 & 1,4734 \\
\hline Áreas de Relevante Interesse Ecológico & 14 & 32.650 & 0,0038 \\
\hline Áreas de Preservação Permanente & 5 & 35.671 & 0,0041 \\
\hline Áreas de Proteção Ambiental & 19 & 1.679 .416 & 0,1964 \\
\hline Reservas Florestais & 9 & 12.377 .976 & 1,4481 \\
\hline TOTAL & $\mathbf{1 9 2}$ & $\mathbf{4 4 . 6 3 7 . 9 9 3}$ & $\mathbf{5 , 2 2 1 8}$ \\
\hline
\end{tabular}

FONTE: Mapa de Unidades de Conservação Federais do Brasil - IBGE - 1994

\subsection{2 - CLASSIFICAÇÃO INTERNACIONAL DAS ÁREAS NATURAIS PROTEGIDAS}

A UICN, de acordo com a SMA (1998), trabalha com a definição de categorias de manejo de áreas protegidas desde 1969 (Parques Nacionais). Essa instituição, que congrega quase uma centena de nações, organizações não governamentais (ONGs) e milhares de cientistas colaboradores, elaborou uma primeira classificação internacional de áreas protegidas, ou UCs, em 1973.

A última classificação antes da atual, data de 1978, contava com 10 categorias. A definição dessas categorias tinha, e ainda tem, como função possibilitar uma linguagem comum para o intercâmbio de informações entre países com classificações variadas, embora tenha servido, e ainda sirva, como orientação para a implantação dos sistemas nacionais. 
A classificação internacional das áreas naturais protegidas, segundo SMA (1998), definida pela UICN em 1994, apresenta seis tipos de UCs (Tabela 3), sendo que um deles é subdivido em dois. De acordo com os objetivos da gestão, ou manejo, e principiando pelo mais restritivo, apresentam:

I - Proteção Estrita, subdivido em:

Ia - Reserva Natural Estrita e,

$\mathrm{Ib}$ - Área Natural Silvestre;

II - Conservação de Ecossistemas e Turismo/Recreação;

III - Conservação das Características Naturais;

IV - Conservação por Meio de Gestão Ativa;

V - Conservação de Paisagens Terrestres e Marinhas e Lazer/Recreação;

VI - Uso Sustentável de Ambientes/Ecossistemas Naturais.

TABELA 3 - CLASSIFICAÇÃO INTERNACIONAL DE UNIDADES DE CONSERVAÇÃO

\begin{tabular}{|c|c|c|}
\hline \multicolumn{3}{|c|}{$\begin{array}{c}\text { CLASSIFICAÇÃO INTERNACIONAL DE UNIDADES } \\
\text { DE CONSERVAÇÃ̃O } \\
\text { (Modificado de UICN, 1994, ampliado) }\end{array}$} \\
\hline \multicolumn{2}{|c|}{$\begin{array}{c}\text { Objetivos da Gestão } \\
\text { (objetivo principal do manejo) }\end{array}$} & $\begin{array}{c}\text { Comparação com UCs Brasileiras } \\
\text { (podem estar citadas em mais de uma categoria } \\
\text { internacional) }\end{array}$ \\
\hline \multirow{2}{*}{$\begin{array}{l}\text { I - Proteção } \\
\text { Estrita }\end{array}$} & Ia - Reserva Natural Estrita & ESEC; REBIO \\
\hline & Ib - Área Natural Silvestre & $\begin{array}{l}\text { REBIO e várias outras, embora não clara } \\
\text { especificamente; ESEC; santuários de vida silvestre }\end{array}$ \\
\hline \multicolumn{2}{|c|}{$\begin{array}{l}\text { II - Conservação de Ecossistemas e } \\
\text { Turismo/Recreação }\end{array}$} & Parque Nacional e Estadual \\
\hline \multicolumn{2}{|c|}{ III - Conservação das Características Naturais } & $\begin{array}{l}\text { Monumento natural; rio cênico; estrada-parque; ARIE; } \\
\text { RE }\end{array}$ \\
\hline \multicolumn{2}{|c|}{ IV - Conservação por Meio de Gestão Ativa } & $\begin{array}{l}\text { FLONA; parque de caça; reserva de recursos; reserva } \\
\text { de fauna }\end{array}$ \\
\hline \multicolumn{2}{|c|}{$\begin{array}{l}\text { V - Conservação de Paisagens Terrestres e } \\
\text { Marinhas e Lazer/Recreação }\end{array}$} & Monumento cultural \\
\hline $\begin{array}{l}\text { VI } \quad- \\
\text { Ambientes/E }\end{array}$ & $\begin{array}{l}\text { Uso Sustentável de } \\
\text { ossistemas Naturais }\end{array}$ & $\begin{array}{l}\text { APA; RESEX; FLONA (parque de caça; reserva de } \\
\text { recursos; Terra Indígena) }\end{array}$ \\
\hline
\end{tabular}

FONTE: SMA (1998) 
Para SMA (1998) o principal avanço das classificações internacionais é exatamente esclarecer as funções dos manejos de cada categoria das UCs, desde a preservação estrita até o uso sustentável. É importante a preocupação com o objetivo de manejo de cada uma, e não com sua nomenclatura.

Para analisarmos melhor as informações da tabela 3, temos segundo SMA (1998), a tabela da matriz de objetivos da gestão e categorias de unidades de conservação da UICN (tabela 4), mostrando que não temos um objetivo único para cada unidade.

TABELA 4 - MATRIZ DE OBJETIVOS DA GESTÃO E CATEGORIAS DE UNIDADES DE CONSERVAÇÃO DA UICN

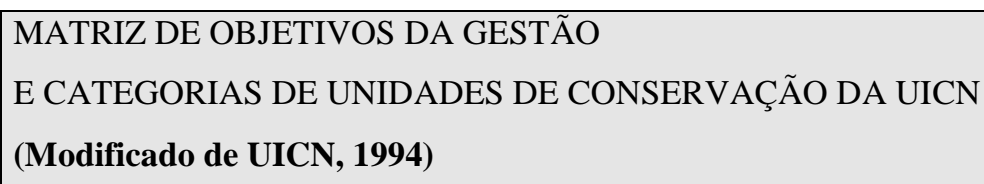

\begin{tabular}{|c|c|c|c|c|c|c|c|}
\hline \multirow{2}{*}{ (a) } & & & & & & & \\
\hline & Ia & $\mathrm{Ib}$ & II & III & IV & $\mathrm{V}$ & VI \\
\hline Pesquisa Científica & 1 & 3 & 2 & 2 & 2 & 2 & 3 \\
\hline
\end{tabular}

Proteção de áreas (espécies) silvestres (naturais)

Preservação da diversidade genética e das espécies

Conservação (manutenção) das funções ambientais (ecológicas)

Proteção de características naturais/culturais específicas

Turismo e lazer

Educação

Uso sustentado dos recursos de ambientes silvestres (ecossistemas naturais)

Conservação (manutenção) de características culturais/tradicionais

1 -Objetivo Principal; 2 - Objetivo Secundário; 3 -Objetivo Potencialmente Aplicável; $x$ - Não Aplicável

FONTE: SMA (1998)

Na tabela 4 observa-se que na categoria VI, apresenta-se como objetivo principal (1), dentre os objetivos da gestão, a preservação da diversidade genética e das espécies, conservação (manutenção) das funções ambientais (ecológicas) e uso sustentado dos recursos de ambientes silvestres (ecossistemas naturais), tendo como 
objetivo potencialmente aplicável, a pesquisa científica, a proteção de características naturais/culturais específicas, o turismo e lazer e a educação, e segundo SMA (1998), nesta categoria recomenda-se o manejo por instituição pública, mas com a participação da comunidade local.

\section{3 - ÁREAS DE PROTEÇÃO AMBIENTAL}

As Áreas de Proteção Ambiental (APAs) representam uma das categorias de UCs que, surgiram no Brasil no início dos anos 80 (artigo $8^{\circ}$ da Lei Federal $\mathrm{n}^{\mathrm{o}}$ 6.902/81), juntamente com diversos outros instrumentos da Política Nacional do Meio Ambiente destinados à conservação ambiental.

As APAs podem ser estabelecidas em terras de domínio público e/ou privado. Segundo SMA (1998) quando em domínio privado, as atividades econômicas podem ocorrer sem prejuízo dos atributos ambientais especialmente protegidos, respeitandose a fragilidade e a importância desses recursos naturais.

O processo de regulamentação das APAs que vem sendo adotado pela Secretaria do Meio Ambiente fundamenta-se em três pontos principais:

Zoneamento ambiental, por meio da identificação e delimitação de áreas homogêneas do território quanto aos objetivos de proteção;

Normatização do uso e ocupação do solo, contemplando normas e diretrizes para cada zona ambiental;

Gestão da APA, por meio do estabelecimento de um Colegiado Gestor, com o objetivo de propor programas, articular os agentes de atuação, priorizar ações e sugerir metas na implementação de atividades de caráter ambiental. Nesse Colegiado, é assegurada a participação do Estado, municípios e da sociedade civil organizada, com a constituição de um fórum para a construção de um modelo de gestão ambiental descentralizado.

\subsection{1 - OBJETIVO, LEIS E DECRETOS DE CRIAÇÃO}


O objetivo principal da APA é disciplinar o processo de ocupação das terras e promover a proteção dos recursos abióticos e bióticos dentro de seus limites, de modo a assegurar o bem-estar das populações humanas que aí vivem, resguardar e conciliar ações humanas com a preservação da vida silvestre, proteger os recursos naturais nela contidos e melhorar a qualidade de vida da população. Nas Áreas de Proteção Ambiental, a atividade humana pode e deve existir, desde que seja orientada e regulada de forma a evitar a degradação ambiental e permitir o uso racional e sustentado do patrimônio natural.

O artigo $9^{0}$ da Lei Federal n⿳0 6.902/81 estabelece que nas Áreas de Proteção Ambiental, o Poder Executivo poderá estabelecer normas limitando ou proibindo atividades humanas, de forma a harmonizar o desenvolvimento e a conservação dos recursos naturais, sendo que estas normas disciplinarão:

a)"a implantação e o funcionamento de indústrias potencialmente poluidoras, capazes de afetar mananciais de água;

b) a realização de obras de terraplenagem e a abertura de canais, quando essas iniciativas importarem em sensível alteração das condições ecológicas locais;

c) o exercício de atividades capazes de provocar acelerada erosão das terras e/ou acentuado assoreamento das coleções hídricas;

d) o exercício de atividades que ameacem extinguir na área protegida as espécies raras da biota regional."

O processo de implantação de uma APA envolve diversas etapas e procedimentos legais e técnicos. Sua criação ocorre através de instrumentos legais (Lei, Decreto, Resolução ou Portaria) que constituem o primeiro passo para sua efetiva implantação. De acordo com o Decreto $n^{0}$ 99.274/90, compete ao CONAMA (Conselho Nacional do Meio Ambiente) estabelecer normas gerais relativas às Unidades de Conservação e às atividades que podem ser desenvolvidas em suas áreas circundantes. No artigo 28 da mesma lei, compete ao Secretário do Meio Ambiente, com base em parecer do IBAMA (Instituto Brasileiro do Meio Ambiente e dos Recursos Naturais Renováveis), propor ao Presidente da República a criação de Áreas de Proteção Ambiental. Ao ser decretada a criação de uma Área de Proteção Ambiental, ficam estabelecidos a sua denominação, seus limites geográficos, os 
principais objetivos e as proibições e restrições de uso dos recursos ambientais nela contidas.

Portanto, para a elaboração desse instrumento legal, faz-se necessária uma caracterização da área em questão, ou seja, há necessidade de se construir uma Base de Informações Ambientais, através do Zoneamento Ambiental e de ferramentas apropriadas, que seja capaz de fornecer subsídios para o planejamento e implantação da APA. Além disso, deve-se contar com o apoio da comunidade local, integrando a sociedade civil e os órgãos governamentais.

\subsection{2 - ÁREAS DE PROTEÇÃO AMBIENTAL NO ESTADO DE SÃO PAULO}

O Estado de São Paulo ocupa uma área de 248.808,8 $\mathrm{km}^{2}$ e tem uma população de 32.697.101 habitantes, distribuídos em 625 municípios, IBGE (1996). Possui 16 APAs estaduais e 3 federais. As APAs existentes no Estado são apresentadas na tabela 5 abaixo:

TABEla 5 - ÁREAS de PROTEÇão ambiental No ESTAdo de SÃo PAUlo PROPOSTAS DE ZONEAMENTO AMBIENTAL

\begin{tabular}{|c|c|c|c|c|c|c|}
\hline & $\begin{array}{l}\text { NOME } \\
\text { DA APA }\end{array}$ & $\begin{array}{c}\text { ATRIBUTOS } \\
\text { PROTEGIDOS }\end{array}$ & MUNICÍPIOS & $\begin{array}{c}\text { ÁREA } \\
\text { (ha) }\end{array}$ & $\begin{array}{l}\text { JURISDIÇ } \\
\text { ÃO }\end{array}$ & $\begin{array}{c}\text { LEI / } \\
\text { DECRETO }\end{array}$ \\
\hline 1 & Serra da Mantiqueira & $\begin{array}{l}\text { Mananciais, Montanhas } \\
\text { e Ecossistema }\end{array}$ & 11 & 93.678 & Federal & $\begin{array}{c}\text { DEC } \\
91304 / 85\end{array}$ \\
\hline 2 & Campos de Jordão & $\begin{array}{l}\text { Montanhas e } \\
\text { Araucárias }\end{array}$ & 1 & 26.900 & Estadual & $\begin{array}{c}\text { LEI } \\
4105 / 84 \\
\end{array}$ \\
\hline 3 & $\begin{array}{l}\text { Mananciais do Vale } \\
\text { do Paraíba do Sul } \\
\end{array}$ & $\begin{array}{l}\text { Mananciais de } \\
\text { Abastecimento } \\
\end{array}$ & 24 & 367.000 & Federal & $\begin{array}{c}\mathrm{DEC} \\
87561 / 82 \\
\end{array}$ \\
\hline 4 & Silveiras & $\begin{array}{l}\text { Patrimônio Cultural, } \\
\text { Fauna e Flora }\end{array}$ & 1 & 42.700 & Estadual & $\begin{array}{c}\text { LEI } \\
4100 / 84 \\
\end{array}$ \\
\hline 5 & $\begin{array}{l}\text { Piracicaba e Juqueri- } \\
\text { Mirim } \\
\end{array}$ & $\begin{array}{l}\text { Mananciais de } \\
\text { Abastecimento } \\
\end{array}$ & 19 & 387.927 & Estadual & $\begin{array}{c}\text { LEI } \\
7438 / 91 \\
\end{array}$ \\
\hline 6 & Cabreúva & Serra do Japi & 1 & 26.100 & Estadual & LEI 4023/84 \\
\hline 7 & Jundiaí & Serra do Japi & 1 & 43.200 & Estadual & LEI 4095/84 \\
\hline 8 & Cajamar & Serra do Japi & 1 & 13.400 & Estadual & LEI 4055/84 \\
\hline 9 & $\begin{array}{l}\text { Várzea do } \\
\text { Alto Tietê } \\
\end{array}$ & \begin{tabular}{|l|} 
Planície \\
Aluvial \\
\end{tabular} & 12 & 7.400 & Estadual & LEI 5598/87 \\
\hline 10 & Ilha Comprida & $\begin{array}{l}\text { Estuários, Lagunas e } \\
\text { Mares Interiores }\end{array}$ & 1 & 17.527 & Estadual & $\begin{array}{c}\text { DEC } \\
26881 / 87 \\
\end{array}$ \\
\hline 11 & $\begin{array}{l}\text { Cananéia, Iguape e } \\
\text { Peruíbe }\end{array}$ & $\begin{array}{l}\text { Estuários, Lagunas e } \\
\text { Mares Interiores }\end{array}$ & 5 & 209.345 & Federal & $\begin{array}{c}\text { DEC's } \\
90347 / 84 \mathrm{e} \\
91892 / 85\end{array}$ \\
\hline
\end{tabular}




\begin{tabular}{|c|c|c|c|c|c|c|}
\hline 12 & Ibitinga & Ecossistema & 1 & 64.900 & Estadual & $\begin{array}{c}\text { LEI } \\
5537 / 87 \\
\end{array}$ \\
\hline 13 & $\begin{array}{l}\text { Corumbataí, } \\
\text { Botucatu e Tejupá }\end{array}$ & $\begin{array}{l}\text { Mananciais, Cuestas } \\
\text { Basálticas e Cerrados }\end{array}$ & 33 & 649.256 & Estadual & $\begin{array}{c}\text { DEC } \\
20960 / 83\end{array}$ \\
\hline 14 & Tietê & $\begin{array}{l}\text { Patrimônio } \\
\text { Cultural }\end{array}$ & 1 & 45.100 & Estadual & $\begin{array}{c}\text { DEC } \\
20959 / 83\end{array}$ \\
\hline 15 & $\begin{array}{l}\text { Represa Bairro da } \\
\text { Usina }\end{array}$ & $\begin{array}{l}\text { Represa em } \\
\text { Atibaia }\end{array}$ & 1 & 1.018 & Estadual & LEI 5280/86 \\
\hline 16 & $\begin{array}{l}\text { Aras de São } \\
\text { Bernardo }\end{array}$ & $\begin{array}{l}\text { Remanescentes de Mata } \\
\text { Atlântica }\end{array}$ & 1 & 35 & Estadual & $\begin{array}{c}\text { LEI } \\
5745 / 87\end{array}$ \\
\hline
\end{tabular}

\section{Continua na próxima página}


Continuação

\begin{tabular}{|c|l|l|c|c|c|c|}
\hline \multicolumn{1}{|c|}{$\begin{array}{c}\text { NOME } \\
\text { DA APA }\end{array}$} & \multicolumn{1}{|c|}{$\begin{array}{c}\text { ATRIBUTOS } \\
\text { PROTEGIDOS }\end{array}$} & MUNICÍPIOS & $\begin{array}{c}\text { ÁREA } \\
\text { (ha) }\end{array}$ & $\begin{array}{c}\text { JURISDIÇ } \\
\tilde{\text { ÂO }}\end{array}$ & $\begin{array}{c}\text { LEI/ } \\
\text { DECRETO }\end{array}$ \\
\hline 17 & $\begin{array}{l}\text { Morro de } \\
\text { São Bento }\end{array}$ & $\begin{array}{l}\text { Remanescentes da } \\
\text { Biota }\end{array}$ & 1 & 2 & Estadual & $\begin{array}{c}\text { LEI } \\
6131 / 88\end{array}$ \\
\hline 18 & $\begin{array}{l}\text { Parque e Fazenda do } \\
\text { Carmo }\end{array}$ & $\begin{array}{l}\text { Remanescentes da Mata } \\
\text { Atlântica }\end{array}$ & 1 & 867 & Estadual & $\begin{array}{c}\text { LEI } \\
6409 / 89\end{array}$ \\
\hline 19 & Serra do Mar & $\begin{array}{l}\text { Montanhas e } \\
\text { Ecossistema }\end{array}$ & 12 & 488.864 & Estadual & $\begin{array}{c}\text { DEC } \\
22717 / 84\end{array}$ \\
\hline
\end{tabular}

FONTE: Série Documentos, Secretaria do Meio Ambiente, 1992

Estas Áreas de Proteção Ambiental apresentadas na Tabela 5, estão distribuídas entre 128 Municípios no Estado de São Paulo com uma área total de $24.852,19 \mathrm{~km}^{2}$, o que equivale a aproximadamente $10 \%$ do território do Estado, e quase $20 \%$ dos Municípios. Como se pode observar, é um espaço muito significativo que está sob a forma legal de Áreas de Proteção Ambiental (APAs). Porém, tem-se um fato que ganha maior relevância, quando se percebe que a utilização das APAs, como instrumento de política ambiental, nem sempre tem sido utilizado de forma criteriosa, devido à falta de uma gestão ambiental planejada e bem executada, acarretando problemas devido a falta de respeito dentro dos critérios que são elaborados às APAs.

Portanto, partindo do princípio de que as razões de existência de uma Área Protegida são fundamentalmente a defesa da biodiversidade e seu valor estético, ao mesmo tempo que propicia à sociedade o usufruto dos espaços naturais, devem os responsáveis pela sua gestão cuidar da preservação do meio ambiente dentro de uma lógica de exploração sustentada, e respeitar as razões pela qual ela foi criada.

\section{4 - ZONEAMENTO AMBIENTAL}

O zoneamento ambiental é um dos instrumentos da Política Nacional do Meio Ambiente definidos pelo artigo $9^{\underline{0}}$, que tem um grande papel no contexto de gestão, e também, destaca-se por ser uma premissa para criação e elaboração de uma Área de Proteção Ambiental, servindo como auxílio para tomadas de decisão frente às restrições presentes. 
A Resolução $n^{0} 10$ do CONAMA de 14/12/1988, estabelece no seu artigo $2^{\underline{0}}$ que todas as APAs terão sempre um zoneamento ecológico-econômico (ZEE), visando atender aos seus objetivos, estabelecendo normas de uso, de acordo com as condições locais bióticas, geológicas, urbanísticas, agro-pastoris, extrativistas, culturais dentre outras.

Para AB'SABER (1989) apud ALVARENGA (1997) o estabelecimento deste procedimento exigido pelas APAs, o ZEE, equivale a realizar um estudo para determinar as vocações e restrições de todos os subespaços que compõem um certo território e efetuar o levantamento de suas potencialidades econômicas, sob um critério basicamente ecodesenvolvimentista.

Para SOUZA (1998) o zoneamento é um instrumento de uso para a salvaguarda ambiental, que cumpre este papel ao estabelecer, que a divisão de uma área, seja baseada em informações fornecidas pela realização de uma caracterização ambiental e que orientem o estabelecimento de empreendimentos e sua postura frente ao entorno.

Para GRIFFITH (1995) o zoneamento ambiental pode ser definido como uma divisão de um área geográfica em setores nos quais, após devida deliberação, certas atividades de uso e ocupação destes setores são permitidas ou não, de maneira que as necessidades antrópicas de alterações físicas e biológicas dos recursos naturais se harmonizem com as de conservação do meio ambiente.

Para SEMA (1988) apud MATTOS (1996) o zoneamento consiste na ordenação do território segundo suas características bióticas e abióticas básicas, através do agrupamento de áreas cujos conjuntos formam unidades de terra relativamente homogêneas, tanto em termos de problemas como de potenciais, facilitando a análise integrada da paisagem.

Segundo MATTOS (1996) o zoneamento ambiental deve convergir de forma adequada para o desenvolvimento sustentado e participativo, baseado em pesquisas básicas sobre o relevo, geomorfologia, solos, hidrologia, flora, fauna e fatores antrópicos, no qual deve-se estabelecer para uma APA as seguintes zonas:

$\checkmark$ Zonas de Preservação da Vida Silvestre;

$\checkmark$ Zonas de Uso Extensivo: pecuária e reflorestamento;

$\checkmark$ Zonas de Uso Intensivo: agricultura mecanizada; 


\section{$\checkmark$ Zonas de Uso Especial: uso urbano e para lazer; \\ $\checkmark$ Zona de Conservação da Vida Silvestre.}

Segundo a Resolução $\mathrm{n}^{0} 10$ do CONAMA de 14 de dezembro de 1988, em seu Art. $4^{\underline{0}}$ estabelece que serão consideradas Zonas de Preservação da Vida Silvestre (ZPVS), nas quais poderá ser admitido um uso demorado e auto-sustentado da biota, regulado de modo a assegurar a manutenção dos ecossistemas naturais. As ZPVS englobam também, as Áreas de Preservação Permanente definidas pelo Código Florestal Brasileiro (Lei 4.771 de 15/9/65).

$\mathrm{Na}$ mesma resolução artigo $5^{0}$ temos as Zonas de Uso Agropecuário, nas quais são proibidos ou regulados os usos ou práticas capazes de causar sensível degradação do meio ambiente. Nessas zonas a utilização de agrotóxicos e outros biocidas que ofereçam riscos sérios na sua utilização, inclusive no que se refere ao seu poder residual, o IBAMA relacionará as classes de agrotóxicos de uso permitido nas APAs. O cultivo da terra será feito de acordo com as práticas de conservação do solo recomendadas pelos órgãos oficiais de extensão agrícola, e não será admitido o pastoreio excessivo, considerando-se como tal aquele capaz de acelerar sensivelmente os processos de erosão.

Para ALVARENGA (1997), o poder público tem como prioridade o incentivo a criação de zoneamentos ambientais em todo o território nacional, para direcionar e controlar os processos de produção do espaço priorizando a conservação ambiental.

De acordo com PAVESI (1998) o zoneamento aplicado ao gerenciamento de bacias hidrográficas, torna-se um dos principais instrumentos para disciplinar o uso do solo, podendo garantir a manutenção da qualidade da água e de sua disponibilidade, além de prevenir conflitos decorrentes do uso irracional dos recursos.

Com a implantação do zoneamento ambiental, e a aplicação dos prognósticos, resultantes dos dados obtidos, ter-se-á num futuro próximo uma orientação melhor e mais moderna para um desenvolvimento sustentável dos recursos naturais existentes (KURTZ et al. 1999).

Assim, o zoneamento ambiental deve ser elaborado de forma a não subjulgar às pessoas que vivem no entorno da área a ser preservada, adotando critérios 
condizentes com a realidade da região e adotando metodologias que visem padronizar este processo.

\section{5 - GESTÃO AMBIENTAL}

A Gestão Ambiental refere-se ao gerenciamento de todas as atividades humanas as quais tenham significante impacto sobre o meio ambiente. Segundo TOLBA (1987) apud CERUCCI (1998), essa forma de gerir alarga o conceito de processo de desenvolvimento, ao incluir como objeto maior a qualidade ambiental, e ao permitir que ele se dê por um longo prazo e em bases sustentáveis.

De acordo com SOUZA (1996) apud CERUCCI (1998), essa abordagem sistêmica do meio ambiente, através da gestão ambiental, propicia uma aplicação mais próxima da realidade. Pois ela cria canais de comunicação nos quais os fatores ambientais serão identificados, analisados, ponderados e administrados, observandose todas as áreas do conhecimento, permitindo assim, a compreensão global dos problemas, e também a aplicação de novas soluções, ambientalmente mais adequadas.

A Gestão Ambiental, para CERUCCI (1998), pressupõe uma ação planejadora, pois trata-se de um conjunto de métodos destinados a captar e sistematizar informações, objetivando racionalizar processos decisórios indutores de modificações na dinâmica de funcionamento de sistemas ecossociais, incorporando os conflitos de valores e interesses entre os segmentos sociais envolvidos, bem como avaliar as conseqüências das alternativas implementadas frente as metas.

Para SOUZA (1996) apud CERUCCI (1998), o método de execução da gestão ambiental deve seguir as seguintes etapas (figura 03): 


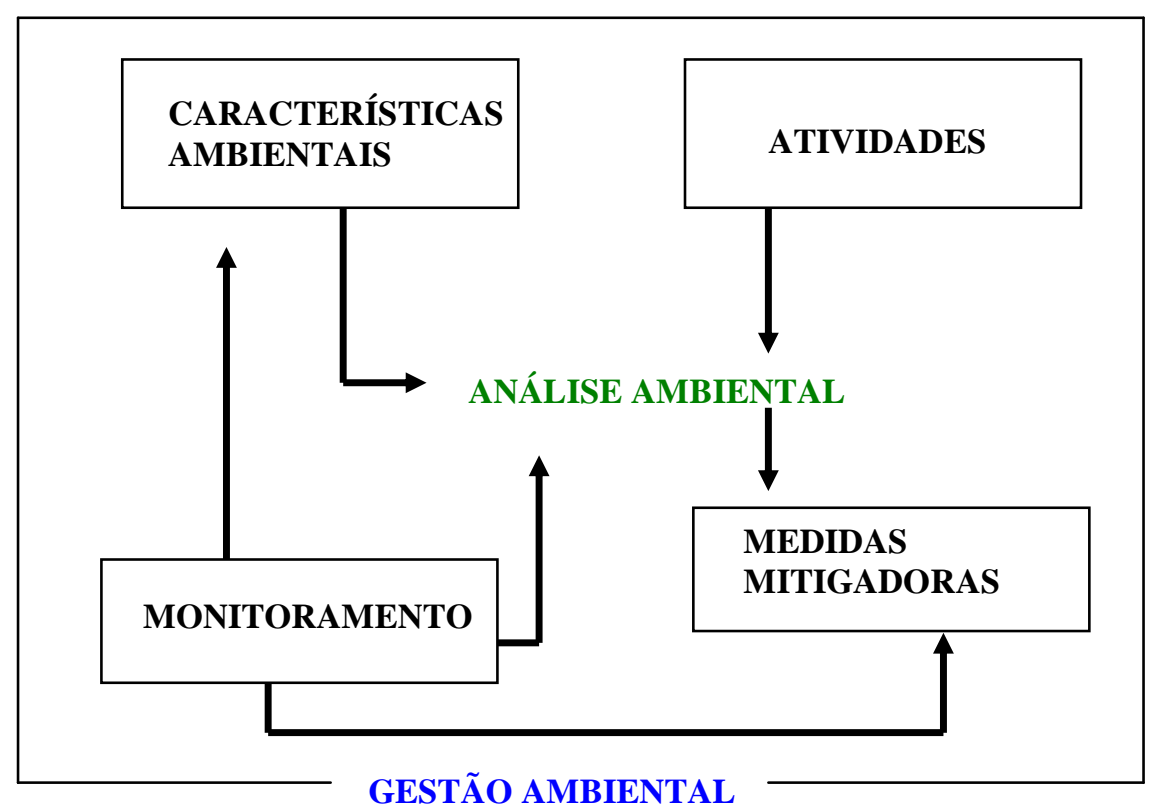

FIGURA 03 - ETAPAS DA GESTÃO AMBIENTAL

FONTE: SOUZA, M. P. (1996) apud CERUCCI (1998)

$\checkmark$ Caracterização Ambiental e da Atividade;

$\checkmark$ Análise Ambiental;

$\checkmark$ Ações Mitigadoras e

$\checkmark$ Monitoramento.

A gestão ambiental tem demonstrado ser o melhor instrumento para administrar as questões ambientais na sua totalidade (FELDMANN, 1997). Aplicada ao setor público, ela pode trazer agentes facilitadores e agilizadores no processo decisório das políticas públicas. Com a gestão ambiental, é possível abrir cada vez mais canais de participação e de parcerias. Ela permite uma postura pró-ativa e solucionadora, evitando que se tenha de correr para sanar danos não previstos.

Assim, de acordo com FELDMANN (1997), a gestão ambiental não é pacífica, ou seja, ela incita discussões e conflitos a partir do momento em que ela se 
defronta com o desafio crucial de integrar as diversas áreas do governo e inserir a dimensão ambiental nas políticas setoriais.

Os objetivos desse sistema de gestão se resumem em:

$\checkmark$ Identificar, em atividades, produtos e serviços, os aspectos ambientais e os respectivos impactos associados que possam ser evitados ou controlados;

$\checkmark$ Estimular à capacitação técnica do corpo funcional nas questões relativas à gestão ambiental, objetivando a difusão de conceitos e práticas ambientais que possibilitem a implementação das diretrizes de desenvolvimento sustentável;

$\checkmark$ Implementar mecanismos de controle ambiental das atividades, produtos e serviços e dos seus respectivos impactos ao meio ambiente, bem como a melhoria dos procedimentos adotados considerando as disposições legais vigentes;

$\checkmark$ Implementar um processo de avaliação ambiental para as políticas, planos ou programas governamentais setoriais de responsabilidade do Estado;

$\checkmark$ Realizar auditorias ambientais para projetos, obras e atividades sob a responsabilidade do Estado.

As auditorias constituem-se numa excelente ferramenta de orientação gerencial, por permitirem aos dirigentes de uma área ou de toda uma organização a identificação dos pontos fracos e fortes de uma determinada atividade, quando sistematicamente comparada a um padrão consagrado como referencial. As normas relacionadas à auditoria ambiental têm por objetivo regulamentar a prática desta ferramenta de especial importância para o funcionamento do sistema de gestão.

A gestão ambiental local supõe a existência de recursos humanos na área de planejamento, que possam aprimorar as ações de controle e melhoria ambiental. A carência de pessoal qualificado constitui um problema para a efetiva ação ambiental nas cidades. Portanto, é um fator que dificulta à tomada de decisão no processo de gerenciamento.

Os processos de gestão nas APAs adquirem uma dimensão distinta em relação aos processos tradicionais de gestão, inclusive os instituídos em outras 
unidades de conservação, em decorrência do fato de não haver uma hierarquia decisória estabelecida, ou seja, enquanto numa organização ou numa UC de uso indireto, existe alguém, ou um colegiado, responsável pela tomada de decisões, com implementação praticamente incontestável. No caso das APAs a situação não é esta.

Na criação das APAs está prevista a existência de um órgão administrativo, o Conselho Gestor, que será o responsável pela tomada de decisões em relação a área. Todavia, a implementação das decisões não é imediata, pois o Conselho não tem este poder. Sendo assim, não há garantias seguras de que decisões tomadas no âmbito da gestão serão implementadas pelos proprietários presentes na área.

\subsection{1 - INSTRUMENTOS DE GESTÃO AMBIENTAL}

Os principais instrumentos de gestão ambiental estão dados no 'artigo $9^{\circ}$ ' da Lei $\mathrm{n}^{\mathrm{o}}$ 6.938, de 31 de agosto de 1981, que 'Dispõe sobre a Política Nacional do Meio Ambiente, seus fins e mecanismos de formulação e aplicação, e dá outras providências'. São eles:

I. o estabelecimento de padrões de qualidade ambiental;

II. o zoneamento ambiental;

III.a avaliação de impactos ambientais;

IV.o licenciamento e a revisão de atividades efetiva ou potencialmente poluidoras;

V. os incentivos à produção e instalação de equipamentos e a criação ou absorção de tecnologia, voltados para a melhoria da qualidade ambiental;

VI. a criação de espaços territoriais especialmente protegidos pelo Poder Público Federal, Estadual e Municipal, tais como áreas de proteção ambiental, de relevante interesse ecológico e reservas extrativistas;

VII. o sistema nacional de informações sobre o meio ambiente;

VIII. o Cadastro Federal de Atividades e instrumentos de defesa ambiental;

IX. as penalidades disciplinares ou compensatórias ao não cumprimento das medidas necessárias à preservação ou correção de degradação ambiental; 
X. a instituição do Relatório de Qualidade do Meio Ambiente, a ser divulgado anualmente pelo Instituto Brasileiro do Meio Ambiente e dos Recursos Naturais Renováveis - IBAMA;

XI. a garantia de prestação de informações relativas ao Meio Ambiente, a ser divulgado anualmente pelo IBAMA;

XII. O Cadastro Técnico Federal de atividades potencialmente poluidoras e/ou utilizadoras dos recursos ambientais

Tais instrumentos oferecem ao gestor a possibilidade de estabelecer limites a ação degradadora dos agentes, sejam eles públicos ou privados. Entretanto, utilizálos em espaços territoriais muito vastos, recortados por um grande número de agentes, como costumam ser as APAs, pode ser muito difícil, devido ao custo de monitoramento das ações individuais.

Decorre dai a convicção de que a implementação das soluções que conduzam à práticas ecologicamente adequadas, especialmente às práticas econômicas, não pode obter resultados satisfatórios se não abranger a maioria (ou um número significativo) dos agentes presentes, através de uma estrutura representativa, como a do Conselho Gestor.

Assim, é de fundamental importância a participação da sociedade como um todo, no processo de gestão, para que não ocorram tomadas de decisões incoerentes com os problemas do local. Mas para apoiar estas decisões é necessário que o zoneamento ambiental, esteja bem elaborado para auxiliar nos possíveis problemas que podem surgir ao longo da gestão.

\section{6 - PLANEJAMENTO AMBIENTAL EM MICROBACIA HIDROGRÁFICA}

Acredita-se que o conceito de microbacia esteja fortemente relacionado aos projetos de planejamento e conservação ambiental e que, para sua definição, se deve acrescentar à própria conceituação de bacia hidrográfica a condição do estabelecimento de uma área, cuja extensão é função de análise de alguns elementos que estarão envolvidos na pesquisa, como técnicas, recursos materiais, equipe de trabalho e tempo disponíveis (BOTELHO, 1999).

A microbacia hidrográfica é a unidade geográfica ideal para o planejamento integrado do manejo dos recursos naturais no ecossistema por ele envolvido e pode 
ser definida como sendo a área fisiográfica drenada por um curso d'água ou por um sistema de cursos d'água conectados e que convergem, direta ou indiretamente, para um leito ou para um espelho d'água (ASSAD et al. 1993, ROSA et al. 1981).

No entanto, BOTELHO (1999) afirma que, por se tratar de uma pequena área, a microbacia hidrográfica, a ser definida como área de estudos, para o desenvolvimento de um projeto de planejamento, precisa ser cuidadosamente selecionada. É essencial que a microbacia seja representativa das condições físicas e sócio-econômicas locais.

A primeira etapa de trabalho envolvida no planejamento é o diagnóstico da microbacia, obtido através das caracterizações fisiográficas, sócio-econômica e das práticas de manejo atualmente utilizadas (ASSAD et al. 1993).

No caso do planejamento em microbacia hidrográfica é necessário um levantamento detalhado de atributos físicos tais como clima, geologia, relevo, solos, rede de drenagem e vegetação. Mas esse levantamento segundo BOTELHO (1999) em geral não se encontra disponível e deve, então, ser produzido com a devida atenção para a necessidade de garantir um nível de investigação ou detalhamento equilibrado entre as variáveis físicas adotadas, sem que haja privilégio de uma sobre a outra.

De acordo com ZAKIA (1998) a área da microbracia tem influência sobre a quantidade de água produzida (deflúvio). A forma e o relevo, por outro lado, atuam sobre a taxa, ou sobre o regime desta produção de água, assim como sobre a taxa de sedimentação. O padrão de drenagem afeta a disponibilidade de sedimentos e a taxa de formação do deflúvio. Muitas das características físicas da microbacia hidrográfica são, em grande parte, controladas ou influenciadas pela sua estrutura geológica.

Assim, ZAKIA (1998) afirma que, a mata ciliar na hidrologia da microbacia hidrográfica, desempenha um papel importante na qualidade da água do deflúvio. Ocupa normalmente as áreas mais sensíveis da bacia, como as margens da rede hidrográfica, ao redor de nascentes e áreas saturadas, e a sua presença ajuda a diminuir a ocorrência de escoamento superficial, que pode causar erosão e arraste de nutrientes e de sedimentos para os cursos d'água. 
Já para GANZELI (1995) as restrições à localização das atividades urbanas, agrícolas e industriais à utilização da água, seja para consumo ou para despejos, devem ser definidas em virtude das características ambientais e das necessidades de proteção de cada microbacia hidrográfica, para que assim, consiga-se dimensionar os problemas e adotar medidas para recuperação, proteção e conservação da microbacia hidrográfica.

Segundo VILLELA \& MATTOS (1975) a declividade de uma bacia hidrográfica tem importância fundamental na velocidade de escoamento superficial e portanto, com fortes implicações no processo de erosão dos solos. Assim, o relevo tem grande influência sobre os fatores metereológicos e hidrológicos, sendo de grande importância a determinação de curvas características do relevo de uma microbacia hidrográfica.

Para BOTELHO (1999) acredita-se que o planejamento ambiental em microbacias hidrográficas possa minimizar a ocorrência de impactos ambientais decorrentes da ação antrópica indiscriminada. Portanto, através deste planejamento pode-se orientar a ocupação humana a fim de que sejam resguardadas as áreas destinadas à preservação ambiental, tendo em vista a conservação dos recursos naturais, a forte instabilidade ou fragilidade ambientais e a alta susceptibilidade à erosão e movimentos de massa que certas porções da paisagem podem apresentar.

\section{7 - SISTEMAS DE INFORMAÇÕES GEOGRÁFICAS - APLICAÇÕES EM PLANEJAMENTO E GESTÃO AMBIENTAL}

Segundo CÂMARA (1996) num país de dimensão continental como o Brasil, com uma grande carência de informações adequadas para a tomada de decisões sobre problemas urbanos e ambientais, o Sistema de Informação Geográfica (SIG) apresenta um enorme potencial, principalmente se baseado em tecnologias de custo relativamente baixo, em que o conhecimento seja adquirido localmente.

Mas segundo WEBER \& HASENACK (1998), a utilização de Sistemas de Informações Geográficas para estudos ambientais no Brasil já acumula alguns anos de experiência, mas apenas recentemente análises relacionadas a empreendimentos que irão afetar o ambiente têm sido contempladas. 
Segundo RANIERI (1996) para o planejamento ambiental, uma técnica de grande utilidade é o Sistema de Informações Geográficas, que permite a manipulação automática de dados espaciais e de atributos.

A necessidade de aquisição de dados sobre a distribuição espacial de propriedades significativas da superfície terrestre, segundo CALIJURI (1995), tem sido uma parte importante das atividades das sociedades organizadas.

Segundo FERRARI (1996) as informações provenientes de SIGs podem ser utilizadas como ferramenta gerencial para planejamentos multidisciplinares como zoneamentos, localização de equipamentos, serviços e redes de infraestrutura urbana, mapas físicos e demográficos, e combinações dessas informações.

\subsection{1 - DEFINIÇÃO}

A evolução dos computadores, seja em memória, periféricos ou pacotes, propiciou segundo MADRUGA \& PEREIRA (1991) apud THUM (1997), o desenvolvimento de sistemas de informação destinado ao processamento de dados referenciados geograficamente, desde a sua aquisição até a geração de saídas na forma de mapas convencionais, relatórios, arquivos em meio magnético, etc, provendo recursos para o armazenamento, gerenciamento, manipulação e análise. Esses sistemas são denominados Sistemas de Informações Geográfica (SIGs).

Os SIGs constituem tecnologia para a investigação de fenômenos diversos, relacionados com engenharia urbana, meio ambiente, geologia, pedologia, vegetação, bacias hidrográficas entre outros (CALIJURI \& ROHM, 1994).

A definição mais comum de um SIG enfatiza que ele é uma ferramenta (CHRISMAN, 1997). Porém, nenhuma ferramenta é totalmente neutra, pois o SIG pode ser projetado para ser efetivo e eficiente para um certo alcance de propósitos. São ferramentas desenvolvidas dentro de um contexto social e histórico para servir necessidades variáveis, mas também são ferramentas que possibilitam mudar seu ambiente.

O SIG tem como objetivos (CHRISMAN, 1997):

U' Medir aspectos de fenômenos e processos geográficos; 
$\mathrm{U}^{\prime} \quad$ Representar estas medidas, normalmente na forma de um banco de dados, enfatizar temas de espaço, entidades e relações no computador;

$\mathrm{U}^{\prime}$ Operar nestas representações, produzir mais medidas e descobrir novas relações integrando fontes discrepantes; e

U' Transformar estas representações para conformar a outras armações de entidades e relações.

Para BURROUGH (1986) SIG é um poderoso conjunto de ferramentas para armazenar, recuperar, transformar e visualizar dados sobre o mundo real.

Para EASTMAN (1998) o SIG é um sistema assistido por computador para aquisição, armazenamento, análise e apresentação de dados geográficos. Este sistema permite a obtenção de dados e relatórios estatísticos, mapas temáticos e modelagem para simulação de diferentes situações do mundo real, a partir de informações inseridas neste sistema como um banco de dados espaciais (que descreve as características geográficas da superfície do terreno), de atributos (que descreve as qualidades dessas características) de mapas georreferenciados ${ }^{1}$ digitais.

Segundo SILVA (1997), o uso crescente de Sistemas de Informações Geográficas (SIGs) como ferramenta em tomadas de decisão está se tornando freqüente em todo o país, pois o SIG é "um sistema de suporte a decisões envolvendo a integração de dados espacialmente referenciados na solução de problemas ambientais" (COWEN, 1988 apud SILVA, 1997).

\footnotetext{
${ }^{1}$ O Estado de São Paulo (1990) - Manual de Redação e Estilo p.176-177- Geo... - Liga-se
} sem hífen ao termo seguinte, dobrando-se o r e o s que iniciem sílaba. 


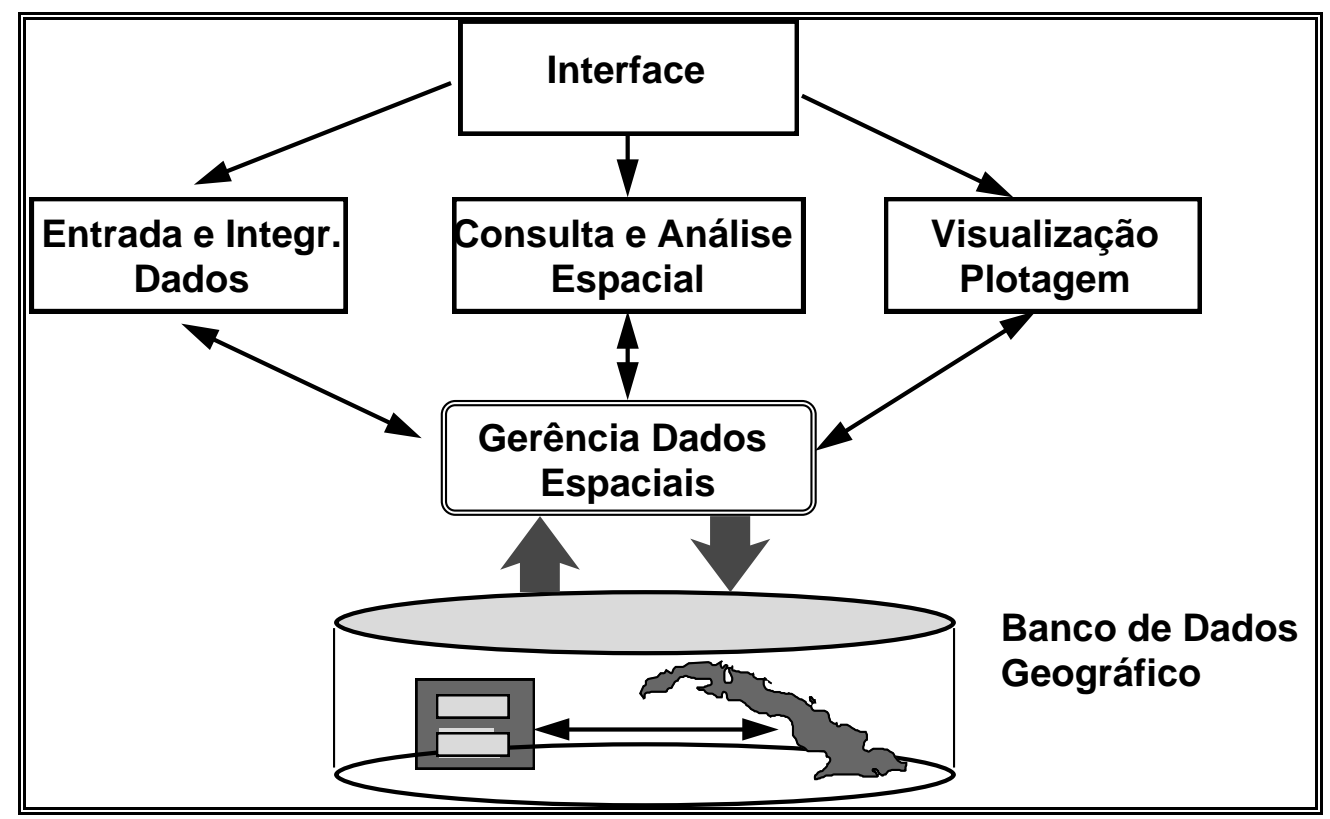

FIGURA 04 - ARQUITETURA DE SISTEMAS DE INFORMAÇÃO GEOGRÁFICA. FONTE: CÂMARA (1996)

$\mathrm{Na}$ figura 04 podemos observar, através das definições citadas, como funciona a arquitetura de um SIG, que tem uma interface para entrada e integração de dados, consulta e análise espacial e uma visualização e plotagem das informações, e isto está interligado num gerenciador de dados espaciais que tem como resultado um banco de dados geográficos. Estas informações podem ser manipuladas dentro do sistema e gerar novas análises espaciais.

\subsection{2 - ELEMENTOS DE UM SIG}

O SIG compreende cinco elementos básicos que operam em um contexto institucional que são (CALIJURI, 1997): software, hardware, metodologias, recursos humanos e dados (figura 05). 


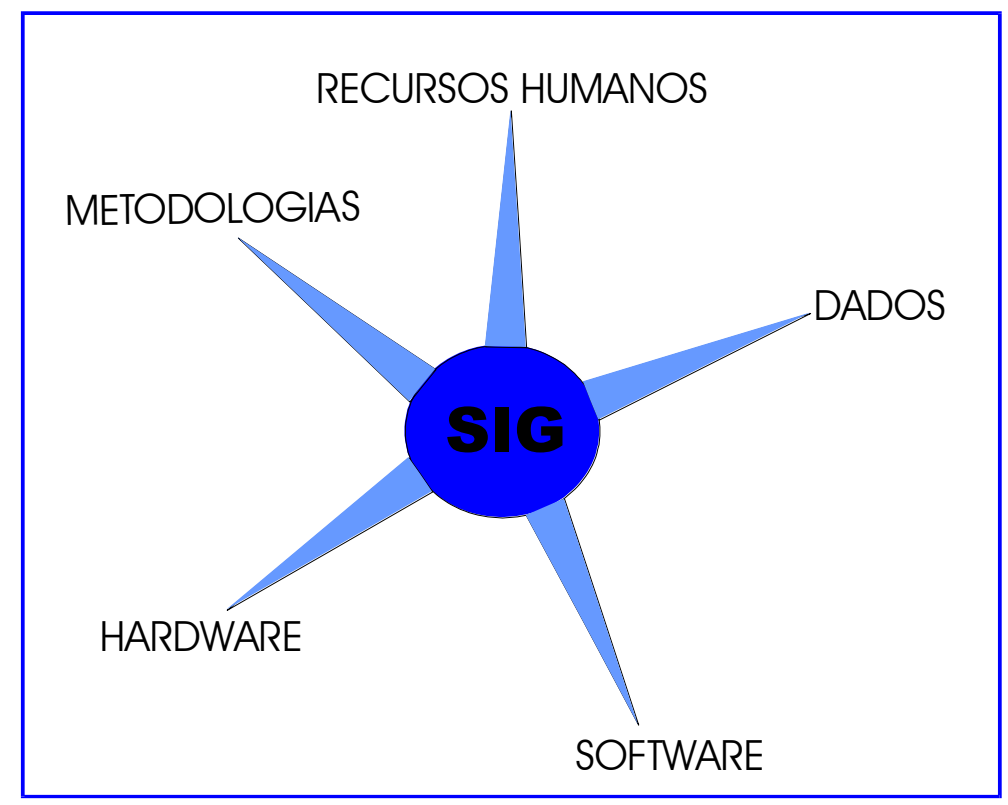

FIGURA 05 - ELEMENTOS DE UM SIG

FONTE: ADPTADO (www.fatorgis.com.br/geoproc/define_tecn.shtml)

Hardware - é o computador no qual o SIG funciona e os periféricos que utiliza. Hoje, um software de SIG funciona num vasto leque de tipos de hardware, desde grandes servidores centralizados a computadores pessoais utilizados em configurações autônomas ou em rede;

Software - disponibiliza as funções e as ferramentas necessárias para armazenar, analisar, e visualizar informação geográfica. Os componentes de software chave são: ferramentas para a entrada e a manipulação de informação geográfica, um sistema de gestão de bases de dados relacional (SGDB) ferramentas que suportam inquirição, análise e visualização geográfica uma interface gráfica com o usuário (GUI - Graphical User Interface) para acesso simples às ferramentas SIG;

Metodologia - executada de acordo com um plano e regras bem definidas, que implementam os modelos e as práticas operacionais que são únicas em cada organização;

Recursos Humanos - a tecnologia SIG é de valor muito limitado sem as pessoas que gerem o sistema e desenvolvem os planos para a sua aplicação na resolução dos problemas reais. Os usuários de SIG vão desde 
especialistas técnicos que concebem e mantém o sistema àqueles que o utilizam como um auxiliar na execução das suas tarefas diárias; Dados - provavelmente o componente mais importante de um SIG são os dados. Os dados geográficos e os dados tabulares relacionados podem ser coligidos internamente ou adquiridos de um fornecedor de dados. O SIG integrará os dados espaciais com os dados provenientes de outras fontes, e poderá usar um SGBD, utilizado em muitas organizações para organizar e manter os seus dados, para gerenciar os dados espaciais.

\subsection{3 - ENTRADA DE DADOS DE UM SIG}

Segundo TEIXEIRA \& CHRISTOFOLETTI (1997) a entrada de dados em um SIG é um processo de introdução de dados num computador, convertendo-os da forma analógica (papel) para a digital, ou de utilização de dados já em forma digital como fonte de alimentação de um base de dados.

Para DAVIS JR. (1999) a entrada de dados é um recurso necessário para o funcionamento do SIG, pois ele é capaz de armazenar informações variadas, de natureza gráfica, como vetores e imagens (raster/matricial).

Os Sistemas de Informações Geográfica trabalham com dois tipos diferentes de modelos geográficos que são:

\section{$\breve{E}$ Modelo Vetorial; \\ $\breve{\mathrm{E}}$ Modelo Raster.}

O modelo vetorial é uma estrutura de dados acerca de pontos, linhas e polígonos (BURROUGH, 1986 e JONES, 1997). É codificada e armazenada como uma coleção de coordenadas x,y. A localização de uma entidade ponto, como por exemplo um furo artesiano, pode ser descrito por uma simples coordenada $\mathrm{x}, \mathrm{y}$. Entidades lineares, como por exemplo estradas e rios, podem ser armazenadas como um coleção de pontos coordenados. Entidades poligonais, como por exemplo uma albufeira ou um território de vendas, podem ser armazenados como uma sequência fechada de coordenadas. 
O modelo vetorial é extremamente útil para descrever entidades discretas, mas menos útil para descrever entidades que variam de forma contínua, como por exemplo o relevo ou a acessibilidade a um hospital.

O modelo raster desenvolveu-se para modelar entidades contínuas como as referidas (BURROUGH, 1986 e JONES, 1997). Uma imagem raster é composta por uma coleção de células, onde a menor célula é denomina de pixel que está associado a uma parcela quadrada da superfície da Terra (figura 06).

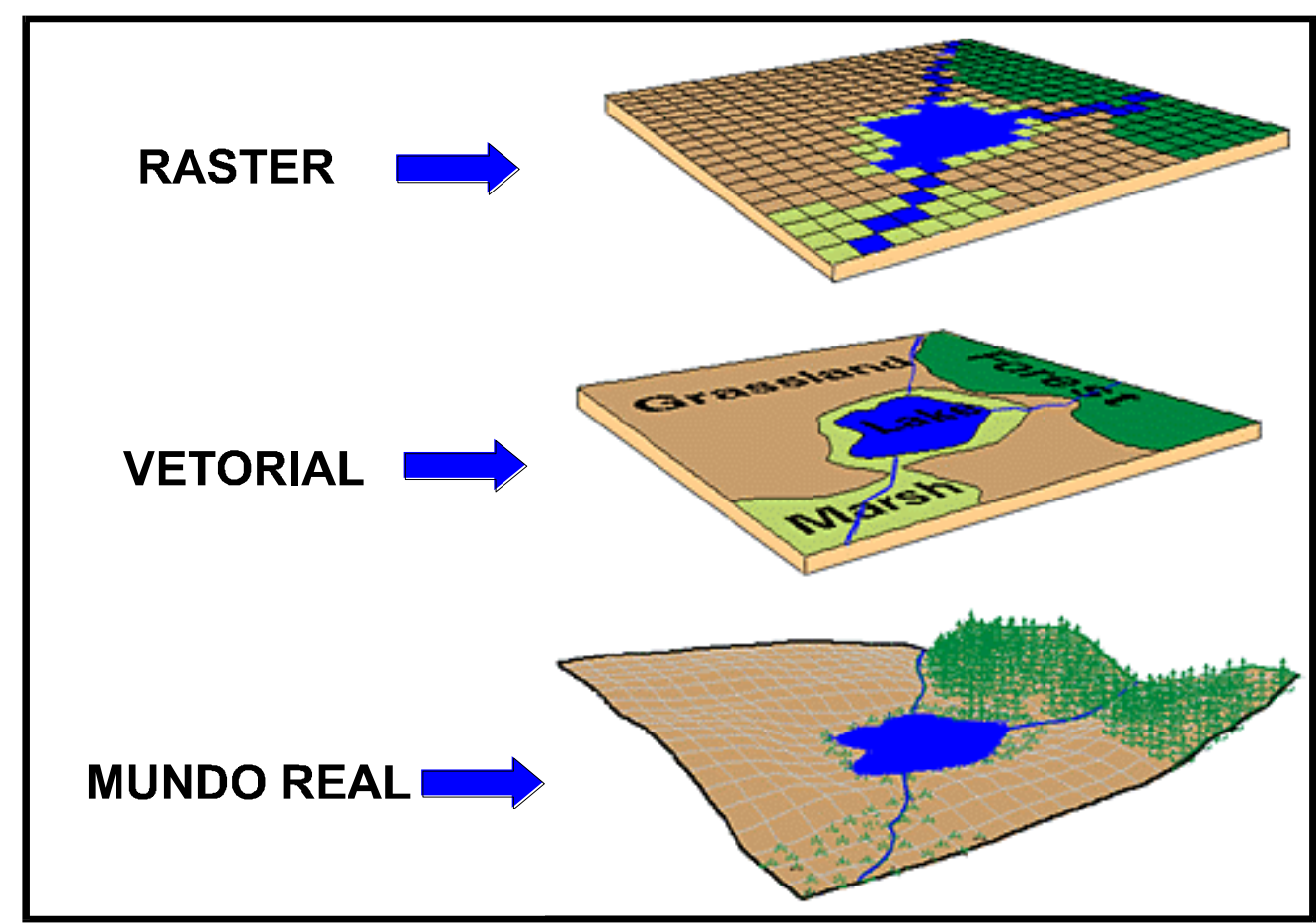

FIGURA 06 - MODELOS DE REPRESENTAÇÃO DO SIG FONTE: ADAPTADO DE ESRI (1999)

O modelo raster é extremamente útil na estimativa de problemas que envolvem combinações matemáticas de dados de células múltiplas, e tem mais poder analítico em análises do espaço contínuo, como estudo de dados sobre solo, biomassa vegetal, chuva entre outros (CALIJURI \& ROHM, 1994).

Um SIG moderno tem que ser capaz de lidar com ambos os modelos, para fornecer ao usuário possibilidades de análises espaciais e interpretações de diversos fenômenos geográficos.

A entrada de dados envolve duas operações distintas: a codificação das informações e a criação de bases de dados (figura 07). É nesta etapa que os dados 
capturados através de observações de campo e do uso de sensores, podendo ser apresentados em forma de mapas, minutas de restituição e tabelas, são transformados para uma forma compatível com o computador, com a utilização de dispositivos tais como: mesa digitalizadora, dispositivos de varredura (scanner), teclado, etc..

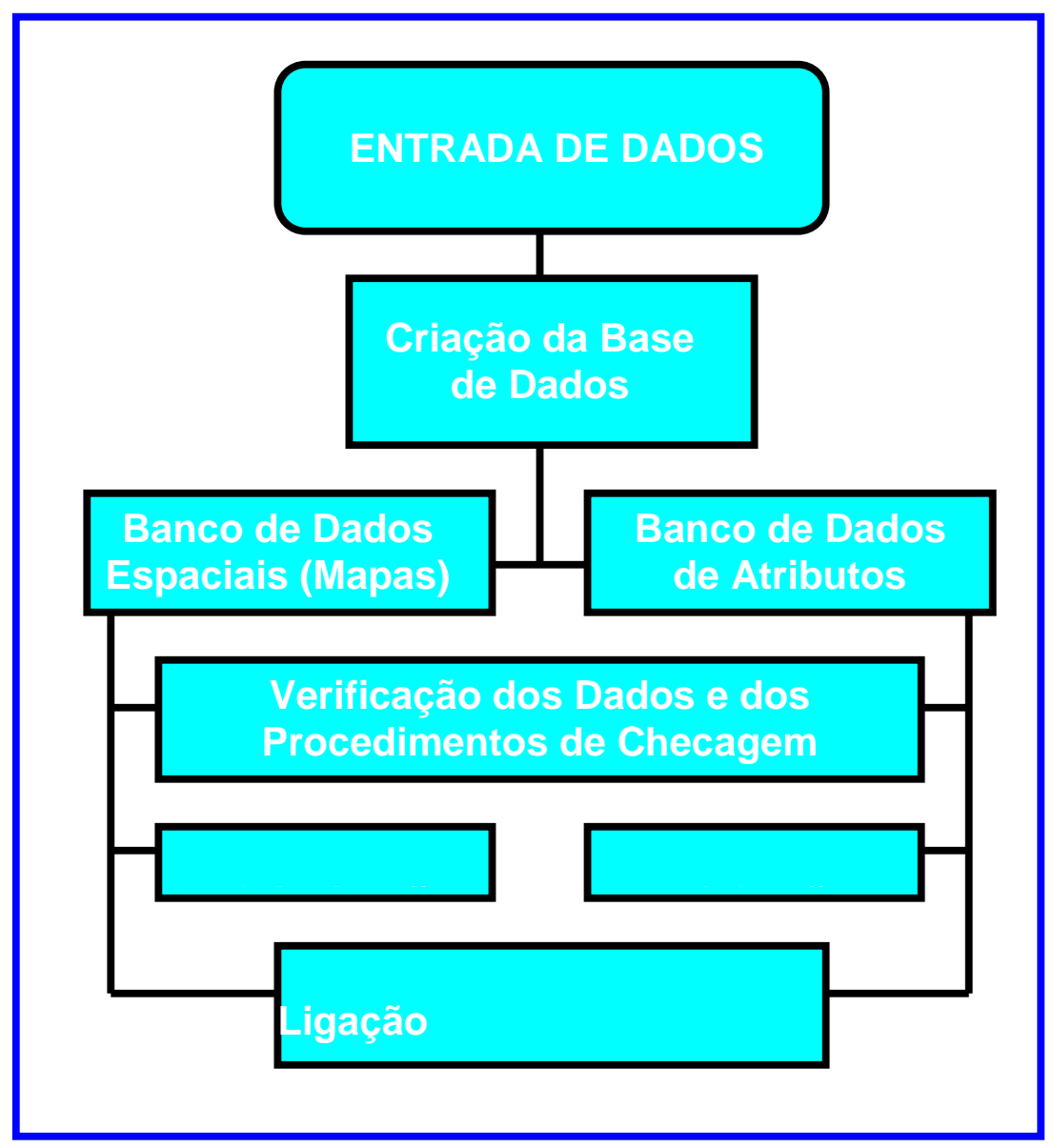

FIGURA 07 - ENTRADA DE DADOS NO SIG

FONTE: ADAPTADO (http://www.geocities.com/WallStreat/Exchange/3012/Aula1.html)

Não se pode pensar em SIG, sem uma base cartográfica digital confiável (com padrões cartográficos definidos como sistema de coordenadas, datum, escala e convenções cartográficas), pois esta dará suporte a maioria das análises realizadas. A confiabilidade da base cartográfica está diretamente relacionada com a escala, e se a mesma está associada a algum sistema de referência cartográfico. Este tipo de conhecimento é de primordial importância, pois suas análises espaciais são realizadas em função de dados georreferenciados. A obtenção dessa base é feita por um processo chamado de digitalização, que é um processo de conversão de pontos, linhas e polígonos de um mapa analógico (papel) para o formato digital. 
A digitalização pode ser feita por uma das seguintes técnicas:

$\checkmark$ Digitalização manual, via mesa digitalizadora (digitalização vetorial);

$\checkmark$ Digitalização semi-automática, usando line follower (digitalização raster);

$\checkmark$ Digitalização automática, usando scanner (digitalização raster);

$\checkmark$ Digitalização sobre tela, usando mapa raster de fundo para vetorização (digitalização raster).

Segundo GUIMARÃES FILHO \& CRÓSTA (1993) antes de começar a digitalizar algum mapa propriamente dito, é importante para o usuário conhecer o objetivo da digitalização e saber o grau de precisão que o produto final deve alcançar.

\subsubsection{1 - VETORIZAÇÃO}

A digitalização vetorial é mais conhecida como digitalização manual, sendo que neste processo utiliza-se a mesa digitalizadora.

A mesa digitalizadora é um equipamento constituído por uma superfície plana ou mesa e por um cursor. Ela possui, na sua parte superior, uma superfície lisa onde é colocado e fixado o mapa a digitalizar, sendo que debaixo desta superfície existe uma malha eletrônica de encoders (registradores numéricos de posição), segundo um sistema de dois eixos perpendiculares. À posição do cursor sobre a superfície da mesa é automaticamente atribuído um par de coordenadas cartesianas $(\mathrm{x}, \mathrm{y})$ pelos encoders. O deslocamento do cursor faz com que haja uma variação nessas coordenadas.

O processo de digitalização manual consiste em utilizar o cursor para acompanhar o desenho das feições representadas no mapa, e a mesa vai gerando automaticamente os pares de coordenadas dos pontos que, no seu conjunto, definem esse deslocamento. Esses dados, gerados no padrão vetorial, são transferidos automaticamente da mesa para o computador, onde são recebidos de acordo com um determinado formato de arquivo definido pelo operador em função do software de captura utilizado, e organizados para formar e estruturar o conteúdo do mapa. 
Nas estruturas de dados vetoriais, as unidades básicas de informação espacial são pontos e linhas, estas organizadas em cadeias (polilinhas), arcos e polígonos.

\subsubsection{2 - RASTERIZAÇÃO}

A conversão de cartas analógicas para o formato digital, em padrão raster, consiste num processo automático de captura de informações digitais através de scanner, que é um equipamento de reconhecimento óptico digital, conceitualmente semelhante a um aparelho de fax, mas cuja saída é feita apenas na forma de arquivos digitais e não em papel. Ou seja, o scanner é um equipamento que produz uma imagem digital, a partir de um input de dados analógicos.

Existem diversos modelos de scanner, mas os principais tipos são os seguintes:

Scanner plano, ou comum de mesa (flatbed);

Scanner de cilíndro;

Scanner de grande formato, para engenharia e CAD.

Para a captura das informações cartográficas digitais em padrão raster, através de scanner, utiliza-se normalmente uma resolução que varia de 200 a 800 dpi. A escolha da melhor resolução é função de vários fatores, tais como: a forma de utilização do arquivo digital que vai ser gerado, qualidade visual do original cartográfico, definição e grau de detalhe do mesmo, quantidade de diferentes feições cartográficas presentes nesse original, capacidade de processamento e de armazenamento de dados do computador utilizado, entre outros.

Como vai ser feita a utilização desse documento cartográfico no SIG, portanto dentro de um referencial de coordenadas, esse documento deverá ser georreferenciado e corrigidas todas as deformações do mesmo, tanto aquelas já existentes no original cartográfico, quanto as originadas pelo scanner (arrastamento da folha, etc.). Deverá também ser feita a eliminação de sujeiras, manchas e marcas que porventura ocorram no original cartográfico. 


\section{8 - O USO DE GPS (GLOBAL POSITIONING SYSTEM) PARA GEORREFERENCIAMENTO DE BASE CARTOGRÁFICA}

A tecnologia GPS revolucionou os métodos de levantamentos geodésicos. É considerada atualmente uma das técnicas mais precisas, exatas e eficazes no posicionamento de pontos.

O sistema GPS é um sistema de multipropósitos, que permite aos usuários determinar posições em coordenadas geográficas geodésicas latitude, longitude e altura geométrica, além de coordenadas cartesianas geodésicas $\mathrm{X}, \mathrm{Y}, \mathrm{Z}$ (SEGANTINE, 1998).

Para SILVA (1997), o sistema GPS é um sistema que nos permite calcular coordenadas geodésicas em WGS 84 a partir dos dados irradiados na mensagem de navegação, cuja seleção da técnica de observação depende do projeto, principalmente da precisão desejada.

Segundo LEICK (1991) apud CHAVES (1998), primeiramente, o GPS chamou a atenção por ser o meio preferido para a densificação das redes geodésicas, dos levantamentos de precisão para a engenharia e o monitoramento das deformações da crosta terrestre. Em seguida, houve a aceitação no mundo da navegação, onde foram atendidas não somente as exigências clássicas dos aviões e embarcações oceânicas, mas também a navegação para lazer, o monitoramento de veículos, de máquinas industriais, etc. E, finalmente, o GPS foi considerado recentemente como a maior ferramenta para proporcionar ou suplementar a referência espacial para o Sistema de Informação Geográfica (SIG).

Segundo CHAVES (1998), os SIGs não estão limitados a uma precisão posicional específica. Sua aplicação é muito variada. Já a teoria geodésica, é comum a todas as referências espaciais e proporciona os fundamentos para relacionar as observações a um sistema de coordenadas bi e tri dimensionais. Portanto, o impacto do GPS nos SIGs é de extrema importância.

O georreferenciamento de base cartográfica é realizado através de levantamentos de campo, de pontos de controle, rastreados com GPS e bem identificáveis na carta e/ou no mapa, para que assim, ao utilizar uma mesa digitalizadora estes pontos sejam inseridos como coordenadas da carta e/ou do mapa não georreferenciado. Mas é bom lembrar que estas coordenadas devem ser 
convertidas antes de serem utilizadas, para um sistema de referência compatível com o objetivo do trabalho.

A utilização de receptores de sistemas de posicionamento global (GPS) por satélite, tem-se assumido como uma das principais fontes de introdução de novos dados geográficos para os SIG. Com um receptor GPS, a digitalização de entidades geográficas (pontos, linhas e áreas) e a respectiva classificação alfanumérica, tem lugar diretamente na superfície da terra, acelerando o processo de entrada de dados no SIG.

Segundo CHAVES \& SEGANTINE (1997) o GPS pode ser utilizado na determinação de pontos de referência para o controle de qualidade de produtos cartográficos, devendo-se ter os devidos cuidados quanto aos referenciais envolvidos.

\subsection{1 - DESCRIÇÃO DO SISTEMA GPS}

O GPS fornece aos usuários, diretamente, a determinação instantânea aproximada da posição de pontos, em três dimensões, sobre a superfície terrestre, próximo a ela ou no espaço. Isto se consegue utilizando-se o efeito Doppler de ondas de rádio emitidas pelo satélites, cujas posições são conhecidas em suas órbitas (SEGANTINE, 1998).

O sistema GPS, formalmente NAVSTAR - GPS (NAVigation System with Time and Ranging - Global Positioning System) é um sistema de satélites de rádio navegação que fornece posição em três dimensões para pontos em qualquer parte do planeta (SILVA, A. S., 1997).

A concepção do sistema foi de um satélite que medisse distâncias de um ponto de coordenadas conhecidas, o satélite, para pontos da Terra, mar e ar que tivessem suas coordenadas a determinar (HOFMANN-WELLENHOF et al. 1997).

O GPS é divido em (KENNEDY, 1996):

๘ Global: Em qualquer lugar da Terra. Bem, quase em qualquer lugar, mas não dentro de edifícios, subterrâneo, em precipitação severa, debaixo de pálio de árvore pesado, ou não tendo outro em qualquer lugar com uma visão direta de uma porção significativa do céu. As ondas de rádio que satélites de GPS transmitem têm durações muito pequenas - 
aproximadamente $20 \mathrm{~cm}$. Uma onda desta duração é boa para medir porque segue um mesmo caminho direto, distinto de seus primos mais longos, como a AM (Amplitude Modulada) e a FM (Freqüência Modulada) que atuam em ondas de rádio e podem dobrar consideravelmente. Infelizmente, ondas pequenas também não penetram muito bem, assim o transmissor e o receptor não devem ter muito assunto sólido entre eles, ou as ondas são bloqueadas, como as ondas da luz que são facilmente bloqueadas;

$\varpi$ Posicionamento: Perguntas que marcaram o homem desde os tempos remotos até hoje são questões como: Onde você está? Com que velocidade você está se movendo e em que direção? Que direção você deveria tomar para chegar a alguma outra localização específica, e quanto tempo levaria a sua velocidade para chegar lá?

๗ Sistema: Uma coleção de componentes com conexões (vínculos) entre eles.

Portanto, podemos definir o GPS, conforme a divisão de KENNEDY (1996), como sendo um sistema capaz de fornecer um posicionamento, ou a localização (de um ponto) em qualquer lugar da Terra, desde que respeitado os critérios para sua determinação.

\subsection{2 - O SISTEMA GPS}

O sistema GPS possui as seguintes características (FREICHO, 1996):

๘ 24 satélites em órbita, sendo 21 satélites ativos e 3 reservas;

$\varpi \quad$ Altitude nominal de $20.183 \mathrm{~km}$;

๘ 6 planos orbitais com inclinação de $54^{0} 44^{\prime}$ e 4 satélites em cada órbita;

$\varpi$ Período orbital de 12 horas siderais;

๘ Órbita elíptica circular;

๘ Freqüência fundamental $\mathrm{f}_{0}$ de 10,23 Mhz;

$\varpi$ Portadoras: $\mathrm{L} 1=1575,42 \mathrm{Mhz} \operatorname{com} \lambda 1=19,05 \mathrm{~cm}$ e $\mathrm{L} 2=1227,60$ Mhz com $\lambda 2=24,45 \mathrm{~cm}$; 
๘ Relógios atômicos com estabilidade de $10^{-12}$;

O sistema GPS é dividido em três grandes segmentos (figura 08) (SEGANTINE, 1998):

7 Segmento Espacial;

7 Segmento de Controle Terrestre;

7 Segmento do Usuário.

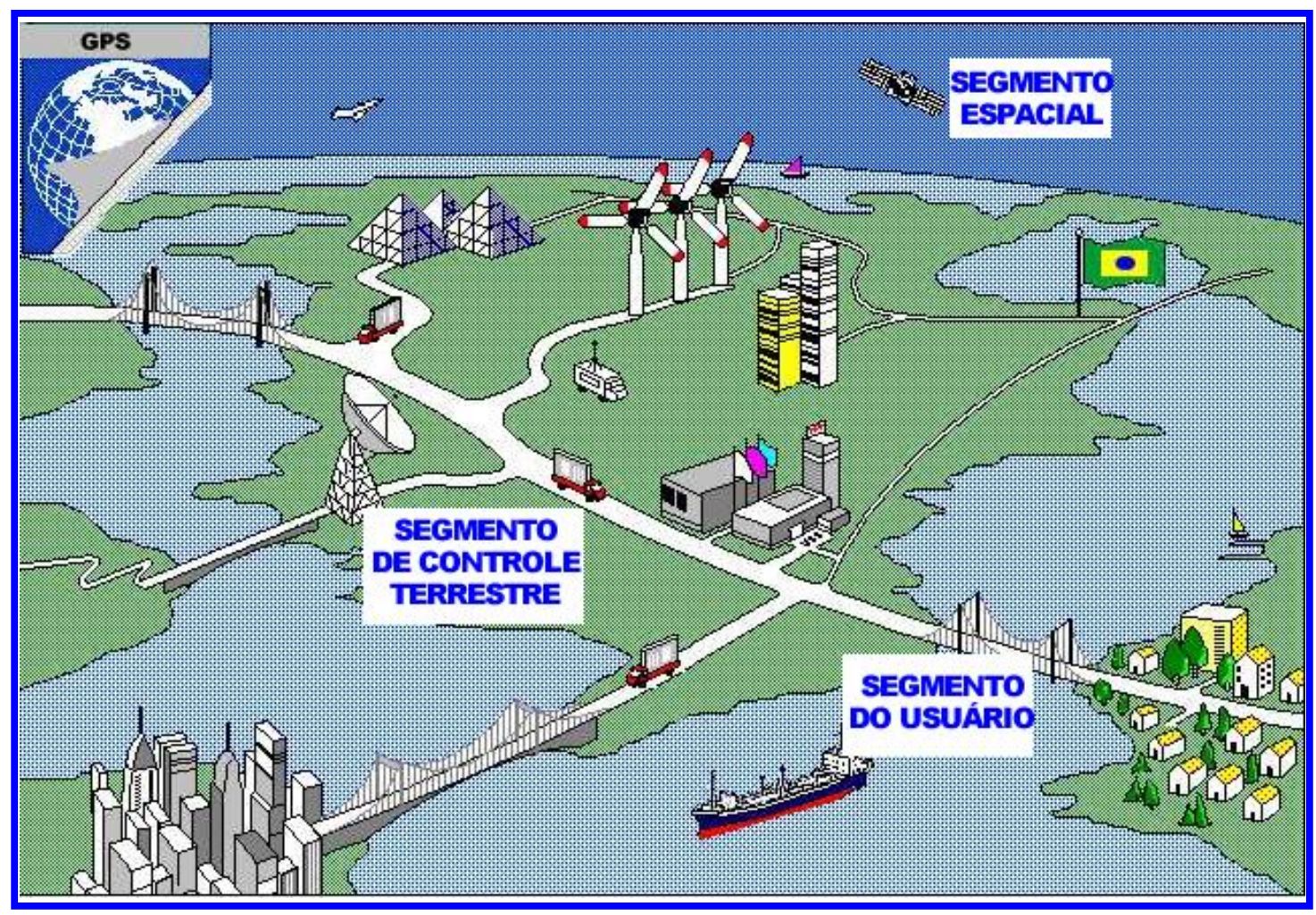

FIGURA 08 - SEGMENTOS DO GPS

FONTE: ADAPTADO DE OSW (1994) 
O segmento espacial é composto pela constelação de satélites (figura 09), e possui a função de gerar e transmitir os sinais GPS (códigos, portadoras e mensagens de navegação).

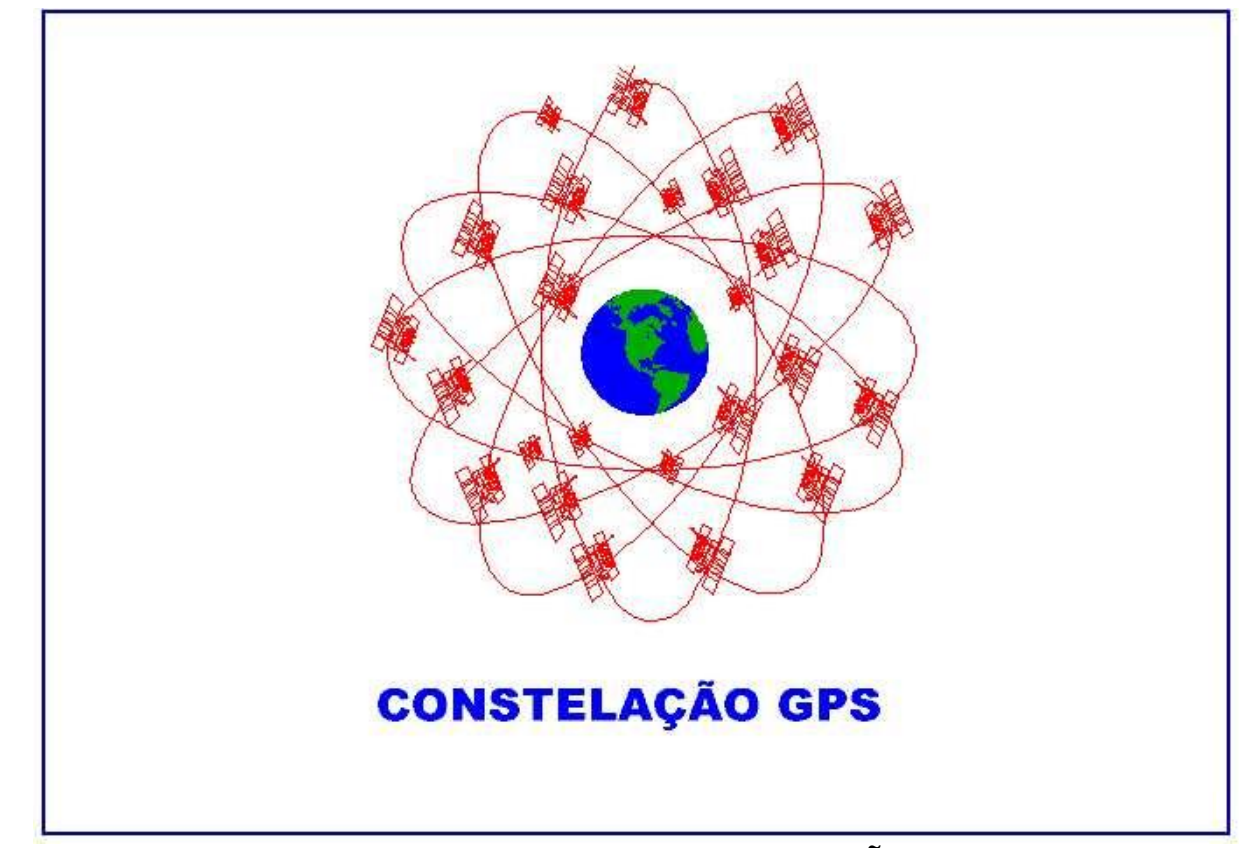

FIGURA 09 - SEGMENTO ESPACIAL - CONSTELAÇÃO GPS (DANA, 1994)

As portadoras são moduladas em fase com os códigos, que são representados por:

Código C/A (Coarse Acquisition code): é modulado sobre a portadora L1 e é afetado pela técnica $\mathrm{SA}^{2}$ (Selective Availability) que tem o objetivo de degradar a sua precisão quando for "necessário". Permite posicionamento através do SPS (Standard Positioning Service);

Código P (Precise Code): modulado sobre as portadoras L1 e L2 é usado na AS (Anti Spoofing), transforma-se no código Y, impedindo seu acesso à usuários não autorizados. Permite posicionamento através do PPS (Precise Positioning Service).

\subsubsection{2 - O SEGMENTO DE CONTROLE TERRESTRE}

\footnotetext{
${ }^{2}$ Esta técnica foi desligada com a autorização do Bill Clinton a partir de 1 de maio de 2000.
} 
O segmento de controle terrestre é composto por três estações (figura 10) que são (HOFMANN-WELLENHOF et al. 1997):

Estação de Controle Master;

Estações de Monitoramento;

皿 Estações de Controle Terrestre (Antenas Terrestres).

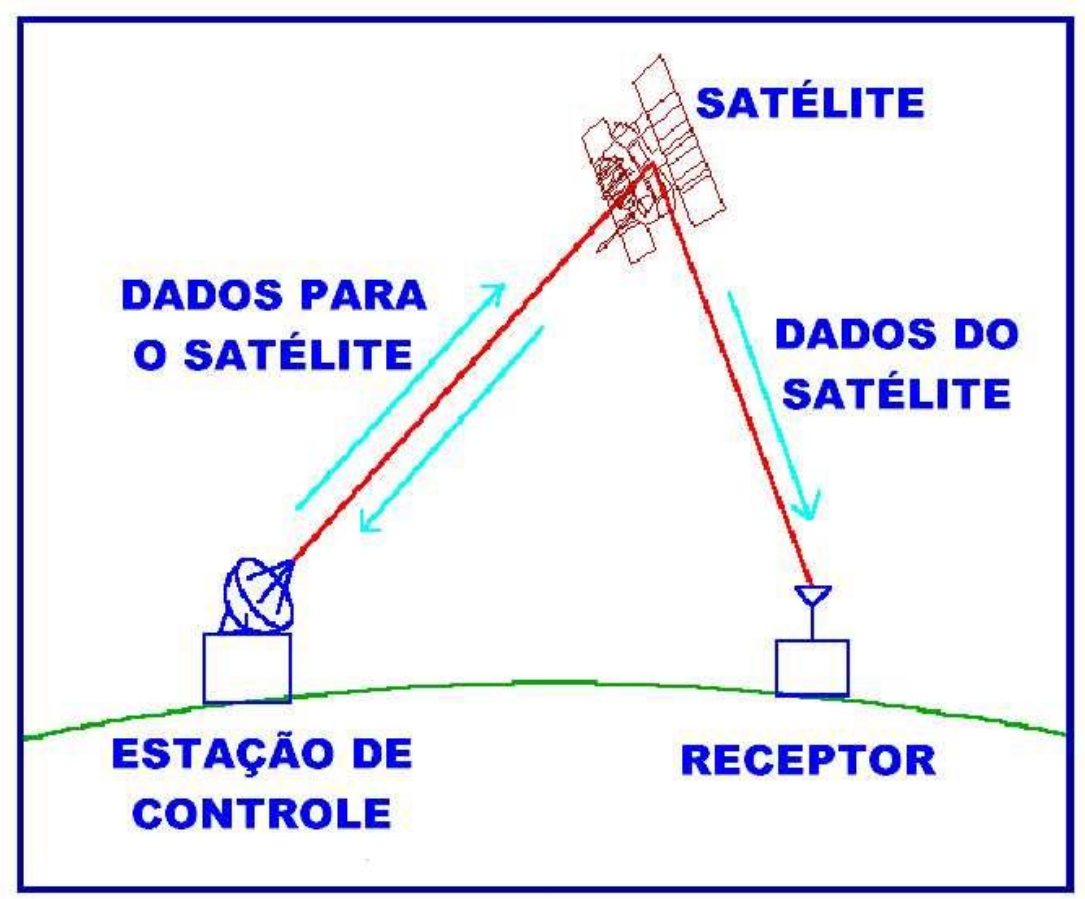

FIGURA 10 - SEGMENTO DE CONTROLE TERRESTRE (DANA, 1994)

Estas estações tem como funções segundo SEGANTINE (1998):

$\varpi$ Rastrear os satélites GPS e fornecer suas posições periodicamente;

$\varpi$ Corrigir as efemérides transmitidas e os erros dos relógios;

๘ Determinar o tempo GPS;

$\varpi$ Predizer as efemérides e o comportamento dos relógios dos satélites;

$\varpi$ Atualizar, periodicamente, a mensagem de navegação para cada satélite em particular.

\subsubsection{3 - O SEGMENTO DO USUÁRIO}


O segmento do usuário (figura 11) é constituído de todos os equipamentos utilizados para recepção dos sinais GPS, e também, é parte deste segmento todos os programas para processamento e planejamento das operações GPS.

Segundo HOFMANN-WELLENHOF et al. (1997) o segmento do usuário é dividido em: usuários militares e civis.

O sistema GPS foi criado pelo Departamento de Defesa dos EUA para fins militares com objetivos variados, que segundo HOFMANN-WELLENHOF et al. (1997) e SEGANTINE (1998) um exemplo típico é o uso de receptores por tropas de infantaria para estimar suas posições e deslocamentos durante as manobras de treinamento e de combate. Devido a isso, durante a Guerra do Golfo em 1991, as tropas aliadas usaram mais de 9000 receptores (manuais e instalados em navios, aviões, tanques etc.) durante a operação "Desert Storm" e com isso puderam se deslocar com rapidez e eficiência através das regiões desérticas dessa área. Esta Guerra marcou um novo conceito de guerra moderna devido a comprovação da precisão desta novidade tecnológica.

Para o usuário civil segundo HOFMANN-WELLENHOF et al. (1997) e SEGANTINE (1998) o sistema GPS tem sido utilizado em diferentes tipos de atividades e além disso, novas aplicações tem surgido no dia a dia.

Podemos observar estas aplicações desde o uso em levantamentos geodésicos, navegações marítimas, aérea, rastreamentos de veículos, e diversas outras áreas da mensuração e até em controle de desastres ambientais. 


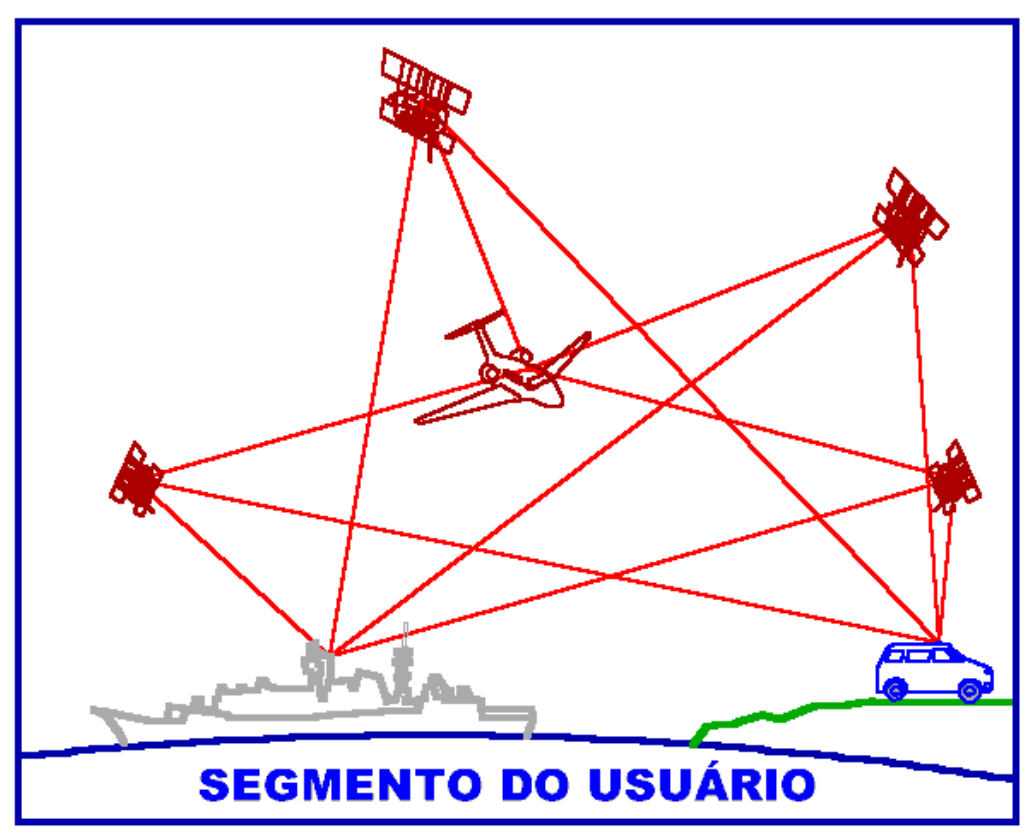

FIGURA 11 - SEGMENTO DO USUÁRIO (DANA, 1994) 


\section{4 - MATERIAIS E MÉTODOS}

\section{1 - CARACTERIZAÇÃO DA CIDADE}

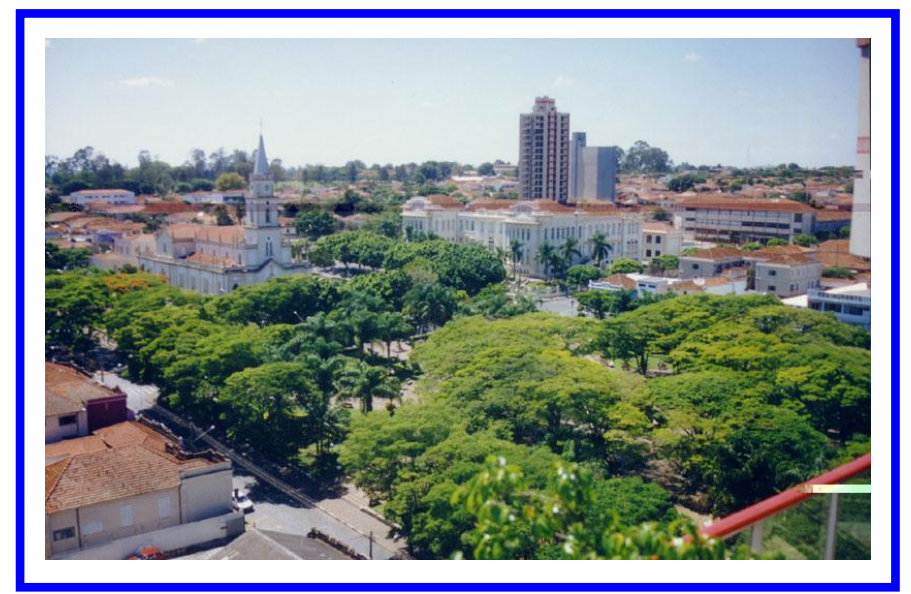

FIGURA 12 - REGIÃO CENTRAL DE PIRASSUNUNGA

O nome Pirassununga provêm da língua Tupi-Guarani, na qual significa "lugar onde o peixe faz barulho". Fundada em 1823 com a vinda de Ignácio Pereira Bueno e sua mulher Ana Francisca da Silva. Pirassununga é um município moderno e dinâmico, servido por uma malha rodoviária que permite alcançar todos os quadrantes do país, destacando-se pelo comércio, indústria e agropecuária fortes.

Pirassununga acolhe à Academia da Força Aérea, que sedia o Esquadrão de Demonstração Aérea, a conhecida Esquadrilha da Fumaça, um dos Campus da Universidade de São Paulo, o Segundo Regimento de Carros de Combate, a Fazenda da Aeronáutica, o Centro de Pesquisa e Treinamento em Aquicultura do Instituto Brasileiro do Meio Ambiente e dos Recursos Naturais Renováveis, e a famosa Cachoeira de Emas. O Ecomuseu, o Parque Municipal "Temístocles Marrocos Leite", o Museu Histórico e Pedagógico "Dr. Fernando Costa", o Teatro Municipal "Cacilda Becker" e o Centro de Educação Física e Esportes "Presidente Médici", entre outros, representam a força cultural do torrão corimbatá. 
Pirassununga (figura 12) é uma cidade com aproximadamente 70 mil habitantes localizada no ponto sede a latitude de $21^{0} 59^{\prime} 46^{\prime \prime}$ sul e longitude de $47^{0}$ 25'33" oeste (em coordenadas SAD69), com uma altitude média de 627 metros e uma área municipal de $728,7 \mathrm{~km}^{2}$, fica entre as cidades de Campinas e Ribeirão Preto. É banhada pelas águas do Rio Mogi Guaçú e possui as seguintes características:

$\checkmark$ Localização: Estado de São Paulo, Brasil, a 207 km da capital, acessível pela Via Anhanguera;

$\checkmark$ Cidades Limítrofes: Aguaí, Araras, Descalvado, Leme, Mogi-Guaçú, Porto Ferreira, Santa Cruz da Conceição e Santa Cruz das Palmeiras;

$\checkmark$ Data de Fundação: 06 de agosto de 1.823;

$\checkmark$ Clima: Tropical de Altitude;

$\checkmark$ Vegetação: Predomínio de cerrado, com faixas de mata atlântica;

$\checkmark$ Hidrografia: Rio Mogi Guaçú, pertencente à Bacia Platina.

\section{2 - CARACTERIZAÇÃO DA ÁREA DE ESTUDO}

A área de estudo (figura 13) possui aproximadamente 860 hectares, localizada entre as latitudes $21^{0} 55^{\prime} 35^{\prime \prime}$ a $21^{0} 57^{\prime} 35^{\prime \prime}$ sul e longitudes $47^{0} 22^{\prime} 00^{\prime \prime}$ a $47^{0} 23$ '45" oeste (em coordenadas SAD69), na Rodovia Faria Lima, km 6 a 9. Nela se encontra a micro bacia do Córrego da Barrinha, um dos afluentes do Rio MogiGuaçú, nas proximidades do Distrito de Cachoeira de Emas, uma área de grande potencial eco-turístico. Nesta região temos o CEPTA - IBAMA (figura 14) um grande centro de desenvolvimento científico e tecnológico na área de aquicultura, que vem procurando fazer a reinserção no seu ambiente natural, o Rio Mogi-Guaçú, da piracanjuba, uma das tantas espécies de peixes em estado de extinção, e trabalhando sobre a reprodução de pintados, através de métodos de indução, com hormônios comprados no exterior. 


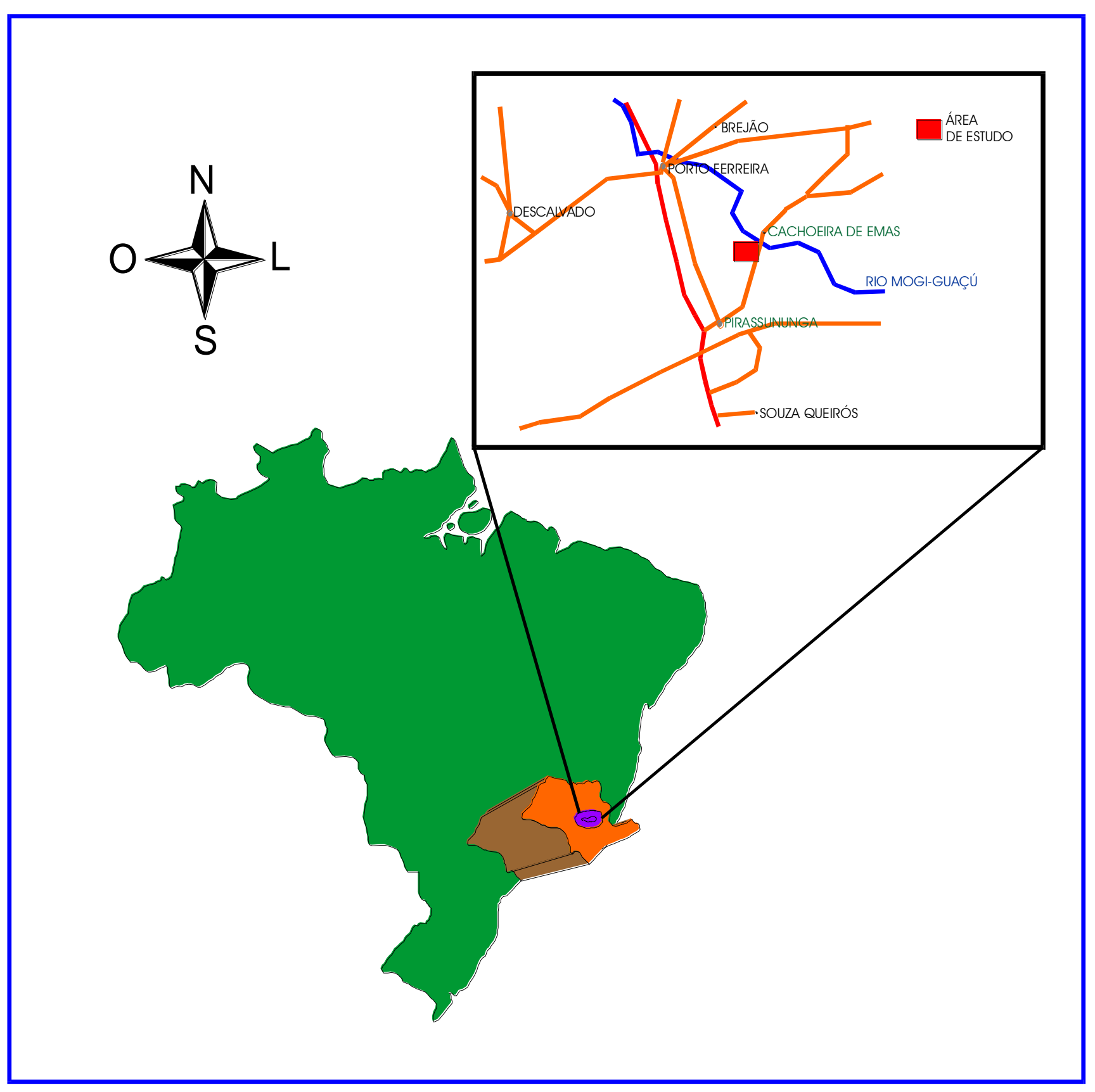

FIGURA 13 - LOCALIZAÇÃO DA ÁREA DE ESTUDO 


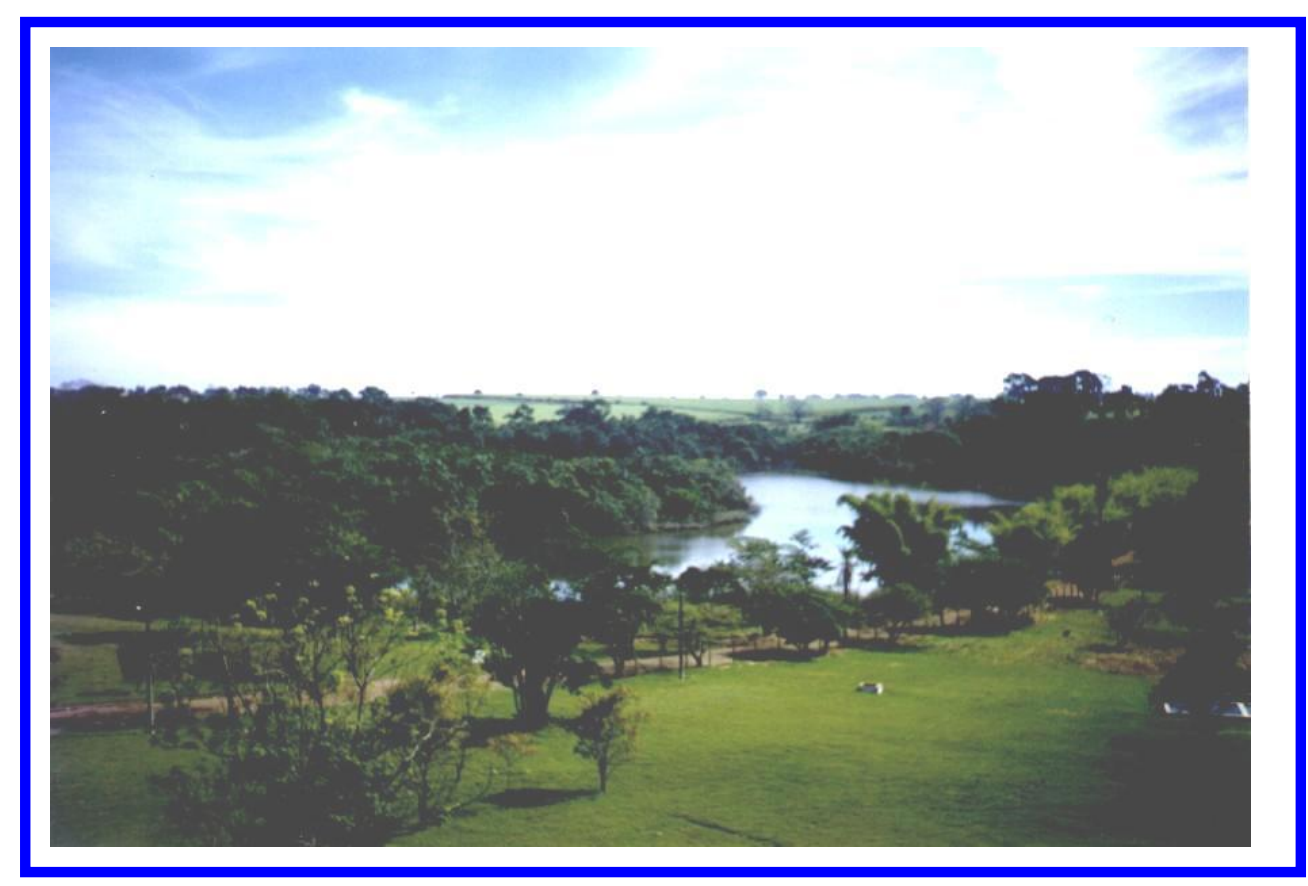

FIGURA 14 - VISTA INTERNA DA LAGOA DO CEPTA (IBAMA) EM PIRASSUNUNGA

\section{3 - MATERIAIS}

Para executar a proposta de zoneamento ambiental desta região foram utilizados os seguintes materiais:

Base cartográfica - Mapa Aerofotogramétrica Planialtimétrica, restituída na escala de 1:5.000 em 1995, fornecido pelo IBAMA - CEPTA utilizado para obtenção das informações de uso e ocupação do solo, hidrografia, curvas de nível, estradas e limite da micro bacia;

罰 Mapa de Formações Geológicas de Superfície, Folha Pirassununga (SF23-V-C-V-3), do Instituto Geológico do Estado de São Paulo, na escala 1:50.000, edição de 1981 - utilizado para obtenção das informações de geologia;

圊 GPS - Sensor GPS SR 9400 com receptor de 12 canais, controladora CR 333 da marca Leica (figura 15) - utilizado no levantamento dos pontos para o georreferenciamento da base cartográfica restituída (informações fornecidas pelo IBAMA - CEPTA); 


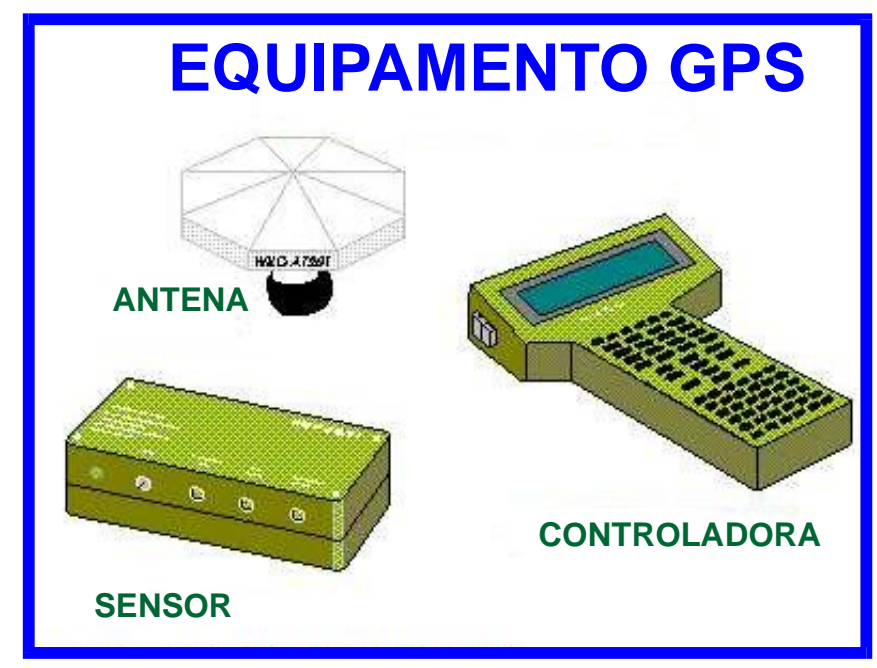

FIGURA 15 - EQUIPAMENTO GPS

賏 Mesa Digitalizadora - Summagraphics modelo Summagrid IV, tamanho A1 - utilizado na entrada de dados espaciais;

辨 Software IDIRISI FOR WINDOWS versão 2.0 - utilizado nas análises espaciais;

璌 Software CARTALINX versão 1.04 - utilizado na digitalização da base cartográfica por ser um software recente (1997) e que se adapta as informações para o software IDRISI FOR WINDOWS;

賏 Software TDAT - utilizado na conversão das coordenadas geodésicas (SAD 69) para coordenadas plano-topográficas locais;

俸 Software AUTOCAD R14 - utilizado para editar as curvas de nível em situações que não foi solucionado o problema no software CARTALINX;

賏 Software SKI v 2.13 - utilizado para o processamento do dados obtidos com o GPS;

罾 Software SURFER - utilizado para gerar o MDT vetorial da microbacia;

圁 GPS - PIONEER da Magellan com recepção de até 12 satélites e acuracidade de 100 metros sem o código SA - utilizado para validação de campo do sistema topográfico local. 


\section{4 - METODOLOGIA}

Para digitalização da base cartográfica foi utilizado como sistema de referência o sistema topográfico local, definido na nova norma técnica, a NBR 14166 (Rede de Referência Cadastral de 1998). Este método foi utilizado porque a área de estudo favorece o uso deste sistema de referência, e através desta metodologia as pessoas que trabalham com sistemas de informações geográficas terão uma outra alternativa de sistema de coordenadas, principalmente quando existem trabalhos em que a área de estudo encontra-se em dois fusos.

Segundo KLEINER \& MENEGUETE (1999) em regiões de mudança de fuso só é permitido o uso de coordenadas no sistema de projeção Universe Transverse Mercator (UTM), quando apenas uma parte da área de estudo, encontra-se no outro fuso, a uma distância de meio grau, o que equivale a aproximadamente $50 \mathrm{~km}$.

O uso de coordenadas no sistema de projeção UTM é muito utilizado por usuários de sistemas de informações geográficas, e portanto, as restrições referentes a trabalhos que envolvam regiões de mais de um fuso, interferem no desenvolvimento do trabalho e na concatenação das cartas. Mas o uso do sistema topográfico local só poderá ser utilizado, desde que, a área de estudo esteja dentro das características deste sistema de coordenadas, e isto está descrito nos próximos sub-itens.

Um outro fator importante nos sistemas de coordenadas para utilização em SIG's é o sistema geodésico de referência, que se refere a um datum planimétrico, que segundo D'ALGE (1999) é desconhecido pela grande maioria na comunidade de usuários de SIG.

Este datum segundo OLIVEIRA (1983), na geodésia, é a superfície de referência que contém cinco parâmetros:

Ponto materializado no terreno;

Altura geoidal;

Elipsóide de referência;

Coordenadas astronômicas do ponto de partida e;

Azimute astronômico deste ponto.

Segundo CORDINI et al (1999) tradicionalmente o termo datum tem sido usado para designar o ponto de origem de uma rede, seja planimétrica ou altimétrica. 
Sendo assim, no Brasil a rede planimétrica fundamental tem como origem o Datum Chuá, localizado em Minas Gerais, e a rede altimétrica tem como origem o Datum Vertical localizado em Imbituba, no Estado de Santa Catarina.

Portanto, é importante observar qual o Datum a ser utilizado, pois no Brasil além do Datum Chuá temos o Datum Córrego Alegre, que pode ser encontrado em cartas do IBGE, IGC (Instituto Geográfico e Cartográfico) e outros mapeamentos, e também, a RBMC (Rede Brasileira de Monitoramento Contínuo) em WGS84 (obtidas com o GPS) que foi estabelecido no Projeto SIRGAS (Sistema de Referência Geocêntrico para a América Latina). Este projeto foi iniciado na Conferência Internacional para definição de um Datum Geocêntrico para a América do Sul, ocorrida de 4 a 7 de outubro de 1993, em Assunção no Paraguai (IBGE 1997). 


\subsection{1 - O SISTEMA TOPOGRÁFICO LOCAL}

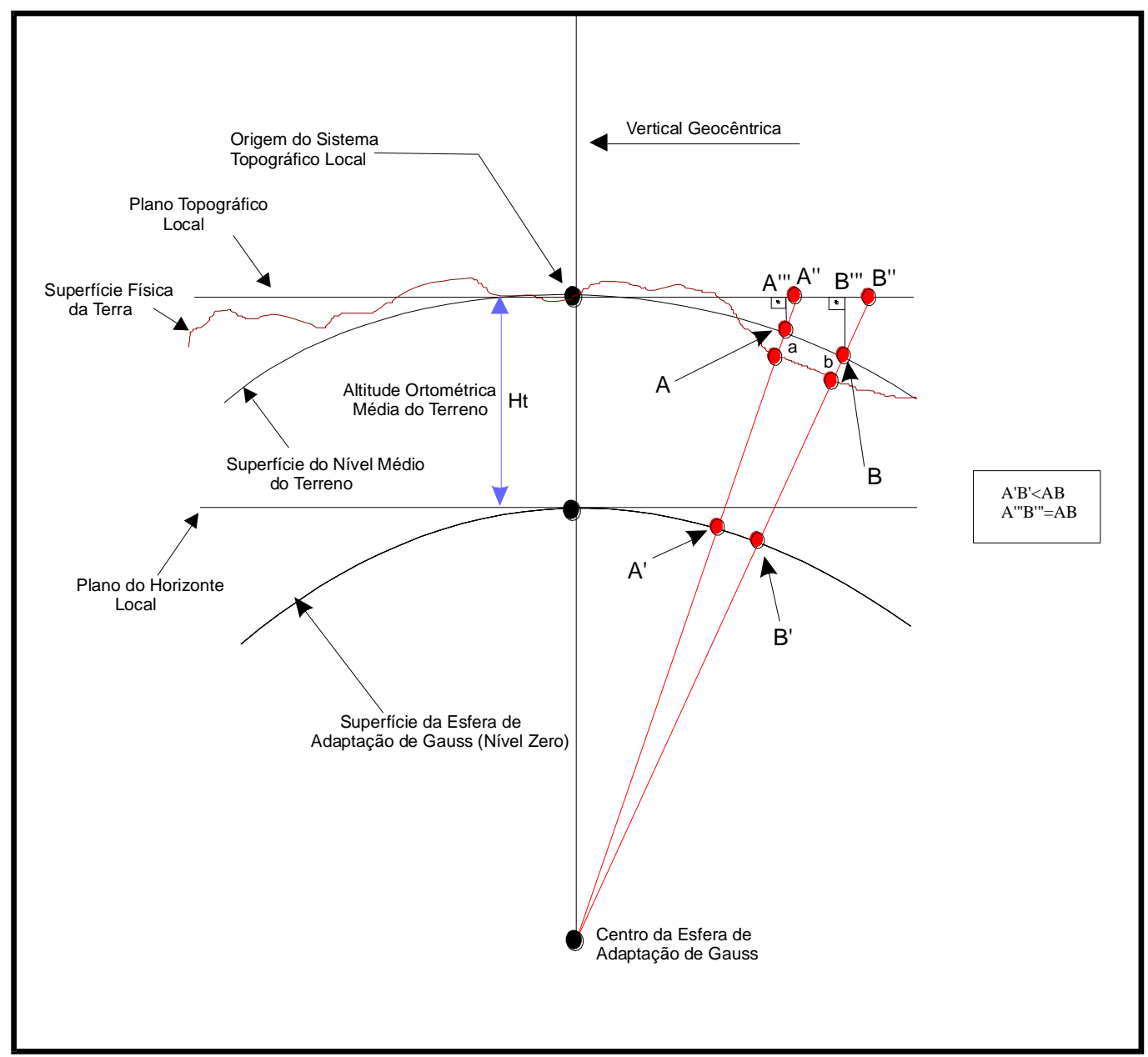

FIGURA 16 - ELEMENTOS DO SISTEMA TOPOGRÁFICO LOCAL FONTE: NBR 14166 (1998)

O sistema topográfico local (figura 16) corresponde a um sistema de representação, em planta, das posições relativas de pontos obtidos por um levantamento topográfico com origem em um ponto de coordenadas geográficas geodésicas conhecidas, onde todos os ângulos e distâncias de sua determinação são representadas, em verdadeira grandeza, sobre o plano tangente à superfície de referência (elipsóide de referência) do sistema geodésico adotado. Isso ocorre na origem do sistema, no pressuposto de que haja, na área de abrangência do sistema, a coincidência da superfície de referência com a do plano tangente, sem que os erros, decorrentes da abstração da curvatura terrestre, ultrapassem os erros inerentes às operações topográficas da determinação dos pontos do levantamento. 
OA'" - é a projeção ortogonal de OA sobre o Plano Topográfico Local;

OB',' - é a projeção ortogonal de OB sobre o Plano Topográfico Local; A "'A" - é o erro devido à desconsideração da curvatura terrestre de OA; B ' 'B' - é o erro devido à desconsideração da curvatura terrestre de OB; OA" - é a representação do arco OA sobre o Plano Topográfico Local; OB” - é a representação do arco OB sobre o Plano Topográfico Local; $A B$ - é a projeção gnomônica ou central de uma distância (ab) medida no terreno, sobre a superfície do nível médio do terreno, correspondendo à distância horizontal entre "a" e "b"; A'B' - é a projeção gnomônica ou central de AB sobre a superfície da esfera de adaptação de Gauss (superfície de nível zero);

A”B" - é a projeção (representação) em verdadeira grandeza de AB sobre o Plano Topográfico Local;

Vertical Geocêntrica - segundo Oliveira (1983) é a reta que contém determinado ponto e o centro do elipsóide;

Esfera de Adaptação de Gauss - é a esfera cujo raio é o centro médio do elipsóide de referência no ponto de tangência do plano do horizonte local, segundo NETO (1997).

\subsubsection{1 - PLANO DE REPRESENTAÇÃO, ORIGEM, EIXOS E ORIENTAÇÃO}

O Plano de representação, a origem, os eixos coordenados e a orientação são os elementos constituintes do sistema, fundamentais para o posicionamento dos pontos do levantamento por intermédio de um sistema cartesiano ortogonal em duas dimensões onde:

$\checkmark$ Os eixos $X$ e $Y$ estão jacentes no Plano do Horizonte Local (plano tangente ao elipsóide de referência), adotando-se, deste instante em diante, para efeitos de cálculos, a esfera de adaptação de Gauss como figura geométrica da Terra (superfície de referência);

$\checkmark$ O eixo $Y$ coincide com a linha meridiana (norte-sul) geográfica, no ponto de tangência, orientado positivamente, para o norte geográfico; 
$\checkmark$ O eixo $X$ é orientado, positivamente, para o leste.

O plano do horizonte local é elevado à altitude ortométrica $H_{\mathrm{t}}$ média da área de abrangência do sistema, passando a chamar-se Plano Topográfico Local.

\subsubsection{2 - COORDENADAS PLANO-RETANGULARES $(X, Y)$}

Correspondem às coordenadas cartesianas definidoras da localização planimétrica dos pontos levantados no terreno e representados, no plano topográfico do sistema topográfico local, cuja origem está no ponto de tangência deste plano com a superfície de referência adotada pelo Sistema Geodésico Brasileiro (SGB).

$\checkmark$ A orientação do sistema de coordenadas plano-retangulares é em relação ao eixo das ordenadas $(Y)$;

$\checkmark$ A fim de serem evitados valores negativos para as coordenadas planoretangulares, a estas são adicionadas termos constantes adequados a esta finalidade;

$\checkmark$ A fim de elevar o plano topográfico de projeção ao nível médio da área objeto do sistema topográfico, as coordenadas planoretangulares são afetadas por um fator de elevação, caracterizando o plano topográfico local;

$\checkmark$ A origem do sistema topográfico local deve ser posicionada, geograficamente, de modo que nenhuma coordenada plano-retangular, isenta do seu termo constante, tenha valor superior a $50 \mathrm{Km}$. A figura (17) ilustra o problema. 


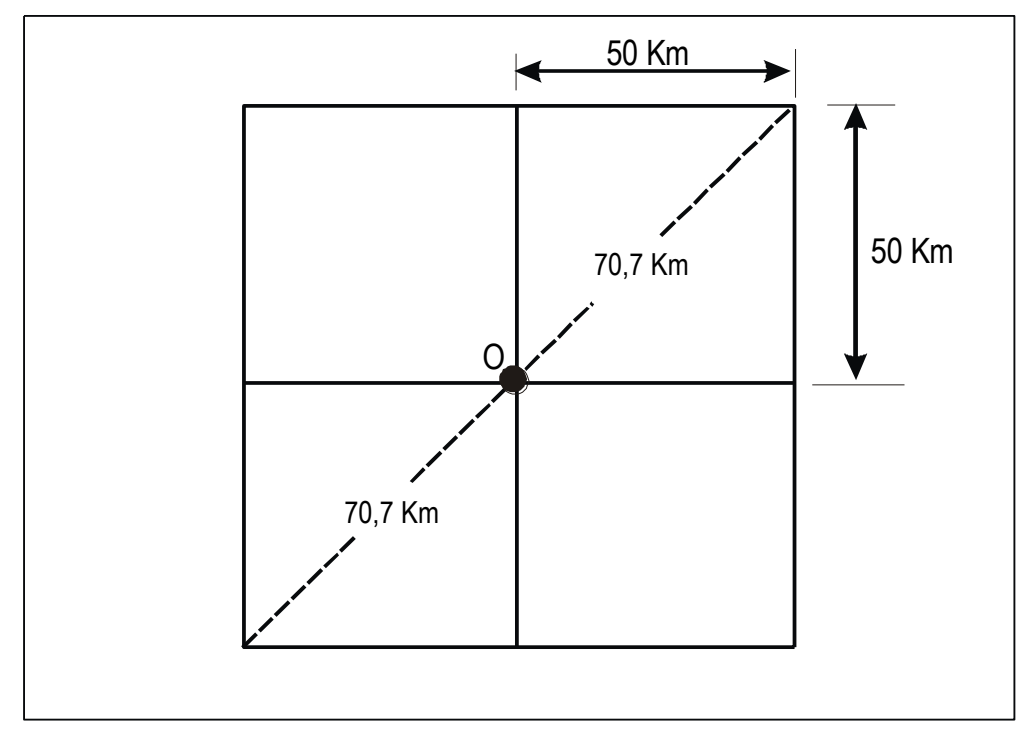

FIGURA 17 - ORIGEM DO SISTEMA TOPOGRÁFICO LOCAL E DISTÂNCIA MÁXIMA A ESTA ORIGEM.

FONTE: NBR 14166 (1998)

\subsubsection{3 - FATOR DE ELEVAÇÃO}

Corresponde a um fator, que aplicado às coordenadas plano-retangulares dos pontos do apoio geodésicos do Sistema, definidores do plano topográfico de projeção, isentas de seu seus termos constantes, eleva este plano ao nível médio do terreno da área de abrangência do sistema, caracterizando o sistema topográfico local, onde serão representados, todos os pontos levantados topograficamente.

$$
c=\frac{R_{m}+H_{t}}{R_{m}}
$$

onde:

$\checkmark \quad c$ corresponde ao fator de elevação, adimensional;

$\checkmark \quad H_{\mathrm{t}}$ corresponde à altitude ortométrica média do terreno;

$\checkmark \quad R_{\mathrm{m}}$ corresponde ao raio médio terrestre igual a $\sqrt{M \cdot N}$, adotado como raio da esfera de adaptação de Gauss;

$\checkmark \quad M$ corresponde ao raio de curvatura da elipse meridiana do elipsóide de referência na origem do sistema topográfico local;

$$
M=\frac{a \cdot\left(1-e^{2}\right)}{\sqrt{\left[1-e^{2} \cdot(\sin (\phi 1))^{2}\right]^{3}}}
$$


$\checkmark \quad N$ corresponde ao raio de curvatura da elipse normal à elipse meridiana na origem do sistema topográfico local ;

$$
N=\frac{a}{\sqrt{\left[1-e^{2} \cdot(\sin (\phi 1))^{2}\right]}}
$$

O plano topográfico local possui uma dimensão máxima limitada a aproximadamente $70 \mathrm{Km}$, a partir da origem do sistema, que o erro relativo, decorrente da desconsideração da curvatura terrestre não ultrapasse 1:50.000 nesta dimensão e 1:20.000 nas imediações da extremidade desta dimensão, sendo que a dimensão máxima do plano topográfico é a metade da diagonal de um quadrado de $100 \mathrm{Km}$ de lado, correspondente à área máxima de abrangência do Sistema Topográfico Local.

Futuramente, este sistema de referência estará popularizado nos meios técnicos e, por ser norma técnica, a sua utilização para referenciar rede de referência cadastral e outros projetos de engenharia, pois a grande maioria de bases cartográficas que estão digitalizadas em um outro sistema de referência (por exemplo o SAD69 em projeção UTM), haverá a necessidade de compatibilização destes referenciais cartográficos, tornando-se desta forma, a necessidade de uma divulgação de procedimentos para georreferenciamento de um Sistema de Informação Geográfica no Sistema Topográfico Local. 


\subsection{2 - ORGANIZAÇÃO DAS INFORMAÇÕES DIGITALIZADAS}

A partir do Mapa Aerofotogramétrica Planialtimétrico, restituída na escala de 1:5.000, fornecido pelo IBAMA - CEPTA foram digitalizadas as informações de uso e ocupação do solo, hidrografia, curvas de nível, estradas e limite da micro bacia (figura 18).

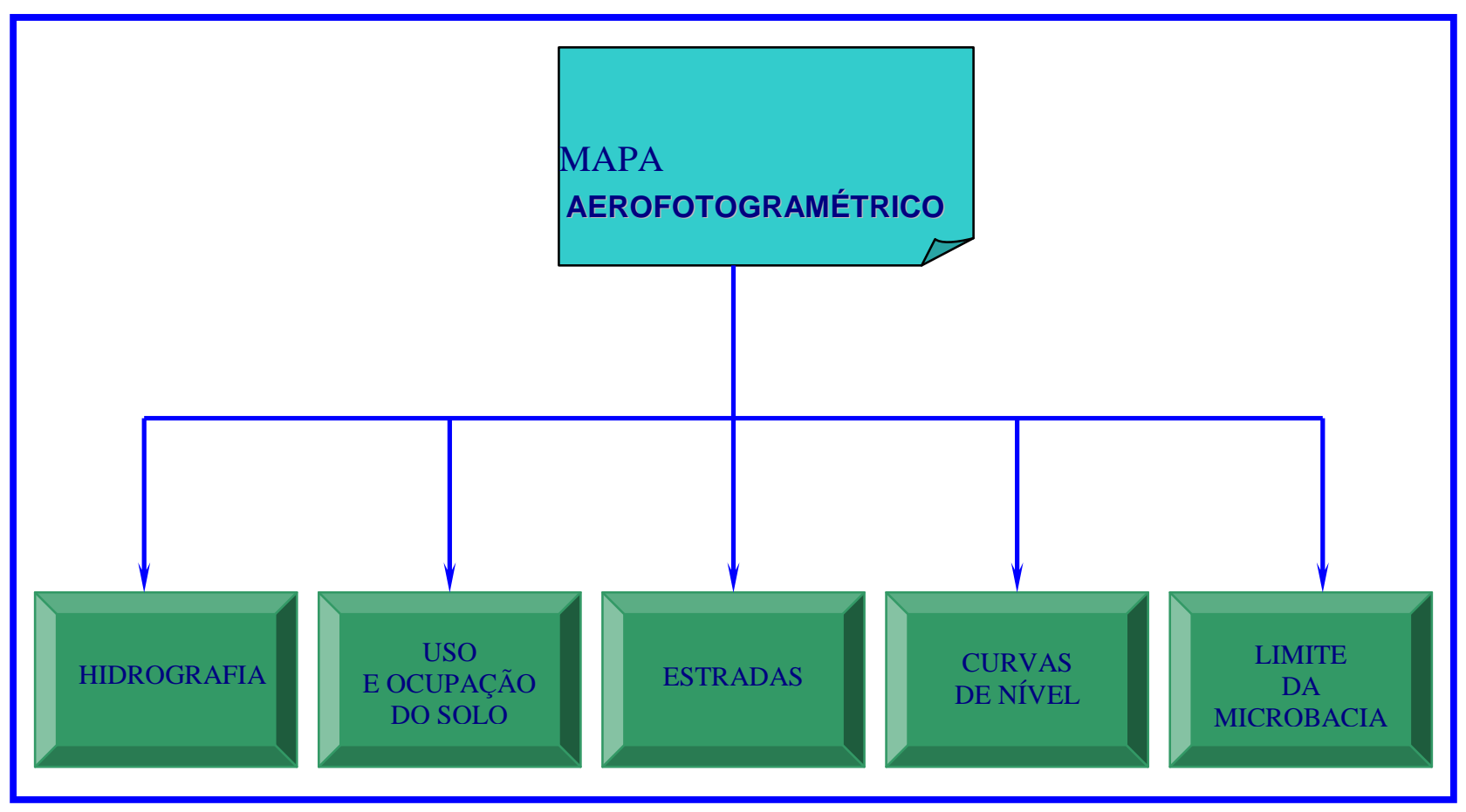

FIGURA 18 - INFORMAÇÕES RETIRADAS DO MAPA AEROFOTOGRAMÉTRICO RESTITUÍDO

A partir do Mapa de Formações Geológicas de Superfície, Folha Pirassununga (SF-23-V-C-V-3), do Instituto Geológico do Estado de São Paulo, na escala 1:50.000, foram digitalizadas as informações de geologia (figura 19). 


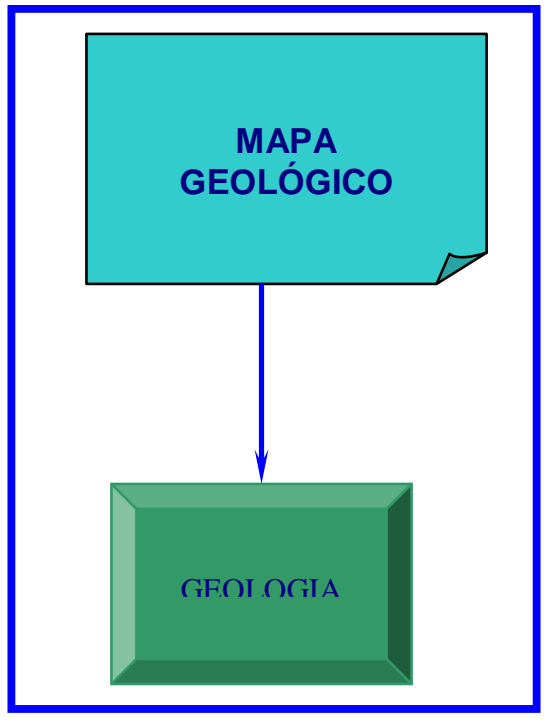

FIGURA 19 - INFORMAÇÕES RETIRADAS DO MAPA GEOLÓGICO

\subsubsection{1 - PREPARAÇÃO DAS COORDENADAS DOS PONTOS DE CONTROLE}

É bom ressaltar que esses pontos de controle foram levantados com GPS que segundo VERONEZ (1998) as observações com este equipamento, depois de processadas, fornecem coordenadas tridimensionais no sistema geocêntrico WGS84 $(\mathrm{X}, \mathrm{Y}, \mathrm{Z})$ ou em coordenadas geodésicas $(\phi, \lambda, \mathrm{h})$.

No trabalho não foi avaliado os parâmetros de transformação entre o sistema de referência WGS84 e o sistema de referência SAD69, pois foram utilizadas as coordenadas processadas e transformadas para o sistema SAD69, que foram convertidas para o Sistema Topográfico Local.

Os pontos de controle foram determinados de maneira que fossem possíveis de serem localizados no campo e que fossem ao mesmo tempo visível no mapa, para facilitar sua identificação no momento da digitalização. As melhores localizações para estes pontos são as intersecções de grid onde os valores das coordenadas não dão margem a dúvidas e as localizações são claramente definidas.

Mas no caso do mapa aerofotogramétrico restituído foram utilizados como pontos de controle (figura 20) quatro pontos distribuídos, levantados com GPS, para o registro da mesa. Esses pontos estão relacionados na tabela 6. 


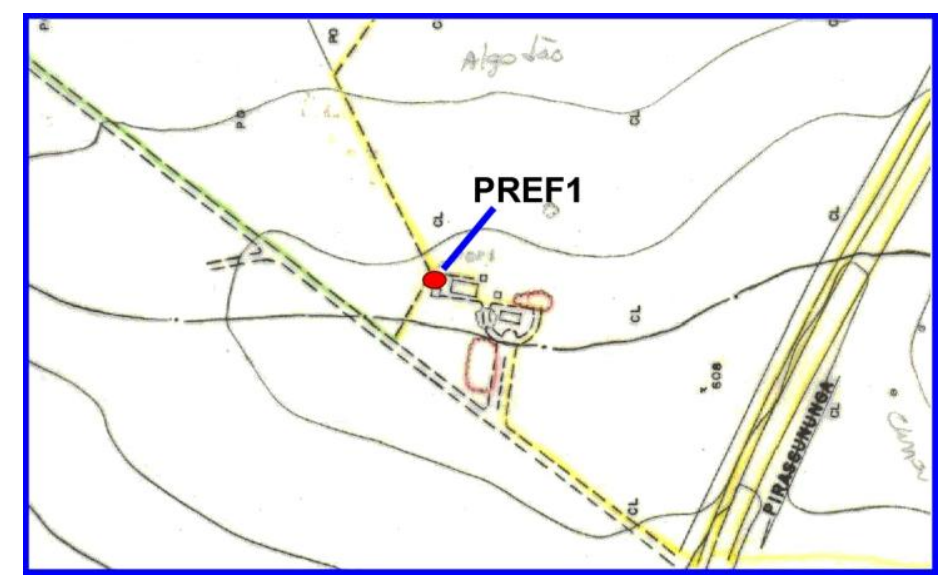

FIGURA 20 - PONTO PREF1 - UM DOS PONTOS DE CONTROLE DO MAPA AEROFOTOGRAMÉTRICO RESTITUÍDO

TABELA 6 - PONTOS DE CONTROLE

\begin{tabular}{|c|c|c|c|c|}
\hline \multirow{2}{*}{\multicolumn{2}{|c|}{ PONTOS UTILIZADOS }} & \multicolumn{3}{|c|}{$\begin{array}{c}\text { COORDENADAS GEODÉSICAS } \\
\text { (SAD 69) }\end{array}$} \\
\hline & & $\bar{G}$ & $\bar{M}$ & $\mathbf{S}$ \\
\hline \multirow[t]{2}{*}{ PCO-8 } & Latitude: & 21 & 55 & $36,633 \mathrm{~S}$ \\
\hline & Longitude: & 47 & 22 & $09,502 \mathrm{~W}$ \\
\hline \multirow[t]{2}{*}{ PCO-6 } & Latitude: & 21 & 56 & $15,109 \mathrm{~S}$ \\
\hline & Longitude: & 47 & 23 & $03,776 \mathrm{~W}$ \\
\hline \multirow[t]{2}{*}{ PCO-3 } & Latitude: & 21 & 57 & $04,003 \mathrm{~S}$ \\
\hline & Longitude: & 47 & 22 & $32,903 \mathrm{~W}$ \\
\hline \multirow[t]{2}{*}{ PREF1 } & Latitude: & 21 & 57 & $27,095 \mathrm{~S}$ \\
\hline & Longitude: & 47 & 23 & $40,337 \mathrm{~W}$ \\
\hline \multirow[t]{2}{*}{ CEPTA1 } & Latitude: & 21 & 55 & $59,289 \mathrm{~S}$ \\
\hline & Longitude: & 47 & 22 & $25,475 \mathrm{~W}$ \\
\hline
\end{tabular}

De posse dessas coordenadas geodésicas utilizou-se o software TDAT para conversão do sistema de coordenadas de SAD69 para o Sistema Topográfico Local, e foi adotado como ponto de origem do Sistema Topográfico Local o ponto CEPTA1 (figura 21), sendo que a altitude média do local foi calculada em relação a cota máxima e a mínima das curvas de nível do mapa aerofogramétirco restituído. Essa conversão teve como resultado as seguintes coordenadas (tabela 7): 
TABELA 7 - COORDENADAS CONVERTIDAS PARA O SISTEMA TOPOGRÁFICO LOCAL

\begin{tabular}{|c|c|c|c|c|c|c|c|c|}
\hline \multicolumn{5}{|c|}{ Ponto de Origem: } & \multicolumn{4}{|l|}{$\mathrm{X}_{\mathrm{O}}=150000,00$} \\
\hline \multicolumn{2}{|c|}{$\begin{array}{l}\text { Latitude: } \\
\text { Longitude: }\end{array}$} & \multicolumn{3}{|c|}{$21^{0} 55^{\prime} 59,289 \mathrm{~S}$} & \multicolumn{4}{|l|}{$Y_{0}=250000,00$} \\
\hline \multicolumn{2}{|c|}{ Ponto Convertido } & \multicolumn{3}{|c|}{ Coordenadas Geodésicas } & Coord. Topogr. Local & \multicolumn{3}{|c|}{ Convergência Meridiana } \\
\hline \multirow{2}{*}{$\mathrm{PCO}-8$} & Latitude: & 21 & 55 & $36,633 \mathrm{~S}$ & \multirow{2}{*}{$\begin{array}{l}X=150458,436 \\
Y=250696,918\end{array}$} & -0 & 00 & 05,965 \\
\hline & Longitude: & 47 & 22 & $09,502 \mathrm{~W}$ & & & & \\
\hline \multirow[t]{2}{*}{ PCO-6 } & Latitude: & 21 & 56 & $15,109 \mathrm{~S}$ & \multirow{2}{*}{$\begin{array}{l}X=148900,790 \\
Y=249513,327\end{array}$} & +0 & 00 & 14,308 \\
\hline & Longitude: & 47 & 23 & $03,776 \mathrm{~W}$ & & & & \\
\hline \multirow[t]{2}{*}{$\mathrm{PCO}-3$} & Latitude: & 21 & 57 & $04,003 \mathrm{~S}$ & \multirow{2}{*}{$\begin{array}{l}X=149786,822 \\
Y=248009,340\end{array}$} & +0 & 00 & 02,776 \\
\hline & Longitude: & 47 & 22 & $32,903 \mathrm{~W}$ & & & & \\
\hline \multirow[t]{2}{*}{ PREF1 } & Latitude: & 21 & 57 & $27,095 \mathrm{~S}$ & \multirow{2}{*}{$\begin{array}{l}X=147851,810 \\
Y=247298,849\end{array}$} & +0 & 00 & 27,978 \\
\hline & Longitude: & 47 & 23 & $40,337 \mathrm{~W}$ & & & & \\
\hline & & & & & & & & \\
\hline
\end{tabular}

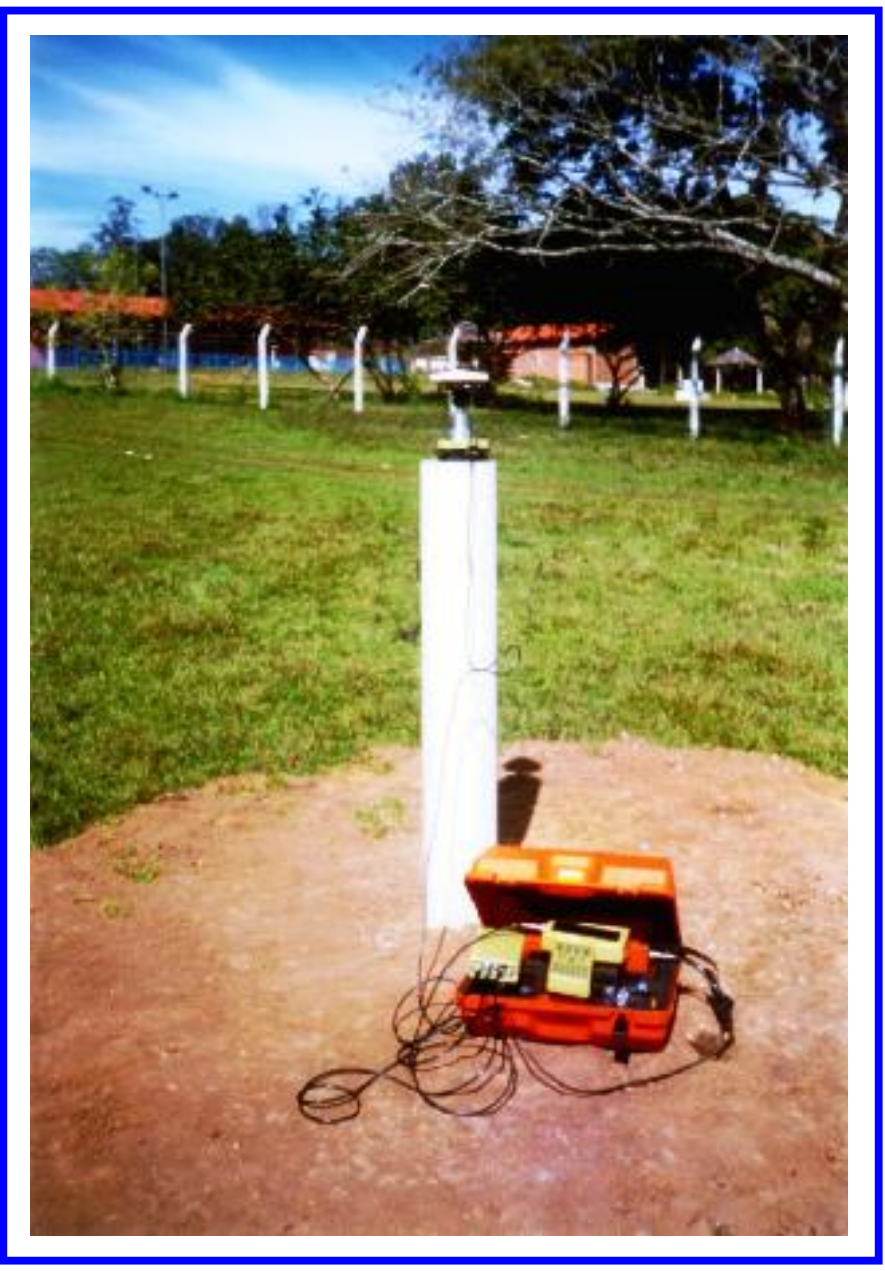

FIGURA 21 - CEPTA1 (PONTO GPS UTILIZADO COMO PONTO DE ORIGEM DO SISTEMA TOPOGRÁFICO LOCAL) 
Para o mapa geológico foram utilizados como pontos de controle o cruzamento das malhas existente no mapa (figura 22), no qual estes pontos possuem coordenadas geodésicas conhecidas. Essas coordenadas geodésicas estavam referenciadas em Córrego Alegre, que foram convertidas, através do software TDAT, para coordenadas geodésicas em SAD69, obtendo-se como resultado a tabela 8:

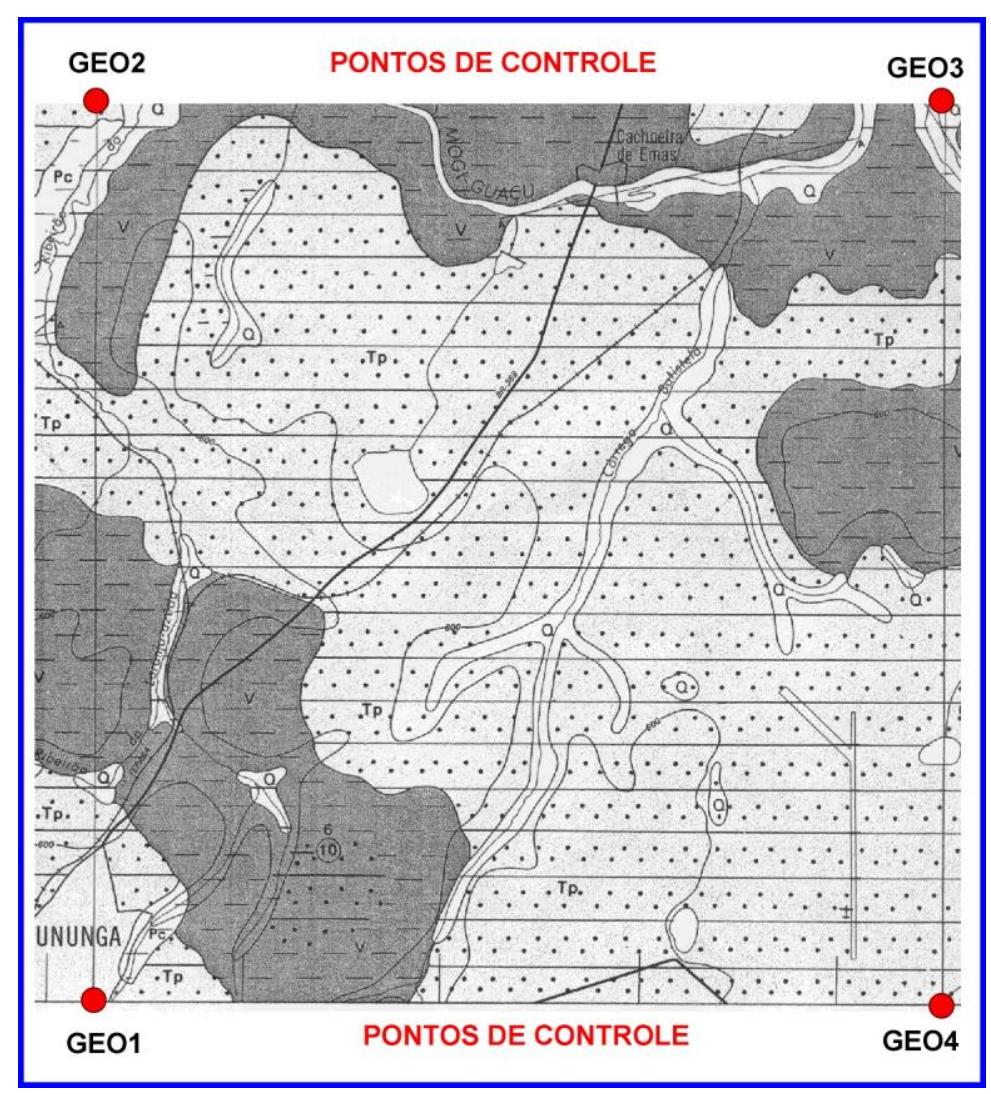

FIGURA 22 - PONTOS DE CONTROLE DO MAPA GEOLÓGICO

TABELA 8 - COORDENADAS CONVERTIDAS DE CÓRREGO ALEGRE PARA SAD69

\begin{tabular}{|l|l|c|c|c|c|c|c|}
\hline \multicolumn{2}{|c|}{ Ponto Convertido } & \multicolumn{3}{c|}{$\begin{array}{c}\text { Coordenadas Geodésicas } \\
\text { em Córrego Alegre }\end{array}$} & \multicolumn{4}{c|}{$\begin{array}{c}\text { Coordenadas } \\
\text { Geodésicas em SAD69 }\end{array}$} \\
\hline \multirow{2}{*}{ GEO1 } & Latitude: & 22 & 00 & S & $\mathbf{2 1}$ & $\mathbf{5 9}$ & $\mathbf{5 9 , 5 3 0 ~ S}$ \\
\cline { 3 - 9 } & Longitude: & 47 & 25 & W & $\mathbf{4 7}$ & $\mathbf{2 4}$ & $\mathbf{5 9 , 6 8 2 ~ W}$ \\
\hline \multirow{2}{*}{ GEO2 } & Latitude: & 21 & 55 & S & $\mathbf{2 1}$ & $\mathbf{5 4}$ & $\mathbf{5 9 , 5 2 6 ~ S}$ \\
\cline { 2 - 9 } & Longitude: & 47 & 25 & W & $\mathbf{4 7}$ & $\mathbf{2 4}$ & $\mathbf{5 9 , 6 8 2 ~ W}$ \\
\cline { 3 - 9 } & & & & & & & \\
\hline \multirow{3}{*}{ GEO3 } & Latitude: & 21 & 55 & S & $\mathbf{2 1}$ & $\mathbf{5 4}$ & $\mathbf{5 9 , 5 2 6 ~ S}$ \\
\cline { 2 - 9 } & Longitude: & 47 & 20 & W & $\mathbf{4 7}$ & $\mathbf{1 9}$ & $\mathbf{5 9 , 6 7 1 ~ W}$ \\
\cline { 2 - 9 } & & & & & & & \\
\hline \multirow{2}{*}{ GEO4 } & Latitude: & 22 & 00 & S & $\mathbf{2 1}$ & $\mathbf{5 9}$ & $\mathbf{5 9 , 5 3 0 ~ S}$ \\
\cline { 2 - 8 } & Longitude: & 47 & 20 & W & $\mathbf{4 7}$ & $\mathbf{1 9}$ & $\mathbf{5 9 , 6 7 1 ~ W}$ \\
\hline
\end{tabular}


$\mathrm{N}$ tabela 8 pôde-se observar que houve uma variação pequena nas coordenadas geodésicas, de um sistema de coordenadas para o outro, e isto ocorreu devido as variações que tem entre os datuns. Portanto, de posse dessas coordenadas geodésicas utilizou-se novamente o software TDAT para conversão do sistema de coordenadas de SAD69 para o Sistema Topográfico Local, e foi adotado como ponto de origem do Sistema Topográfico Local, também, o ponto CEPTA1 (figura 21). Essa conversão teve como resultado as seguintes coordenadas (tabela 9):

TABELA 9 - COORDENADAS CONVERTIDAS PARA O SISTEMA TOPOGRÁFICO LOCAL

\begin{tabular}{l} 
Ponto de Origem: \\
$\begin{array}{l}\text { CEPTA1 } \\
\text { Latitude: } \\
\text { Longitude: }\end{array}$ \\
\hline \multirow{2}{*}{$\begin{array}{l}21^{0} 55 ' 59.289 \mathrm{~S} \\
47^{0} 22\end{array} 25.475 \mathrm{~W}$}
\end{tabular}

Portanto, de posse das coordenadas convertidas (tabelas 7 e 9) para o sistema topográfico local foram executadas as digitalizações das informações para a geração dos mapas temáticos.

\subsubsection{2 - REGISTRANDO A MESA DIGITALIZADORA NO CARTALINX}

O registro da mesa digitalizadora no Cartalinx é estabelecido entre a relação das coordenadas da mesa e as coordenadas do mapa para um conjunto de pontos de controle dispersos sobre o mapa. Os erros primários estão relacionados com a expansão e contração do papel e os decorrentes do operador. Estes erros devem recair em um RMS (Root Mean Square Error) 0,25mm na escala do mapa, e nas tabelas 10 e 11 temos algumas referências sobre os erros máximos que são permitidos para cada escala, em coordenadas planas e geográficas. 


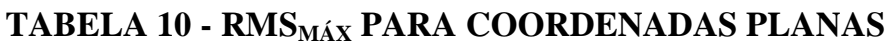

\begin{tabular}{|c|c|}
\hline Escala & RMSmáx (m) \\
\hline $1: 1.000$ & 0.309 \\
\hline $\mathbf{1 : 2 . 0 0 0}$ & $\mathbf{0 . 6 1 9}$ \\
\hline $1: 5.000$ & 1.54 \\
\hline $\mathbf{1 : 1 0 . 0 0 0}$ & $\mathbf{3 . 0 9}$ \\
\hline $1: 20.000$ & 10.32 \\
\hline $\mathbf{1 : 5 0 . 0 0 0}$ & $\mathbf{2 5 . 8 1}$ \\
\hline $1: 100.000$ & 51.62 \\
\hline $\mathbf{1 : 2 0 0 . 0 0 0}$ & $\mathbf{1 2 9 . 0 5}$ \\
\hline $1: 500.000$ & 258.10 \\
\hline $\mathbf{1 : 1 . 0 0 0 . 0 0 0}$ & $\mathbf{5 1 9 . 2 0}$ \\
\hline
\end{tabular}

FONTE: SILVA (1997)

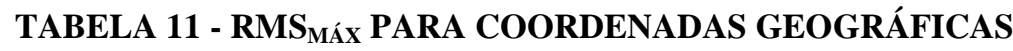

\begin{tabular}{|c|c|}
\hline Escala & RMSmáx (m) \\
\hline $1: 1.000$ & 0.000002861 ou $\left(0^{0} 00^{\prime} 00.01 "\right)$ \\
\hline $1: 2.000$ & 0.000005731 ou $\left(0^{0} 00^{\prime} 00.02 "\right)$ \\
\hline $1: 5.000$ & 0.000014259 ou $\left(0^{0} 00^{\prime} 00.05^{\prime \prime}\right)$ \\
\hline $1: 10.000$ & 0.000028611 ou $\left(0^{0} 00^{\prime} 00.10^{\prime \prime}\right)$ \\
\hline $1: 20.000$ & 0.00009595 ou ( $\left(0^{0} 00^{\prime} 00.34 "\right)$ \\
\hline $1: 50.000$ & 0.000238981 ou $\left(0^{0} 00^{\prime} 00.86^{\prime \prime}\right)$ \\
\hline $1: 100.000$ & 0.000477037 ou (0000'01.72”) \\
\hline $1: 200.000$ & 0.001194907 ou $\left(0^{0} 00^{\prime} 04.30^{\prime \prime}\right)$ \\
\hline $1: 500.000$ & 0.002389514 ou (000'08.60") \\
\hline $1: 1.000 .000$ & 0.004779629 ou $\left(0^{0} 00 ' 17.21 "\right)$ \\
\hline
\end{tabular}

FONTE: SILVA (1997)

OBS: Estes valores foram calculados de acordo com o padrão adotado pelo Idrisi for Windows.

O processo de registro da mesa resultou em um RMS associado ao processo de estabelecimento da relação entre as coordenadas do mapa e da mesa e não excedeu o RMS, que deve ser de acordo com a escala do mapa e o tipo de coordenada (plana ou geográfica).

O mapa aerofotogramétrico restituído em papel vegetal foi fixado na mesa digitalizadora, pretendo-se com fita adesiva nas extremidades, deixando-se bem esticado de maneira que não ficasse com ondulações e colocando-se toda a área a ser digitalizada ou o máximo possível, dentro da área útil da mesa digitalizadora. A região onde encontra-se os pontos de controle seguiram os mesmos critérios, onde nenhum deles ficaram fora da área útil. 
Para a digitalização tanto do mapa aerofotogramétrico restituído quanto o mapa geológico foram utilizados quatro pontos de controle, e sendo utilizado como parâmetros do RMS os valores descritos nas tabelas 10 e 11 .

O CartaLinx usa um vetor gráfico para a representação de frames na forma digital. O elemento básico de dado do vetor é o ponto. Características lineares são representadas como uma série de pontos conectados, com os vértices interligados por linhas retas, conhecidas como segmentos. Os pontos inferiores dessas características lineares são conhecidos como vértices, enquanto os pontos finais são conhecidos como nós. A coleção de segmentos lineares dois nós é conhecido como um arco. Arcos e nós tem uma função especial no vetor gráfico.

É importante reconhecer que na maioria dos SIG's, os arcos não podem se cruzar e podem somente converter-se a outros arcos, em um nó. A definição mais comum de um arco é descrevê-lo como uma linha que não se cruza e que tem um nó como seu ponto final.

As características de áreas são sempre limitadas por arcos unidos de uma coleção de segmentos de linhas retas (polilinhas), já as características de áreas geralmente são denominadas como polígonos.

As informações dos mapas que foram digitalizadas separadamente, seguiram o seguinte padrão de topologia (tabela 10):

TABELA 12 - TOPOLOGIA DOS MAPAS DIGITALIZADOS

\begin{tabular}{ll}
\hline INFORMAÇÕES & TOPOLOGIA \\
\hline Hidrografia & Polilinhas e Polígonos \\
Uso e Ocupação do Solo & Polígonos \\
Estradas & Polilinhas \\
Curvas de Níveis & Polilinhas \\
Limite da Microbacia & Polígono \\
Geologia & Polígonos \\
\hline
\end{tabular}

OBS: Topologia segundo TEIXEIRA \& CHRISTOFOLETTI (1997) é a relação espacial existente entre os elementos, tais como conectividade, contiguidade e proximidade. 


\subsubsection{3 - EDIÇÃO DAS INFORMAÇÕES DIGITALIZADAS}

Após digitalizadas as informações dos mapas foram feitas a edição de cada informação, que consistiu na verificação de erros ocorridos no processo de digitalização. Estes erros estão associados a erros sistemáticos ocorridos durante a digitalização que segundo MELLO \& CINTRA (1993) são erros detectáveis e de causas conhecidas, geralmente introduzidas pelo operador (digitalizador).

Dentro os erros que são verificados na edição podemos destacar segundo DAVIS JR \& FONSECA (1994):

$\breve{I}$ Erros de codificação dos atributos;

$\breve{I}$ Erros de fechamento de polígonos;

I Erros de junção de vértices e nós;

$\breve{I}$ Erros de desencontro de bordas e;

I Erros de sobreposição de linhas e/ou polilinhas.

Para as informações de Uso e Ocupação do Solo, Limite da Microbacia, Hidrografia (represas) e Geologia, foram verificados os identificadores e o fechamento dos polígonos, sendo atribuindo para cada polígono um identificador de acordo com as características presentes em cada layer, executados no software CARTALINX.

A edição das curvas de níveis consistiu na verificação das cotas de cada curva e a junção de cada polilinha digitalizada, sendo executado no AUTOCAD, pois neste software a execução deste serviço foi mais prático. 


\subsubsection{4 - ENTRADA DOS DADOS NO IDRISI FOR WINDOWS}

Com os mapas editados procedeu a entrada dos dados no IDRISI FOR WINDOWS da seguinte maneira:

\section{1 - Informações Editadas no CARTALINX}

Com as informações editadas no CARTALINX foram executadas a exportação das informações (uso e ocupação do solo, hidrografia, estradas, limite da microbacia e geologia) do formato LNX (cartalinx) para o formato VEC (idrisi).

\section{2 - Informações Editadas no AUTOCAD}

Com as curvas de nível editadas no AUTOCAD foi executado a exportação desta informação do formato DWG (autocad) para o formato DXF (autocadR12), para importação no IDRISI.

No IDRISI foi importado o arquivo do formato DXF para o formato VEC e com os outros arquivos, neste mesmo padrão (vec), fez-se a conversão dos arquivos para a estrutura raster (matricial), com extensão IMG.

Para a conversão da estrutura raster definiu como tamanho do pixel $5 \times 5$ metros, devido ao tamanho da área de estudo (aproximadamente 860 ha).

A estrutura raster no IDRISI permite fazer as análises espaciais, cruzando-se as informações digitalizadas para geração de mapas temáticos, o que na estrutura vetorial não permite.

\section{CURVAS DE NÍVEL}

Os dados das curvas de nível foram utilizados, para elaboração de um mapa de declividades, no qual pode-se analisar a influência que a inclinação do terreno apresenta em relação ao uso e ocupação do solo e na conservação ou desmatamento da mata ciliar e das áreas de cerrado.

Para elaboração deste mapa gerou-se primeiro o MDT (modelo de elevação digital do terreno), através do módulo de interpolação do IDRISI (intercon) e posteriormente as classes de delividades em percentagem (surface analysis - slope), 
que depois foram agrupados em intervalos de declividade (tabela 11), baseados nos trabalhos de DONZELI et al (1992) e RAMALHO FILHO \& BEEK (1994).

TABELA 13 - CLASSES DE DECLIVIDADES

\begin{tabular}{ccc}
\hline CLASSES & INTERVALOS $(\%)$ & CLASSIFICAÇÃO \\
\hline 1 & 0 a 3 & Relevo Plano \\
2 & 3 a 6 & Suave Ondulado \\
3 & 6 a 12 & Moderadamente Ondulado \\
4 & 12 a 20 & Ondulado \\
5 & $>20$ & Forte Ondulado \\
\hline
\end{tabular}

Com as curvas de nível no formato vetorial gerou-se um modelo numérico de terreno para visualizar a forma do relevo em que se encontra a microbacia do Córrego da Barrinha. Isto foi feito utilizando-se o software SURFER e utilizando a interpolação linear pelo método de triangulação, pois no software IDRISI, isto é feito através de grid, que segundo TEIXEIRA \& CHRISTOFOLETTI (1997) é um conjunto retangular de pontos que resultam da interseção ortogonal de uma série de linhas paralelas com outra série de linhas paralelas, resultando numa estrutura matricial, já que no IDRISI se trabalha com estruturas raster/matricial.

\section{HIDROGRAFIA}

Para a hidrografia, foi utilizado como parâmetro de estudo dos buffers de distâncias o Código Florestal Brasileiro (BRASIL lei 4771/65), respaldada segundo SANTOS \& SOUSA-SILVA (1998) pela lei 7511/86 (Diário Oficial) que determina que sejam consideradas como área de preservação permanente, as florestas e demais formas de vegetação natural situadas:

a) ao longo dos rios ou de outro qualquer curso d'água desde o seu nível mais alto em faixa marginal cuja largura mínima (tabela 12):

TABELA 14 - FAIXAS MARGINAL DE RESERVA PERMANENTE

\begin{tabular}{cc}
\hline $\begin{array}{c}\text { Largura dos Rios } \\
(\mathrm{m})\end{array}$ & $\begin{array}{c}\text { Faixas Naturais de Vegetação }(\mathrm{m}) \text { a serem } \\
\text { protegidas em cada margem }\end{array}$ \\
\hline até 10 & 30 \\
10 a 50 & 50 \\
50 a 100 & 100 \\
100 a 200 & 150 \\
mais de 200 & Largura igual a distância entre as margens \\
\hline
\end{tabular}

FONTE: SANTOS \& SOUSA-SILVA (1998)

b) ao redor das lagoas, lagos ou reservatórios d'água, naturais ou artificiais; 
c) nas nascentes, ainda que intermitentes e nos chamados "olhos d'água", qualquer que seja a sua situação topográfica, num raio mínimo de 50 (cinquenta) metros de largura;

d) no topo de morros, montes, montanhas e serras;

e) nas encostas ou partes destas com declividade superior a $45^{\circ}$ equivalente a $100 \%$ na linha de maior declive;

f) nas restingas, como fixadoras e dunas ou estabilizadoras de mangues;

g) nas bordas dos tabuleiros ou chapadas, a partir da linha de ruptura do relevo, em faixa nunca inferior a 100 (cem) metros em projeções horizontais;

h) em altitude superior a 1.800 (mil e oitocentos) metros, qualquer que seja a vegetação.

Parágrafo único - No caso de áreas urbanas, assim entendidas as compreendidas nos perímetros urbanos definidos por lei municipal, e nas regiões metropolitanas e aglomerações urbanas, em todo o território abrangido, observar-se-á o disposto nos respectivos planos diretores e leis de uso do solo, respeitados os princípios e limites a que se refere este artigo.

Assim, de acordo com a tabela 12 foram adotados como buffers de distância para o Córrego da Barrinha o valor de 30 metros e para o Rio Mogi um valor de 50 metros.

Para as represas foram utilizados como referência dos buffers de distância as informações contidas na RESOLUÇÃO CONAMA 004/85 que estabelece no artigo $3^{\mathrm{o}}$ sobre reservas ecológicas, na alínea $\mathrm{b}$, inciso II, ao redor das lagoas, lagos ou reservatórios d'água naturais ou artificiais, desde o seu nível mais alto medido horizontalmente, em faixa marginal cuja largura mínima seja:

$\breve{I}$ de 30 (trinta) metros para os que estejam situados em áreas urbanas;

$\breve{I}$ de 100 (cem) metros para os que estejam em áreas rurais, exceto os corpos d'água com até 20 (vinte) hectares de superfície, cuja faixa marginal será de 50 (cinqüenta) metros;

I de 100 (cem) metros para as represas hidrelétricas.

Portanto, como as represas possuem uma superfície menor que 20 hectares foi utilizado um buffer de 50 metros. 


\section{LIMITE DA MICROBACIA}

O limite da microbacia foi digitalizada tomando-se como referência a informação contida no mapa aerofotográmetrico restituído, sendo que este layer serviu como parâmetro para recortar as áreas excedentes (fora do limite da microbacia) dos outros layers (uso e ocupação do solo, geologia, estradas, hidrografia e curvas de nível).

Portanto, os resultados e as análises foram discutidas em função deste limite e os mapas temáticos gerados e as integrações entre as informações digitalizadas estão baseadas nesta referência, abrangendo uma área de aproximadamente 860 hectares. 


\section{5 - RESULTADOS E DISCUSSÃO}

\section{1 - INTEGRAÇÃO DAS INFORMAÇÕES DIGITALIZADAS}

Com as informações geradas foram utilizadas as seqüências de trabalho resumida no digrama apresentado na figura 23, para integração e análise dos mapas temáticos gerados, e caraterização ambiental da microbacia do Córrego da Barrinha.

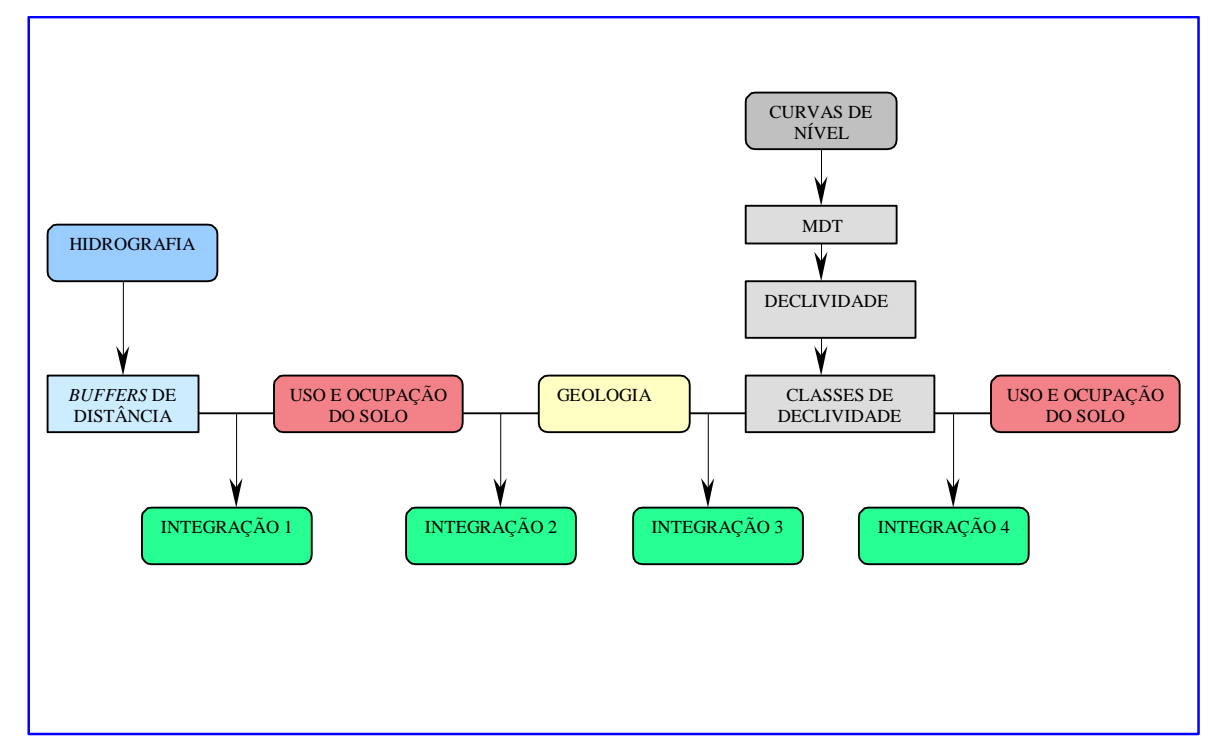

FIGURA 23 - DIAGRAMA DE INTEGRAÇÃO DAS INFORMAÇÕES

No diagrama da figura 23 podemos observar que a INTEGRAÇÃO 1 foi feita entre as informações de buffers de distância e uso e ocupação do solo, já para a INTEGRAÇÃO 2 foram utilizados como informação os layers de uso e ocupação do solo com a geologia, para a INTEGRAÇÃO 3 foram utilizados a geologia com as classes de declividades e para INTEGRAÇÃO 4 foram utilizados os layers de classes de declividade e uso e ocupação do solo. 


\subsection{1 - ANÁLISE DA INTEGRAÇÃO 1 (Buffers de Distância X Uso e Ocupação do Solo)}

A integração 1 tem como objetivo analisar através da lei 7511/86 que institui o novo Código Florestal e da Resolução Conama 004/85 sobre Reservas Ecológicas a influência do uso e ocupação do solo sobre a região de mata ciliar ao longo da hidrografia da microbacia do Córrego da Barrinha.

De posse das informações estabelecidas no mapa de buffers de distância (figura 24), pode-se fazer uma integração com o mapa de uso e ocupação do solo (figura 25) atualizado no campo, pois as informações de uso e ocupação do solo que continham no mapa aerofogramétrico restituído (figura 26) estavam desatualizadas.

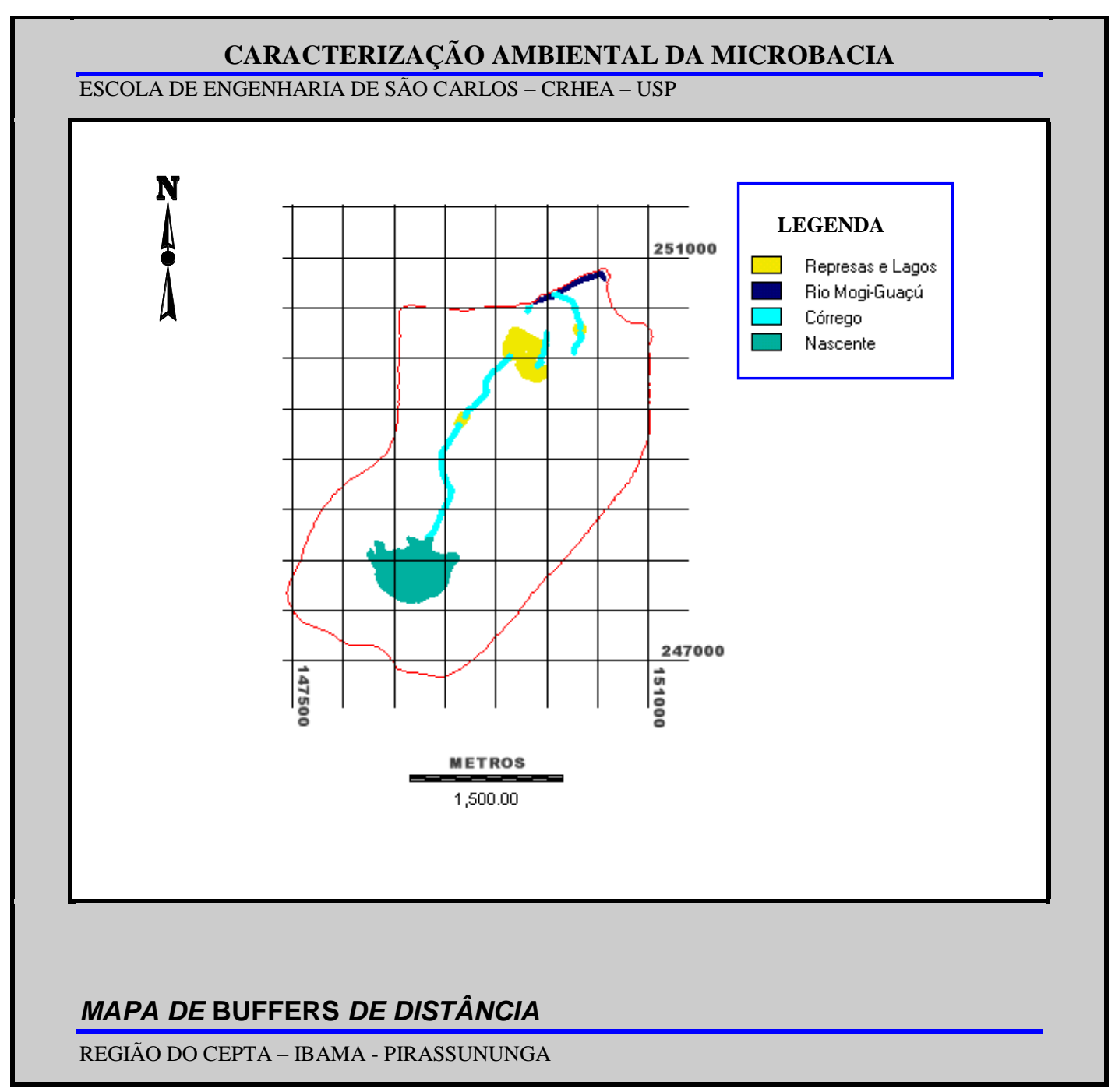

FIGURA 24 - MAPA DE BUFFERS DE DISTÂNCIA DA HIDROGRAFIA 
CARACTERIZAÇÃO AMBIENTAL DA MICROBACIA

ESCOLA DE ENGENHARIA DE SÃO CARLOS - CRHEA - USP

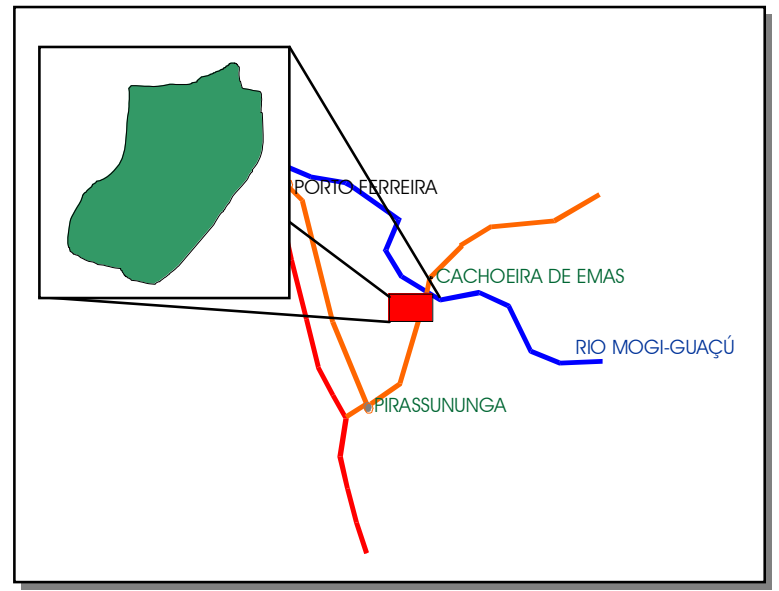

9

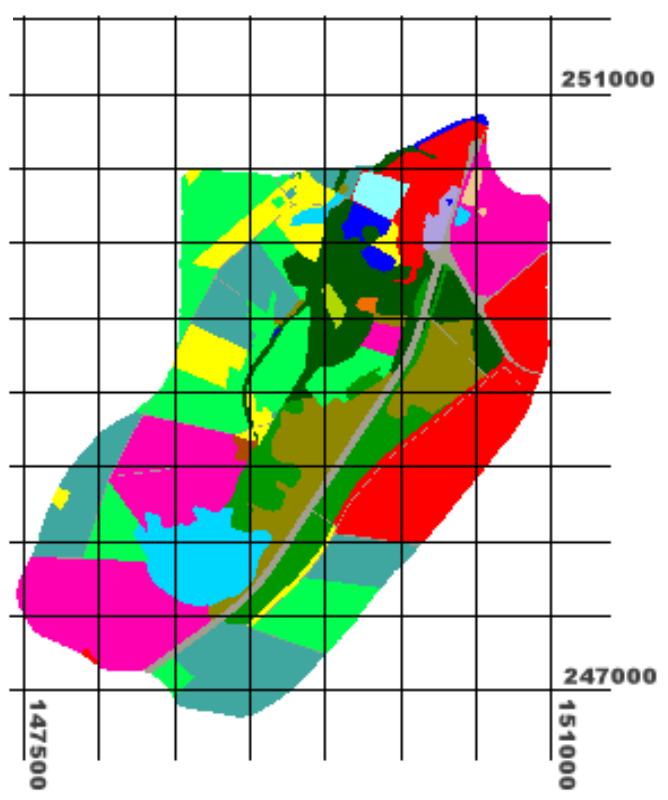

LEGENDA

Larania

Cana de Açúcar

Area Urbanizada

Cerrado Típico

Cerradão

Parque Ecológico

Mineração

Depósito de Lixo

Area de Empréstimo

Reflorestamento

Pasto

Culturas Temporárias

Capoeira

Represas, Lagos e Rio

Várzeas

Tanques de Psicultura

Estradas

MAPA DE USO E OCUPAÇÃO DO SOLO ATUALIZADO

REGIÃO DO CEPTA - IBAMA - PIRASSUNUNGA

FIGURA 25 - MAPA DE USO E OCUPAÇÃO DO SOLO ATUALIZADO 
CARACTERIZAÇÃO AMBIENTAL DA MICROBACIA

ESCOLA DE ENGENHARIA DE SÃO CARLOS - CRHEA - USP

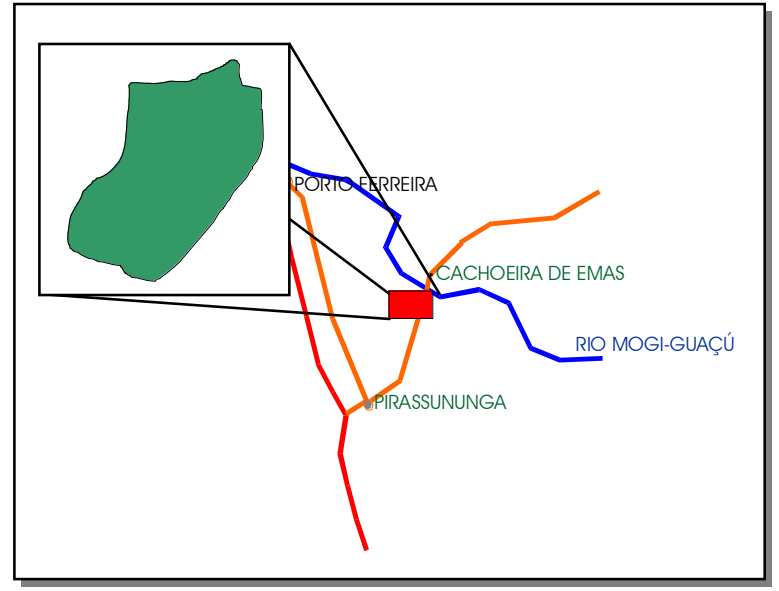

\{
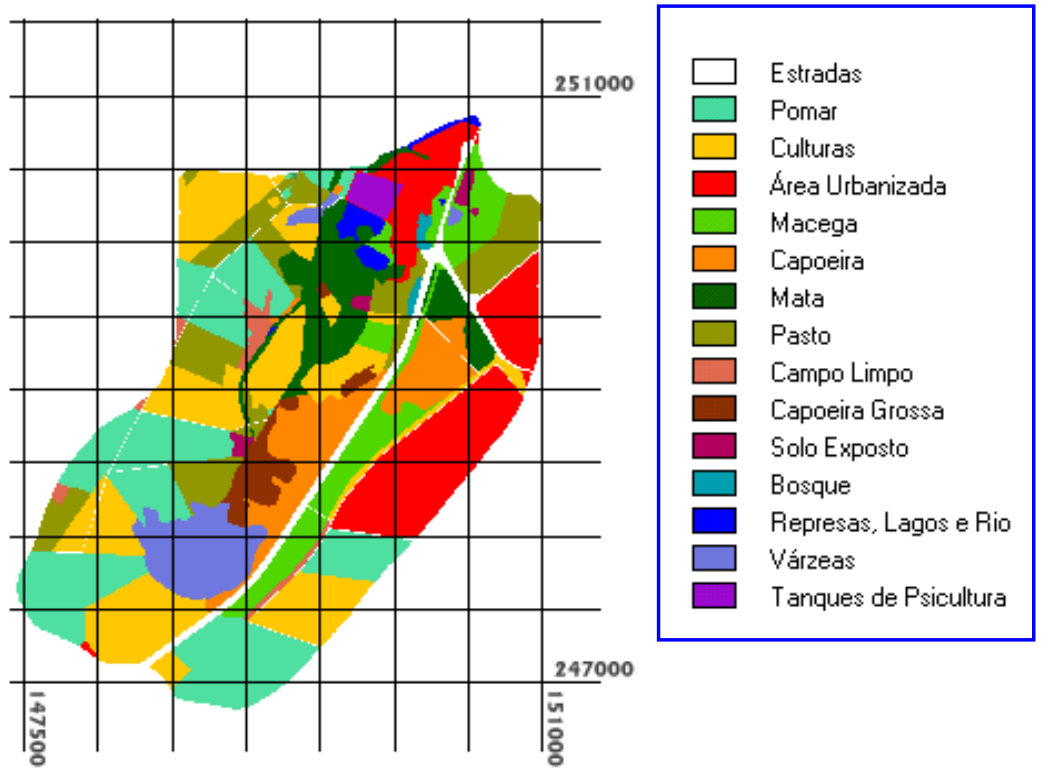

METROS

$1,500.00$

MAPA DE USO E OCUPAÇÃO DO SOLO DESATUALIZADO

REGIÃO DO CEPTA - IBAMA - PIRASSUNUNGA

FIGURA 26 - MAPA DE USO E OCUPAÇÃO DO SOLO DESATUALIZADO 
Com os mapas das figuras 24 e 25 obteve-se o seguinte mapa temático (figura 27):

\section{CARACTERIZAÇÃO AMBIENTAL DA MICROBACIA}

ESCOLA DE ENGENHARIA DE SÃO CARLOS - CRHEA - USP

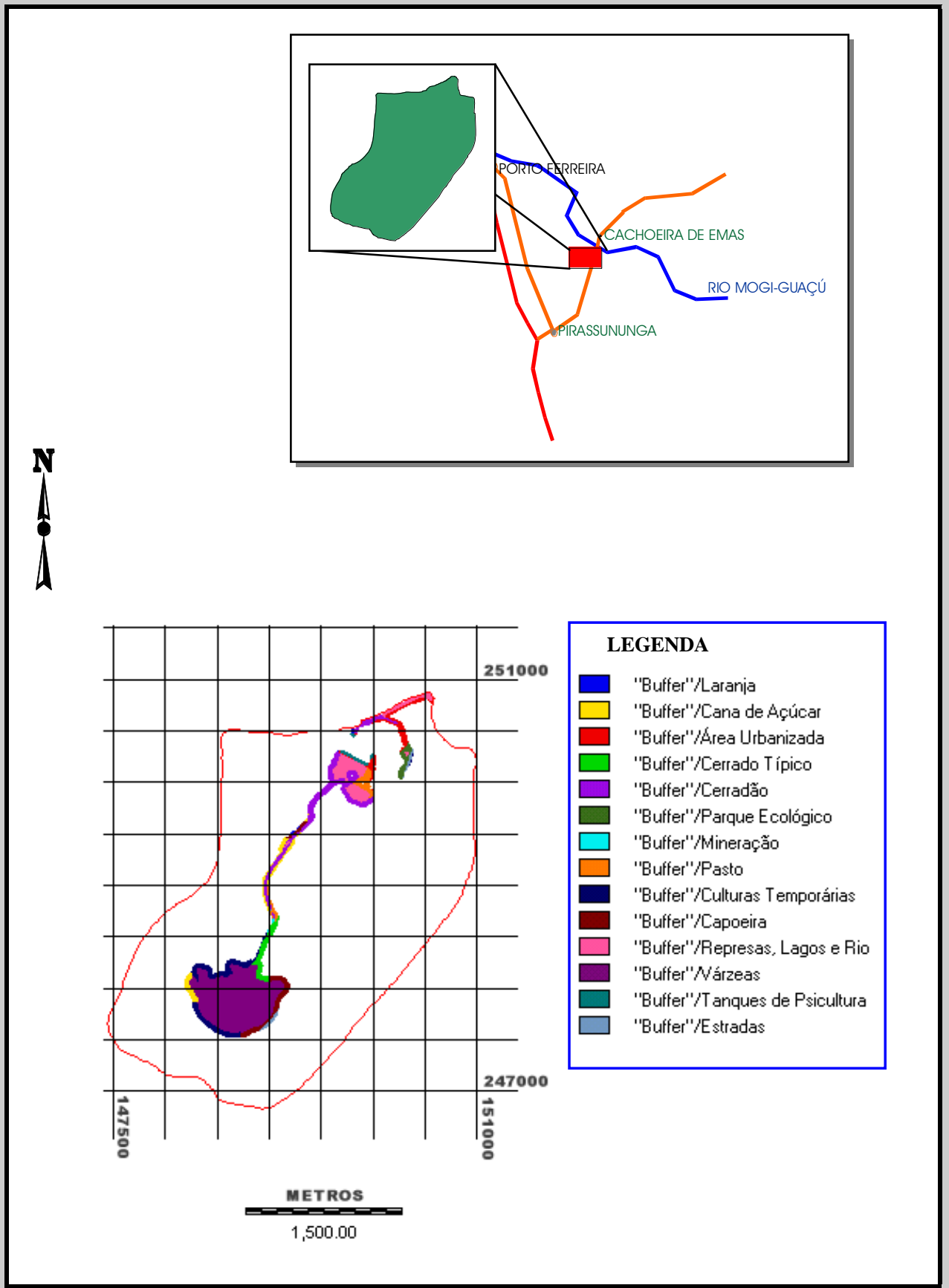

MAPA DA INTEGRAÇ̃̃O 1

REGIÃO DO CEPTA - IBAMA - PIRASSUNUNGA

FIGURA 27 - MAPA DA INTEGRAÇÃO 1 
O mapa de integração 1 teve como resultado em relação a porcentagem de áreas ocupadas o seguinte (figura 28):

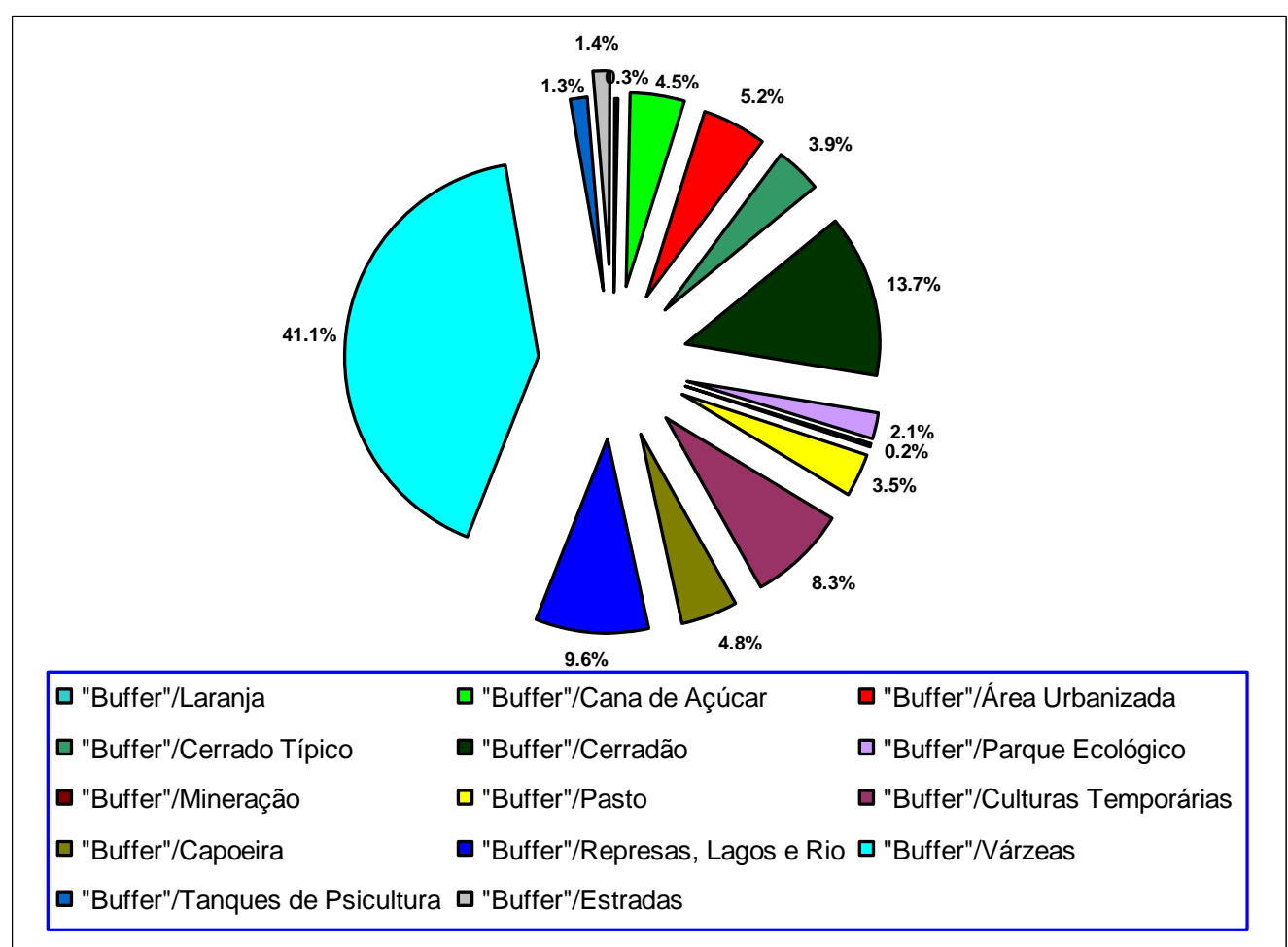

FIGURA 28 - PORCENTAGEM DAS ÁREAS DO MAPA DA INTEGRAÇÃO 1

$\mathrm{O}$ artigo $2^{\circ}$ do Código Florestal tem como finalidade precípua proteger a cobertura vegetal, onde encontra-se expressamente alencada como floresta de preservação permanente aquelas situadas ao longo dos rios ou de qualquer curso d'água.

Nesse sentido afirma-se que tais florestas não podem ser manejadas de forma a sofrerem cortes rasos. Embora tal restrição exista, não há que se falar da ausência de finalidade econômica na preservação dessas florestas, pois qual melhor investimento senão aquele que visa garantir, através da preservação dessas florestas, o bem estar da população, num sentido amplo. Mesmo porque, ao se preservar tais formas de vegetação, protege-se o solo dos processos erosivos, preserva-se a fauna e a flora.

O solo quando privado de sua cobertura florestal fica modificado em sua estrutura e perde as propriedades físico-químicas capazes de garantir a retenção de água. 
A vegetação existente ao longo dos rios funciona como um obstáculo natural ao escoamento das águas, que ficam retidas e são absorvidas, em grande parte, pela mata, evitando que uma quantidade exagerada de partículas sólidas sejam arrastadas e depositadas no leito dos rios.

Além de evitar o assoreamento do leito dos rios, a mata ciliar consiste num ecossistema peculiar que abriga uma diversidade florística e faunística de vital importância para o equilíbrio de toda uma região. Além de proteger indiretamente a fauna aquática, posto evitar o transporte de resíduos de agrotóxicos utilizados largamente na agricultura, o que, na ausência da mata ciliar, são arrastados para os rios ocasionando, não raras vezes, a morte de peixes em função da poluição que provoca.

Assim, podemos analisar através do gráfico 1 a influência das atividades antrópicas ao longo da área de preservação permanente, conforme determinado na lei 7511/86 que institui o novo Código Florestal e da Resolução Conama 004/85, e neste caso temos como atividades antrópicas atuando nesta região o seguinte (tabela 15):

TABELA 15 - ATIVIDADES ANTRÓPICAS NA FAIXA DE MATA CILIAR

\begin{tabular}{cc}
\hline ATIVIDADE ANTRÓPICA & \% SOBRE A ÁREA TOTAL \\
\hline Laranja & $0.3 \%$ \\
Mineração & $0.2 \%$ \\
Tanques de Psicultura & $1.3 \%$ \\
Cana de Açúcar & $4.5 \%$ \\
Pasto & $3.5 \%$ \\
Estradas & $1.4 \%$ \\
Área Urbanizada & $5.2 \%$ \\
Culturas Temporárias & $8.0 \%$ \\
\hline
\end{tabular}

Podemos observar que a atividade antrópica que tem maior influência na mata ciliar são as culturas temporárias com $8 \%$ sobre a área total, tendo a área urbanizada em segundo lugar com 5.2\% e a cana de açúcar com $4.5 \%$.

As culturas temporárias são os locais onde ocorrem rotação de cultura como soja, milho e algodão.

Apesar da mineração ter um valor menor que $1 \%(0.2 \%)$ sua atividade tem poder de degradação muito grande visto que ocorre nesta área extração de saibro e areia, conforme levantado por BUFON (1999), onde observa-se processos erosivos devido ao local ficar exposto a céu aberto e não haver nenhum plano de controle para minimizar o impacto ambiental que pode ocorrer nesta área, pois a porcentagem que 
está invadindo a área de preservação permanente é apenas um indício de problemas que podem acontecer futuramente na região, pois pode-se observar melhor no mapa de uso e ocupação do solo atualizado (figura 25).

Segundo REZENDE (1998) um dos grandes problemas decorrentes da degradação da mata ciliar é o acentuado escoamento superficial de resíduos para o leito dos rios, e nesta região isto já está ocorrendo, conforme análise feita por BUFON (1999) na represa velha, que se encontra na área interna do CEPTA, onde observou-se que em 50 anos houve uma perda de $70 \mathrm{~cm}$ de profundidade da represa, e isto foi provocado pela deposição de sedimentos ao longo do Córrego da Barrinha.

Os efeitos catastróficos, provocados pela supressão da mata ciliar não se restringem aos limites geográficos da área em que está localizado o dano, pois isto pode vir a atingir dimensões regionais ainda maiores.

\subsection{2 - ANÁLISE DA INTEGRAÇÃO 2 (Uso e Ocupação do Solo X Geologia)}

A integração 2 tem como objetivo analisar a influência do uso e ocupação do solo atualizado (figura 25) com a geologia (figura 29), influindo informações sobre a possível formação pedológica da microbacia do Córrego da Barrinha, visto que a região não possui um mapa pedológico publicado pelo IAG (Instituto Agronômico de Campinas), e nem pelo próprio CEPTA. Porém a busca das informações referente a pedologia não se restringiram nestes dois órgãos públicos, pois também, buscaram-se informações com o pessoal do IPT (Instituto de Pesquisa Tecnológica) em São Paulo, contactando os senhores Mário Otávio e Samuel Sussumu Agena do Departamento de Geologia, e na região de Pirassununga buscou-se informações com os professores Pedro Henrique de Cerqueira e Neli Marisa Azevedo Silva do Departamento de Zootecnia da Universidade de São Paulo, campus de Pirassununga. 


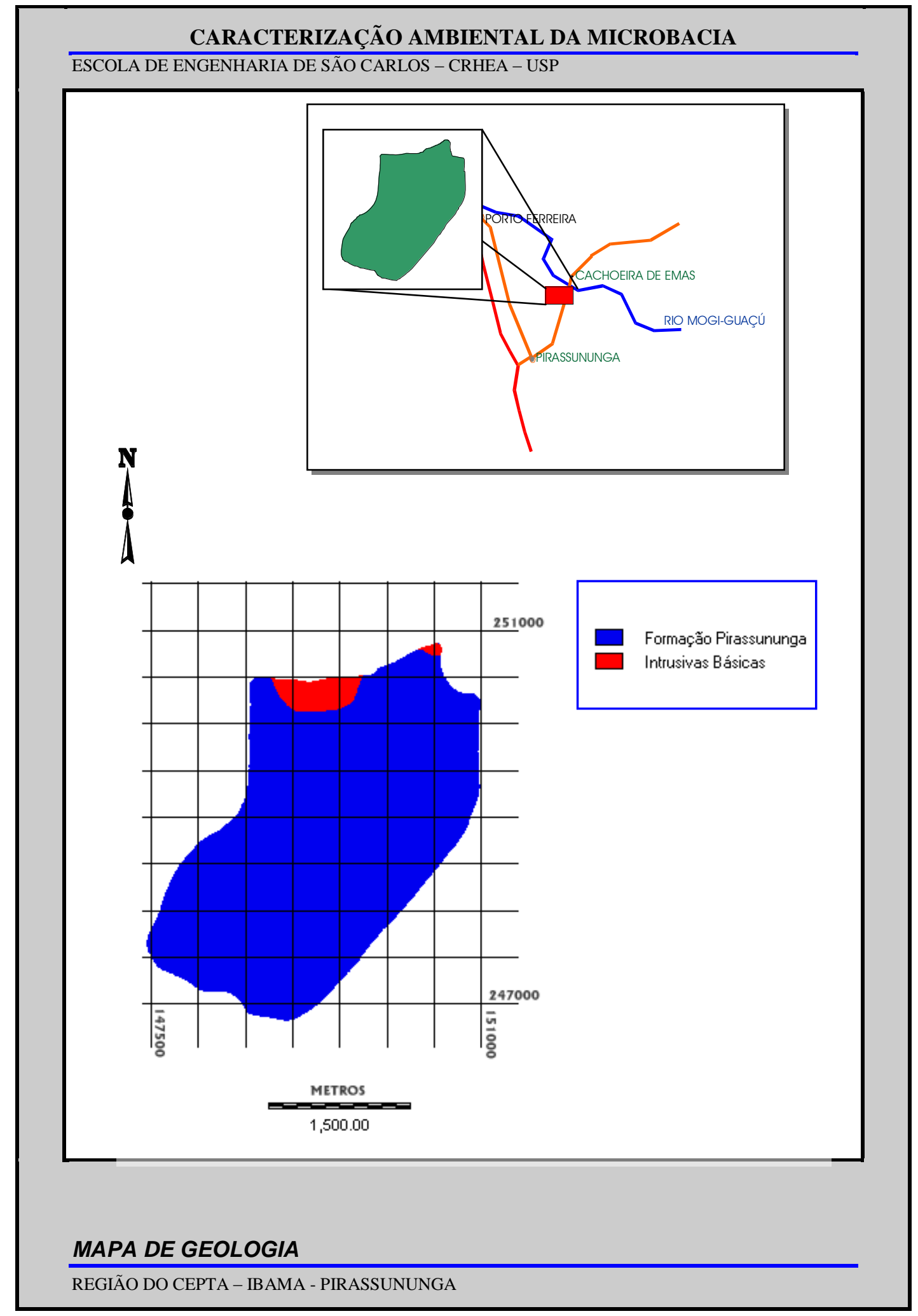

\section{FIGURA 29 - MAPA DE GEOLOGIA}

$\mathrm{Na}$ figura 30 podemos notar que $96,6 \%$ da área total é composta pela Formação Pirassununga, sendo que está formação geológica é composta por areias e conglomerados, da era Cenozóica e do período Terciário. 
Já a formação geológica de Intrusivas Básicas correspondem a 3,4\% da área total (figura 30) e esta formação corresponde aos diabásios da era Mesozóica e do período Jura-Cretáceo que dão origem ao latossolo roxo.

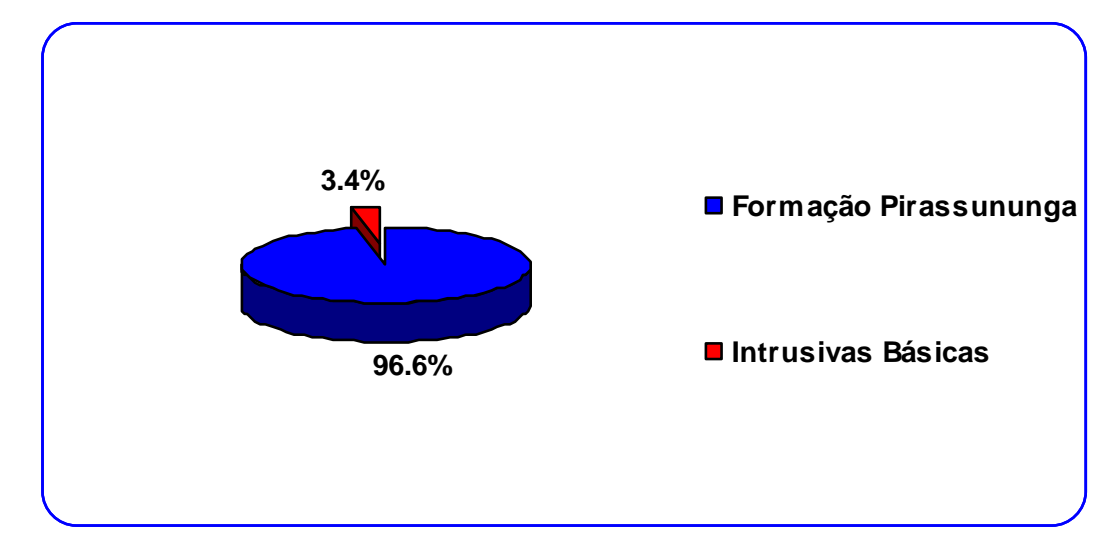

\section{FIGURA 30 - PORCENTAGEM DOS TIPOS DE FORMAÇÃO GEOLÓGICA}

O mapa de uso e ocupação do solo atualizado (figura 25) possui dezessete classes com áreas distribuídas da seguinte forma (figura 31) na microbacia do Córrego da Barrinha:

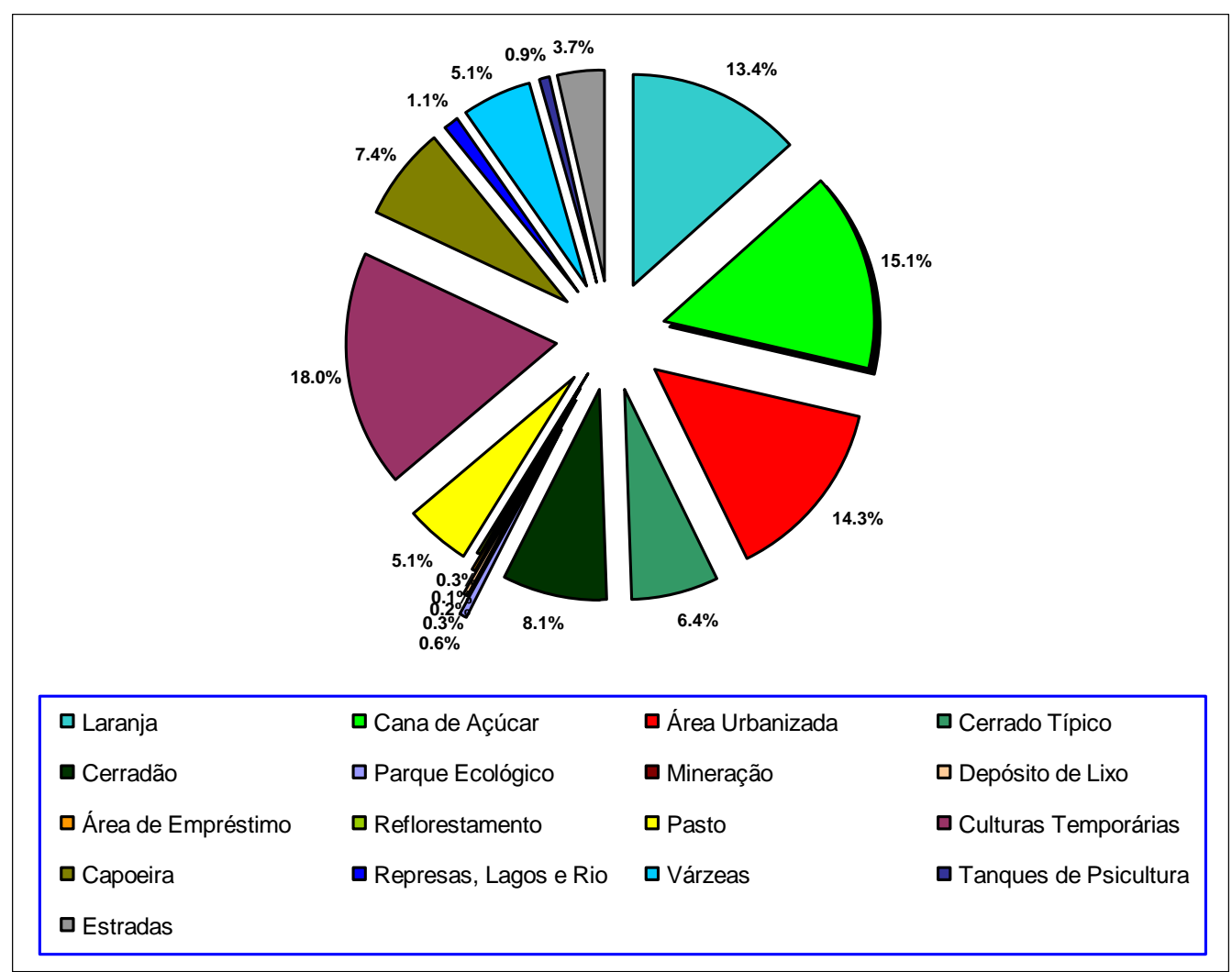

FIGURA 31 - PORCENTAGEM DAS ÁREAS DO MAPA DE USO E OCUPAÇÃO DO SOLO ATUALIZADO 
$\mathrm{Na}$ figura 31 podemos notar que área tem maior porcentagem de uso na atividade agrícola, pois somando-se as classes de culturas temporárias, cana de açúcar e laranja, temos um total de $46,5 \%$ do total da área da microbacia.

Portanto, para obter o mapa da integração 2, agrupou-se o resultado inicial (uso e ocupação do solo atualizado com a geologia) em um grupo menor com apenas nove classes, e o critério adotado para esse agrupamento está especificado na tabela 16, pois assim, as análises sobre o resultado gerado, propiciaram uma compreensão melhor.

TABELA 16 - CRITÉRIO ADOTADO PARA O USO E OCUPAÇÃo DO SOLO ATUALIZADO

\begin{tabular}{ll}
\hline NOVAS CLASSES & CLASSES AGRUPADAS \\
\hline 1 - Atividade Agrícola & Laranja, Cana de Açúcar e Culturas Temporárias \\
2 - Atividade Impactante & $\begin{array}{l}\text { Área Urbanizada, Mineração, Depósito de Lixo, Área } \\
\text { de Empréstimo, Tanques de Pscicultura e Estradas }\end{array}$ \\
$3-$ Vegetação & $\begin{array}{l}\text { Cerrado Típico, Cerradão, Reflorestamento, Pasto e } \\
\text { Capoeira }\end{array}$ \\
$4-$ Parque Ecológico & Parque Ecológico \\
$5-$ Hidrografia & Represas, Lagos, Rio e Várzeas \\
\hline
\end{tabular}

Para a geologia mantiveram-se as mesmas classes, já que este layer possui somente duas, e assim chegou-se ao seguinte resultado (tabela 17):

TABELA 17 - RESULTADO DAS CLASSES DO MAPA DA INTEGRAÇÃO 2

\begin{tabular}{cl}
\hline CLASSES DA INTEGRAÇ̃̃O 2 & CLASSES AGRUPADAS \\
\hline 1 & Atividade Agrícola/Geologia 1 \\
2 & Atividade Agrícola/Geologia 2 \\
3 & Atividade Impactante/Geologia 1 \\
4 & Atividade Impactante/Geologia 2 \\
5 & Vegetação/Geologia 1 \\
6 & Vegetação/Geologia 2 \\
7 & Parque Ecológico/Geologia 1 \\
8 & Hidrografia/Geologia 1 \\
9 & Hidrografia/Geologia 2 \\
\hline
\end{tabular}

Portanto, temos como resultado o seguinte mapa da integração 2 (figura 32): 


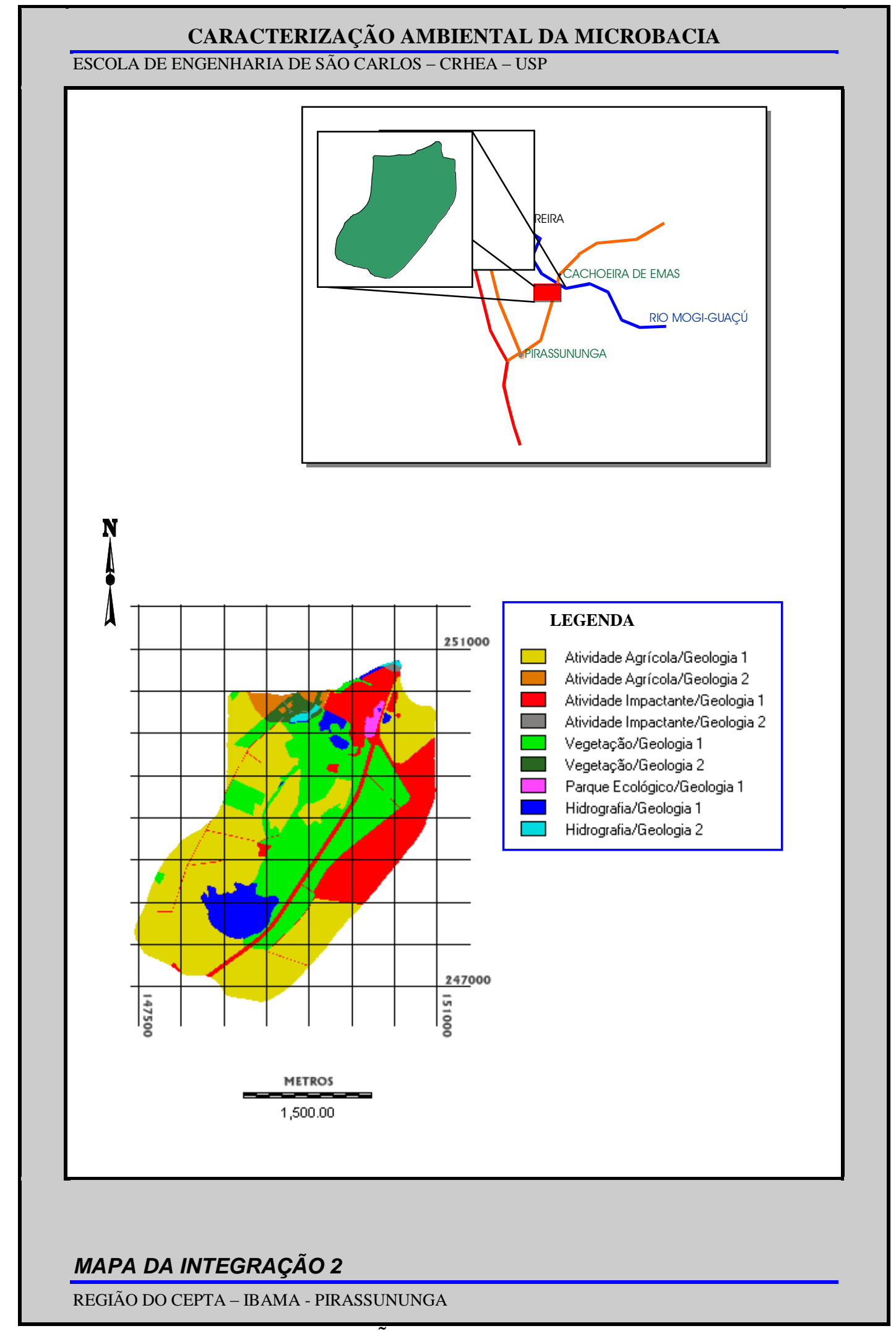

FIGURA 32 - MAPA DA INTEGRAÇÃO 2

De posse do mapa de integração 2 gerou-se a figura 33 com a porcentagem total das classes em função da área total da microbacia. 


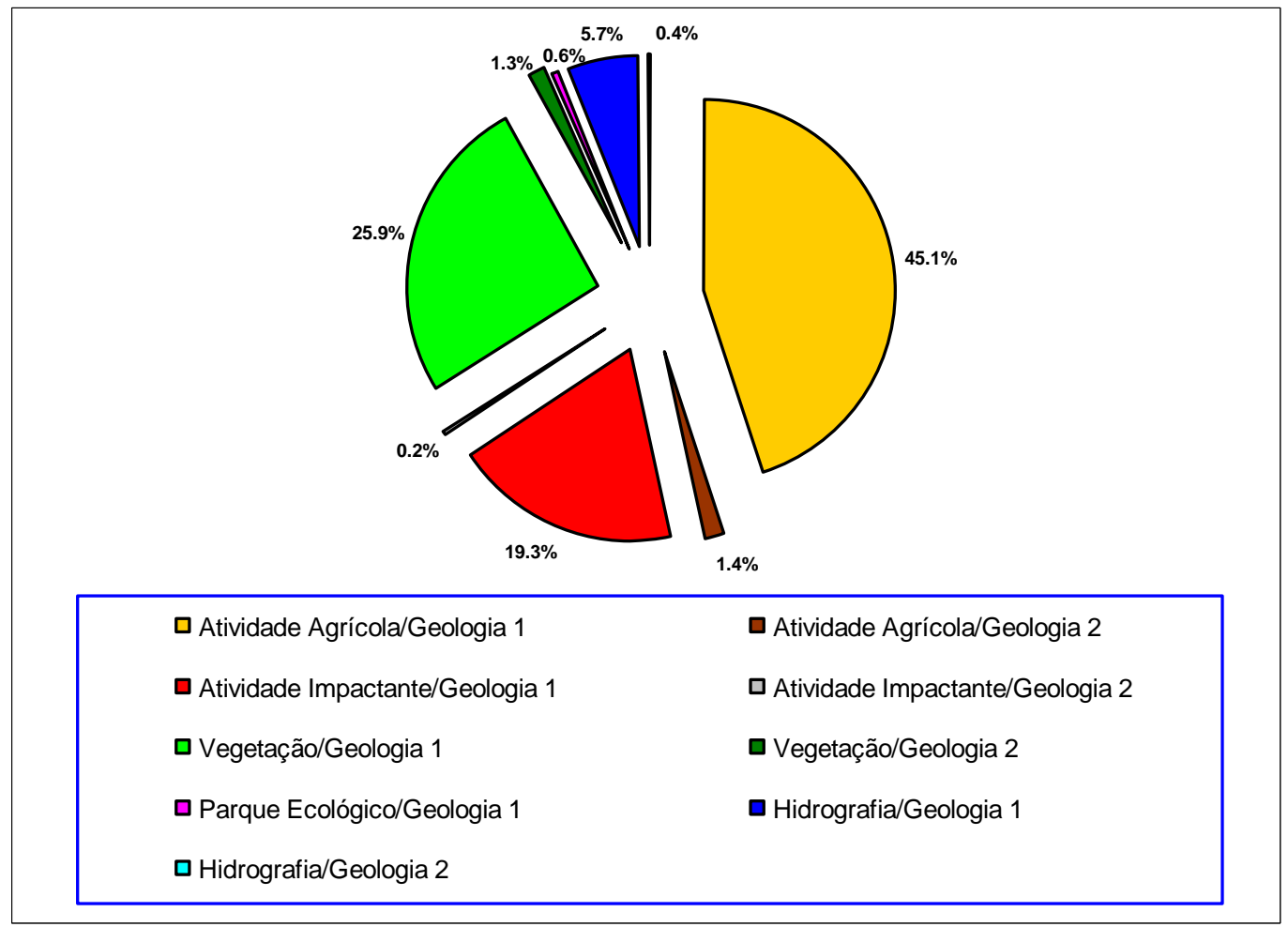

FIGURA 33 - PORCENTAGEM DAS ÁREAS DO MAPA DA INTEGRAÇÃO 2

$\mathrm{Na}$ figura 33 podemos observar que $45.1 \%$ da área está sendo utilizada como atividade agrícola numa geologia do tipo 1, cuja formação corresponde a áreas de areias e conglomerados, que são solos altamente susceptíveis a erosão, que segundo RAMALHO FILHO \& BEEK (1995), de acordo com a influência das condições climáticas, do relevo e da cobertura vegetal poderá se tornar uma área restrita a aptidão agrícola de acordo com o tipo de manejo que está sendo aplicado no local.

Em uma das regiões onde ocorre a atividade agrícola com a geologia do tipo 1, pode-se observar na figura 34 , que o solo presente neste local é arenoso, conforme a geologia do tipo 1, e existe atividade agrícola neste local feita com culturas temporárias, como o algodão (foto da figura 34). Pode-se observar que esta cultura localiza-se próximo da região de várzea onde está a nascente do Córrego da Barrinha, uma área de preservação permanente, conforme determinado na lei 7511/86 que institui o novo Código Florestal, que portanto, não poderia estar sendo explorado, pois pode ocorrer carreamento de sedimentos visto que este solo permanece sem cobertura, até a próxima cultura começar a crescer.

Segundo GUERRA (1999) o volume de material erodido é muito maior nos campos agrícolas arenosos do que nos argilosos, e isto pode ser apontado pelo papel da textura na erodibilidade dos solos. 


\section{ESCOLA DE ENGENHARIA DE SÃO CARLOS - CRHEA - USP \\ CARACTERIZAÇÃO AMBIENTAL DA MICROBACIA}
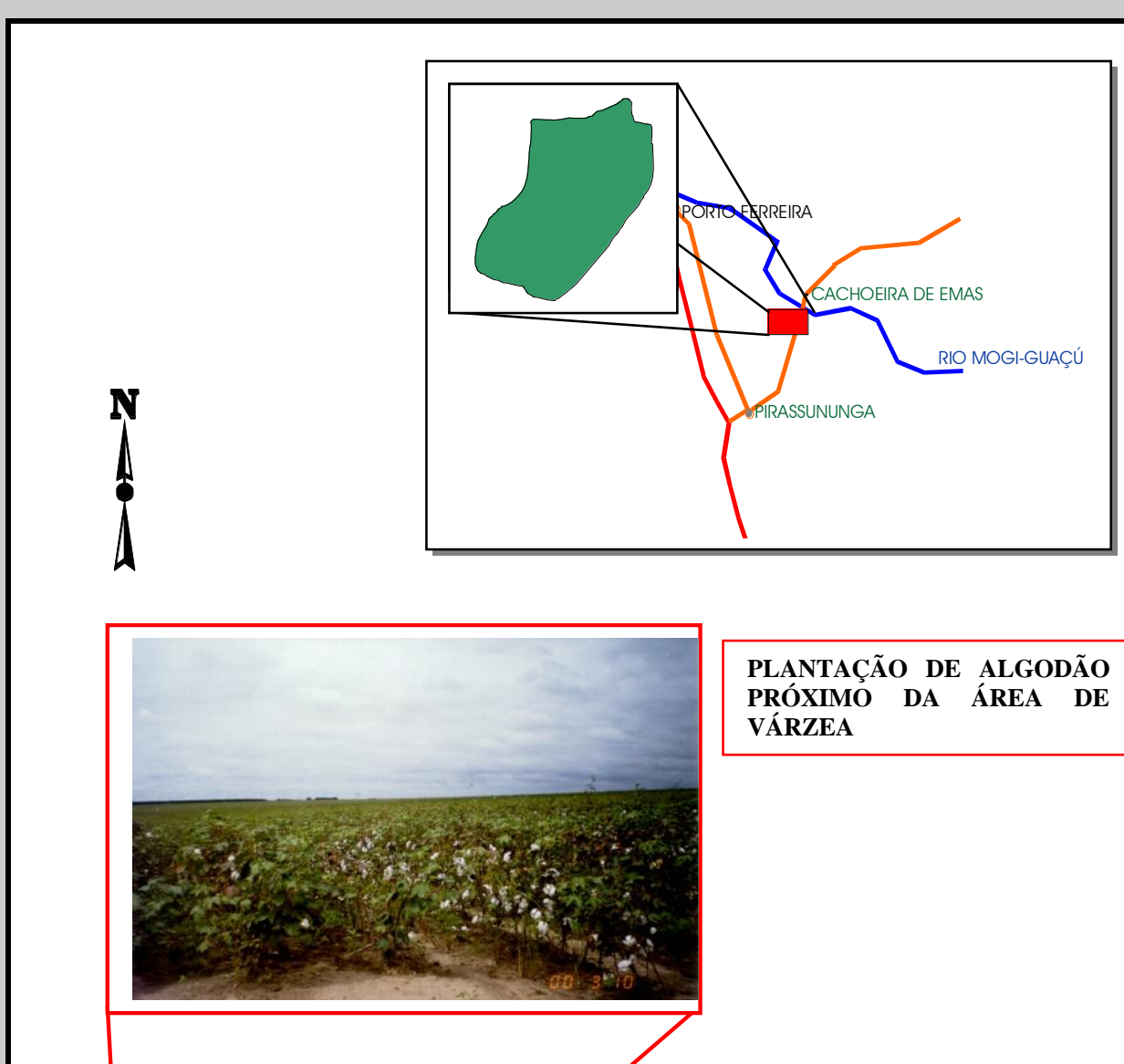

PLANTACÃO DE ALGODÃo PRÓXIMO DA ÁREA DE VÁRZEA

SOLO ARENOSO NA REGIÃO DA PLANTAÇÃO DE ALGODÃO

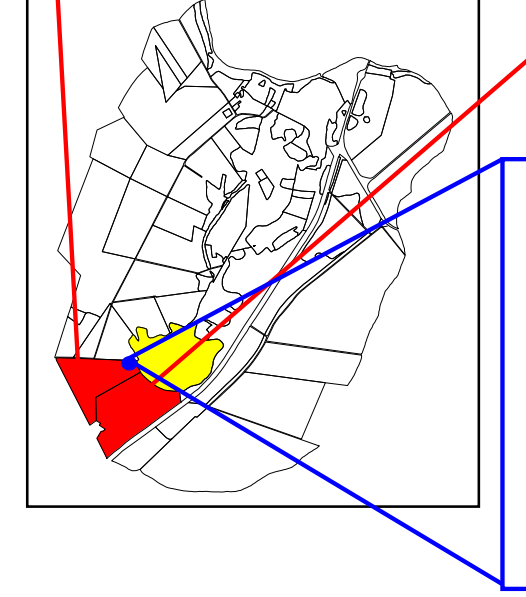

VÁRZEA/NASCENTE

\section{USO E OCUPAÇÃO DO SOLO ATUALIZADO}

REGIÃO DO CEPTA - IBAMA - PIRASSUNUNGA 
Na figura 33 podemos observar, também, que a atividade impactante com a geologia 1 possui $19.3 \%$ da área total e nestas regiões a preocupação é maior pois, dentre estas atividades temos a mineração de saibro e areia que é uma atividade altamente impactante, se não houver medidas mitigadoras para recuperação da área degradada, por serem regiões arenosas.

Quanto as regiões de vegetação podemos observar que $25.9 \%$ da área total estão em regiões com geologia do tipo 1, e portanto, neste caso estas regiões devem ser preservadas para que não ocorra degradação ambiental, pois a vegetação é um fator importante para evitar erosões, já que estão localizados em áreas de solos arenosos.

$\mathrm{Na}$ geologia do tipo 2 temos uma pequena porcentagem na atividade agrícola (1.4\%), atividade impactante $(0.2 \%)$ e na vegetação (1.3\%) e nestas áreas temos um latossolo roxo, um solo fértil e muito bom para agricultura.

Esta formação pode ser observada na figura 35, próximo do Rio Mogi Guaçú e no local onde possui a geologia do tipo 2, que dá origem esta formação pedológica. 
CARACTERIZAÇÃO AMBIENTAL DA MICROBACIA

ESCOLA DE ENGENHARIA DE SÃO CARLOS - CRHEA - USP

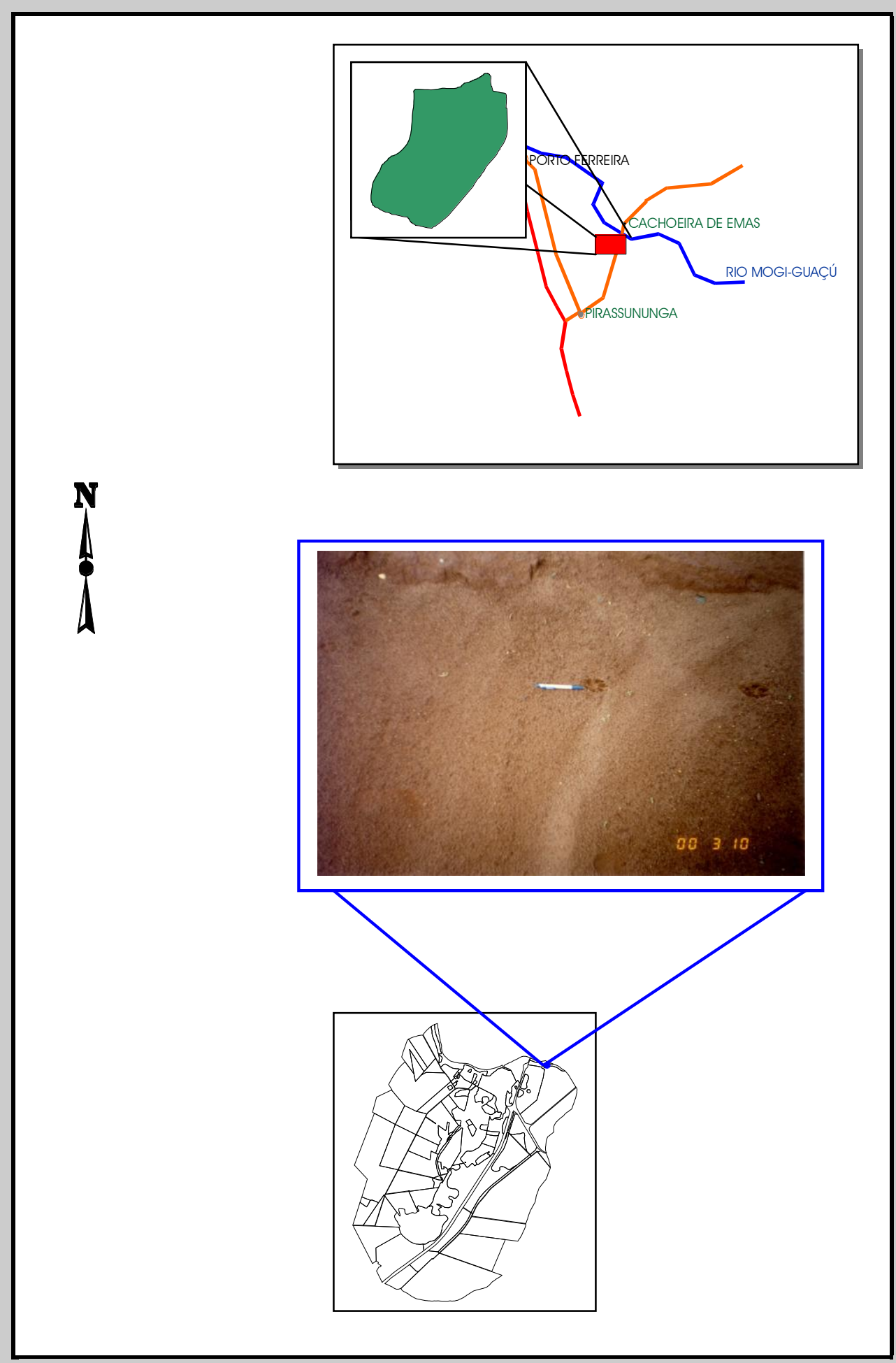

USO E OCUPAÇÃO DO SOLO ATUALIZADO

REGIÃO DO CEPTA - IBAMA - PIRASSUNUNGA

FIGURA 35 - LATOSSOLO ROXO PRÓXIMO DO RIO MOGI GUAÇÚ 


\subsection{3 - ANÁLISE DA INTEGRAÇÃO 3 (Geologia X Classes de Declividade)}

A integração 3 tem como objetivo caracterizar a microbacia do Córrego da Barrinha, com a influência da geologia (figura 29) em relação as classes de declividades (figura 36) geradas a partir das curvas de nível da região.

Segundo FUCHS ( 1986 ) comenta que do ponto de vista estritamente prático, a declividade do terreno é de grande interesse para uma gama de atividades, tais como: conservação do solo; determinação da capacidade de uso da terra; planejamento agropecuário e florestal; seleção de áreas mecanizáveis; manejo de bacias hidrográficas e propósitos de conservacionismo.

Através da integração 2 inferimos as possíveis formações pedológicas que ocorrem na região da microbacia, analisando alguns problemas que podem ocorrer relacionado a erosão, mas com o mapa de classes de declividade teremos mais um fator de influência, conforme um dos itens citados por RAMALHO FILHO \& BEEK (1995), sobre as condições do relevo.

Na figura 36 podemos observar que a maior parte da região está variando de 0 a 3\% de declividade, e assim podemos caracterizar está área como sendo basicamente plana, ocorrendo algumas alterações na declividade, somente na região próximo do Córrego da Barrinha. Isto pode ser bem observado no modelo de sombreamento da região (figura 37) onde observa-se um pequeno "vale" no leito do córrego e onde prevalece as classes de declividades que variam de 12 a 20\% e maior do que $20 \%$. 


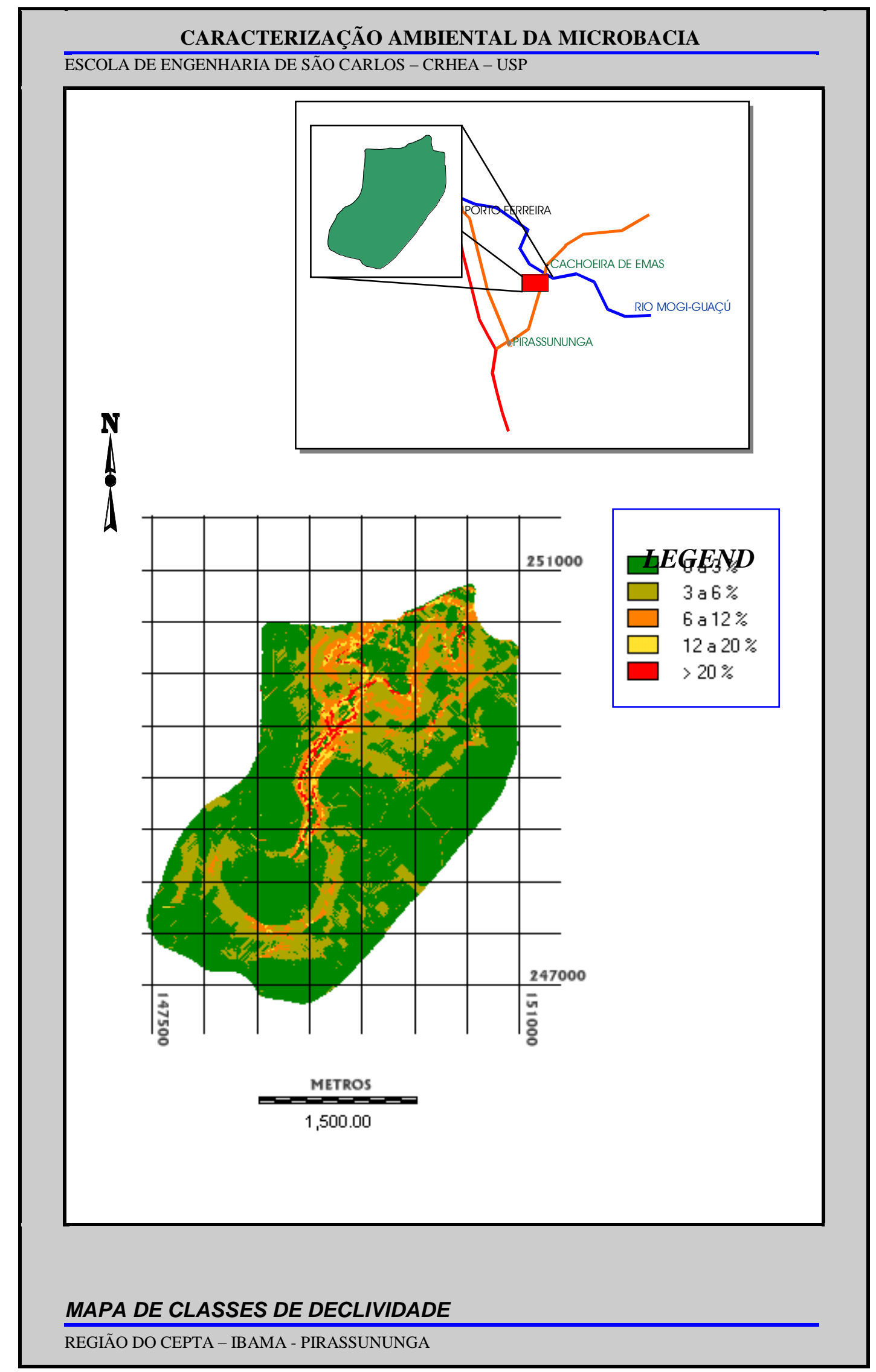

FIGURA 36 - MAPA DE CLASSES DE DECLIVIDADE 


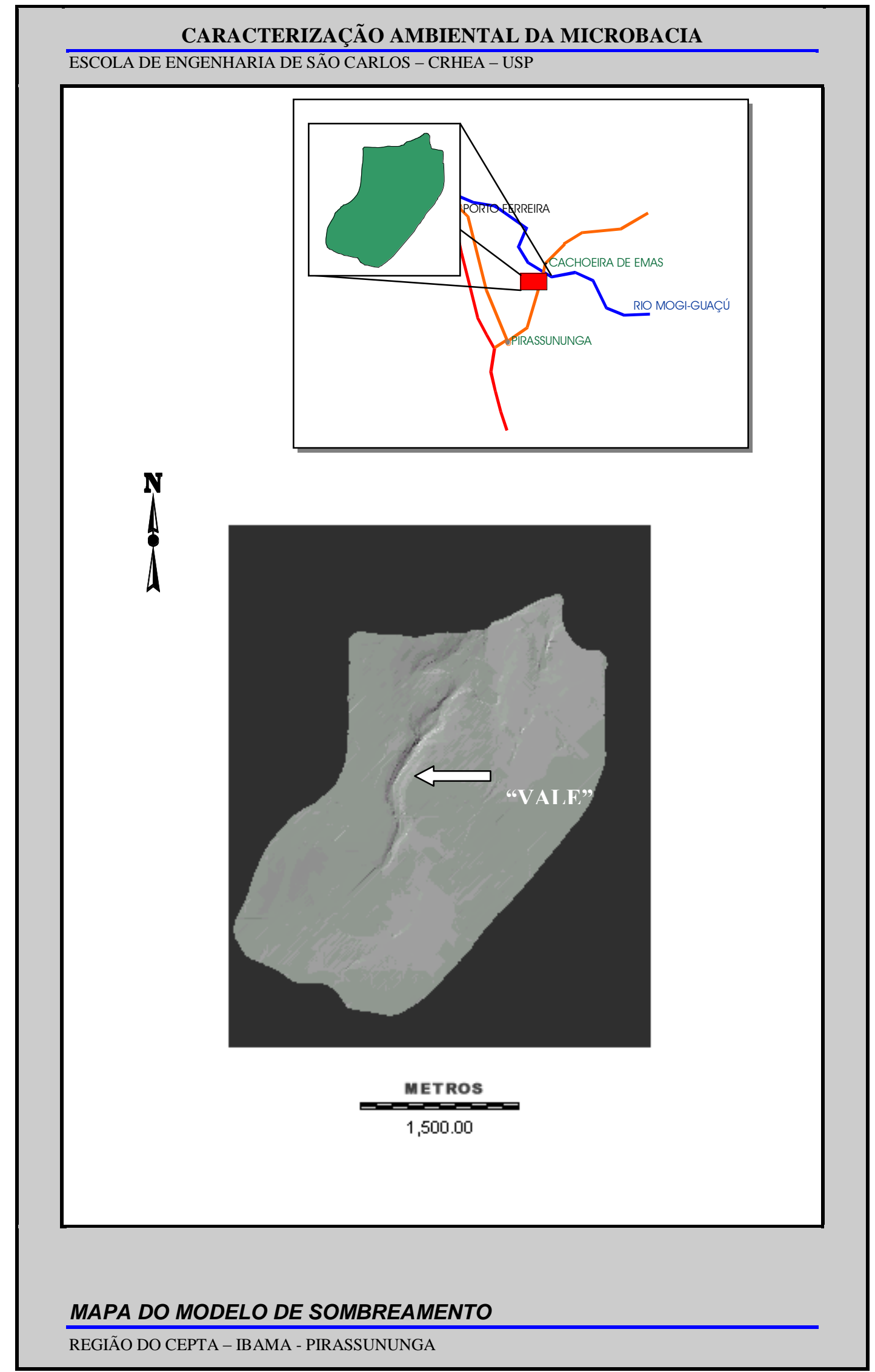

FIGURA 37 - MAPA DO MODELO DE SOMBREAMENTO 
Na figura 38 podemos observar a variação da porcentagem de cada classe de declividade em relação a área total da microbacia.

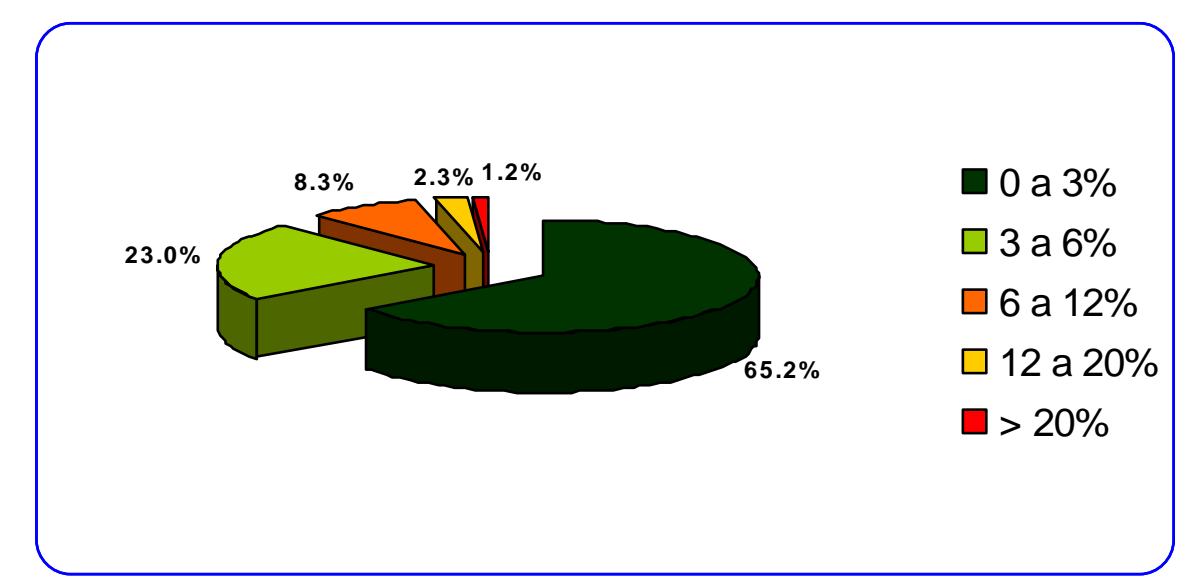

FIGURA 38 -PORCENTAGEM POR CLASSE DE DECLIVIDADE

Podemos observar que a classe de declividade que varia de 0 a $3 \%$ possui $65.2 \%$ da área total da microbacia, região considerada plana, 23\% da área estão enquadrados na classe de 3 a 6\%, região considerada como área suave ondulada, $8.3 \%$ da área estão enquadrados na classe de 6 a 12\%, região considerada como área moderadamente ondulada e $3.5 \%$ estão entre as classes de 12 a $20 \%$ e maior do que $20 \%$, sendo localizadas na região onde encontra-se o leito do Córrego da Barrinha, conforme observação feita na figura 36.

Portanto, com essas características descritas do mapa de classes de declividade e do mapa de geologia, obtivemos como resultado final da integração 3 o mapa da figura 39 com dez classes geradas. 


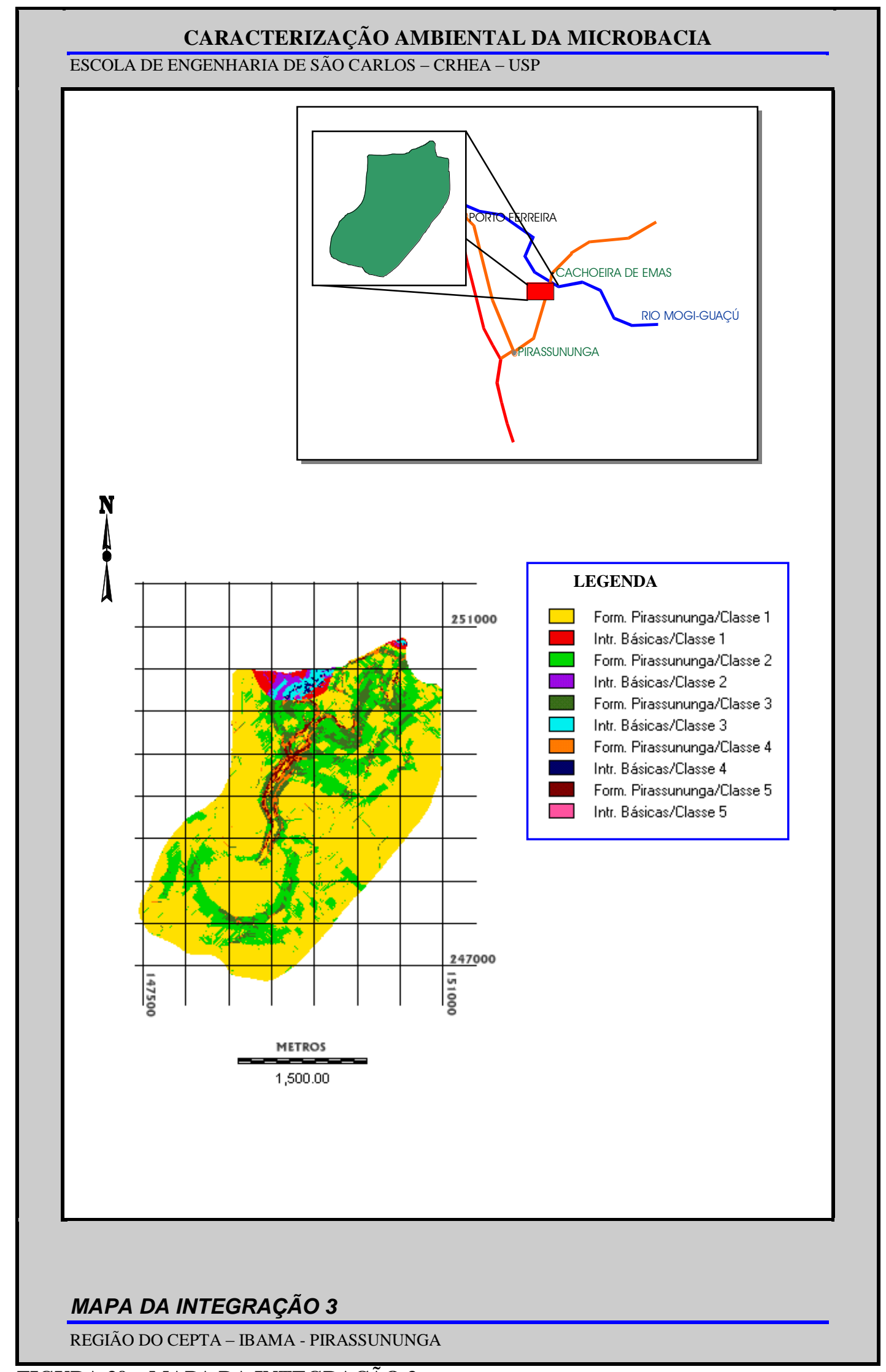

FIGURA 39 - MAPA DA INTEGRAÇÃO 3 
No mapa da integração 3 (figura 39) podemos observar que a maior parte da região está localizada na Formação Pirassununga integrado a classe de declividade 1 (0 a 3\%) e na figura 40 podemos observar que esta região possui $64 \%$ da área total da microbacia, ou seja a maior parte da microbacia está num local de relevo plano, mas numa região de areias e conglomerados pela formação geológica da área.

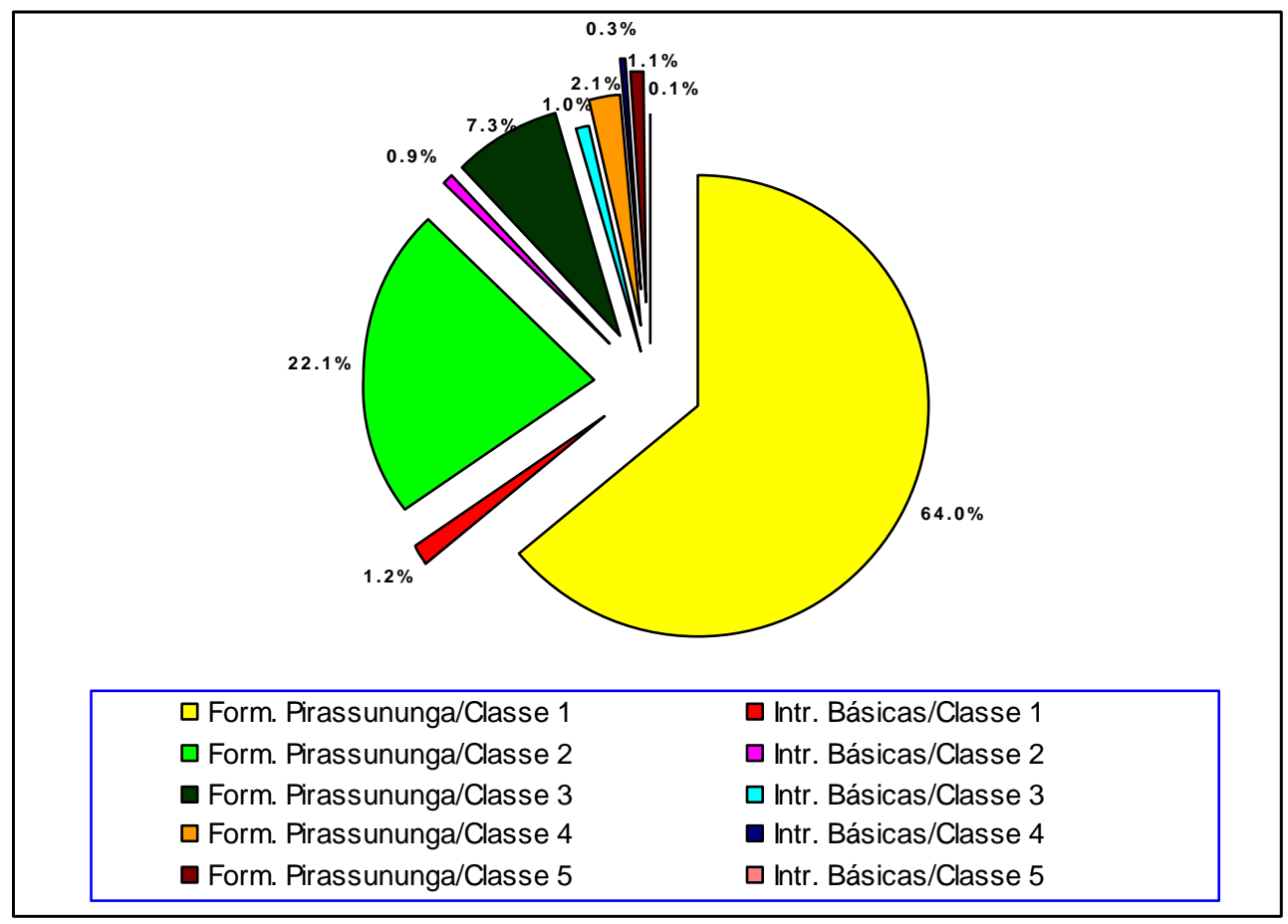

FIGURA 40 - PORCENTAGEM DAS ÁREAS DO MAPA DE INTEGRAÇÃo 3

Podemos observar na figura 40 que a segunda maior área (22.1\%), também pertence a Formação Pirassununga, mas na classe de declividade 2 (3 a 6\%), suave ondulada, o que pode apresentar pouca susceptibilidade a erosão, porém, segundo RAMALHO FILHO \& BEEK (1995) quando utilizadas com lavouras, por um período de 10 a 20 anos, mostram normalmente uma perda de $25 \%$ ou mais do horizonte superficial, e isto pode se evitado com práticas consevacionistas simples.

Em relação a classe 3 (6 a 12\%), moderadamente ondulado, possui $7.3 \%$ da área total na Formação Pirassununga, e está classe se concentra mais na região próximo do leito do Córrego da Barrinha (figura 36), e portanto, está região se destaca por sua susceptibilidade a erosão moderada, pois de acordo com RAMALHO FILHO \& BEEK (1995) se utilizadas fora dos princípios conservacionistas, essas 
terras podem apresentar sulcos e voçorocas, requerendo práticas de controle à erosão desde o início de sua utilização agrícola.

Segundo BUFON (1999) existem regiões com erosão laminar nas propriedades, próximos ao terraço fluvial, onde observa-se a presença de voçorocas, sulcos e ravinas, e esta região compreende as maiores classes de declividade, como pode ser observado no mapa da figura 36, regiões estas com presença de solos arenosos.

Na classe 4 com a Formação Pirassununga podemos observar que possui $2.1 \%$ da área total o que compreende regiões com declividades entre 12 e 20\%, e a caracteriza como área com forte susceptibilidade a erosão, cuja prevenção depende de práticas intensivas de controle.

Já na classe 5 com a Formação Pirassununga temos apenas $1.1 \%$ da área total, mas esta área compreende regiões com declividades maior do que $20 \%$, e portanto, são regiões com susceptibilidade muito forte, e que segundo RAMALHO FILHO \& BEEK (1995) na maioria dos casos o controle à erosão é dispendioso, podendo ser antieconômica.

No que se refere a geologia de Intrusivas Básicas, que dão origem ao latossolo roxo, temos uma maior representação na classe 1 com $1.2 \%$ da área total e nesta região a declividade varia de 0 a 3\%, uma área basicamente plana e que temos uma susceptibilidade à erosão nula, e quando cultivadas por 10 a 20 anos podem apresentar erosão ligeira, que pode ser controlada com práticas simples de manejo.

Em relação as outras classes de declividade as Intruvisas Básicas apresentam áreas menores ou igual a $1 \%$ da área total (figura 40), e a região que poderia ter maior influência seria na declividade maior do que $20 \%$ e neste caso possui somente $0.1 \%$ da área total, o que pode ser observado na figura 40.

$\mathrm{Na}$ figura 41 podemos observar o modelo digital de terreno com as classes de declividade gerado no Idrisi.

A criação de um modelo digital de terreno corresponde a uma nova maneira de enfocar o problema da elaboração e implantação de projetos. 


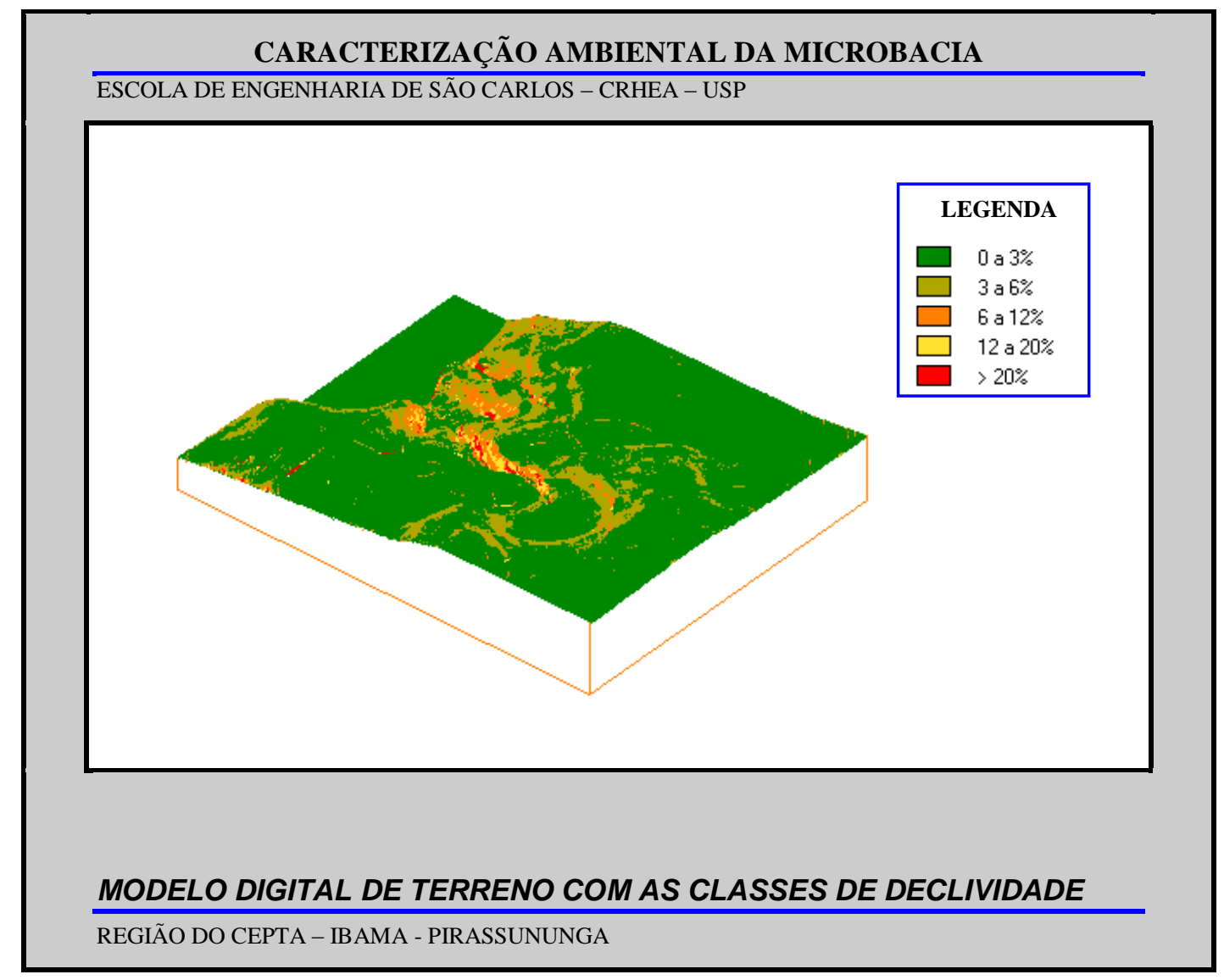

FIGURA 41 - MODELO DIGITAL DE TERRENO COM AS CLASSES DE DECLIVIDADE

Para uma melhor compreensão gerou-se também um modelo digital de terreno no SURFER (figura 42), que neste caso, o modelo gerado é de formato vetorial. Através deste modelo foi sobreposto o contorno das curvas de nível para verificar, que nos locais onde a declividade é maior as curvas de nível estão mais próximas.

No modelo digital de terreno (figura 41) podemos observar que as classes de declividades maiores, como descrito anteriormente, estão acompanhando todo o leito do córrego. 


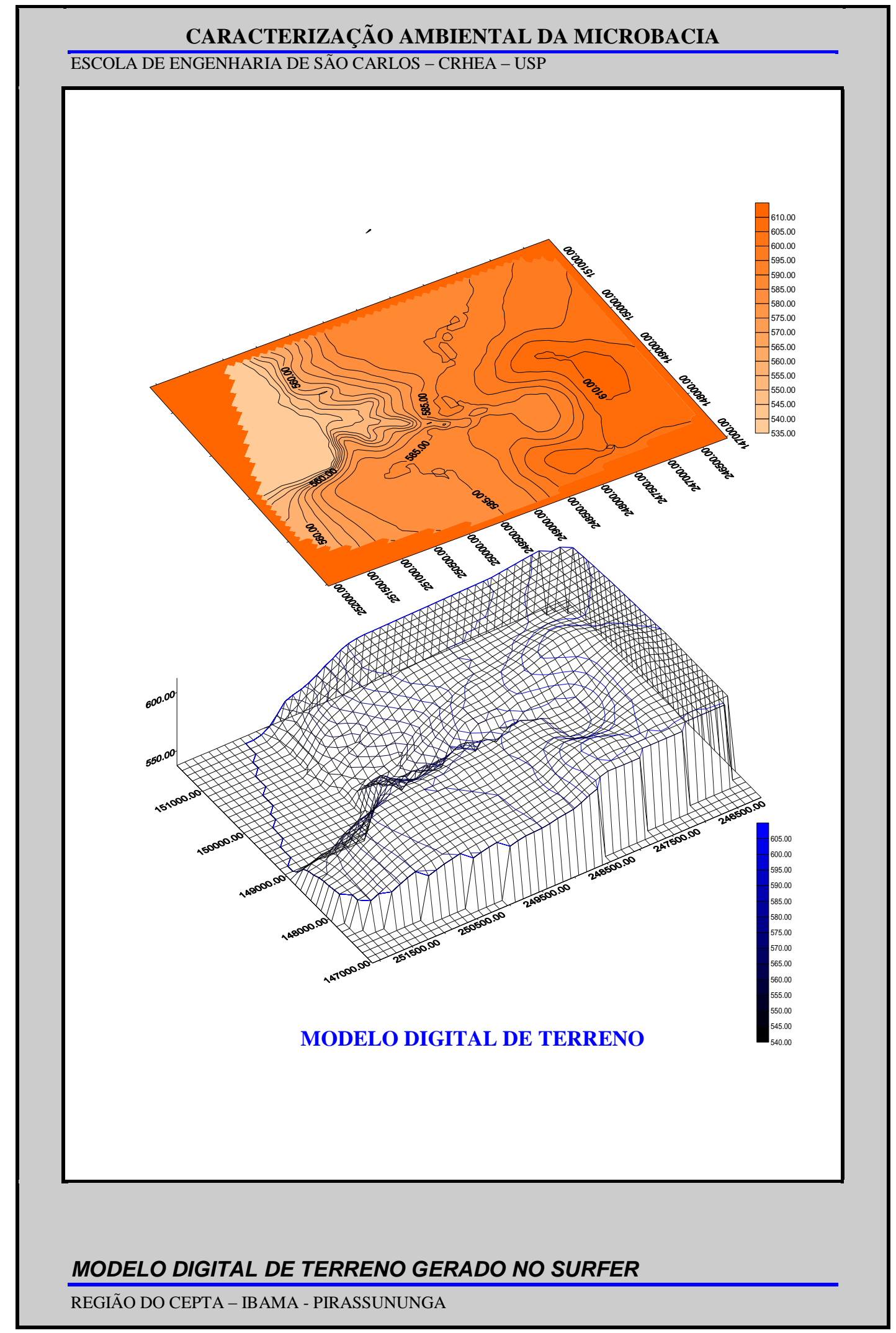

FIGURA 42 - MODELO DIGITAL DE TERRENO GERADO NO SURFER 


\subsection{4 - ANÁliSE DA INTEGRAÇÃO 4 (Classes de Declividade X Uso e Ocupação do Solo)}

A integração 4 tem como objetivo caracterizar a microbacia do Córrego da Barrinha, através da influência das classes de declividade (figura 36) em relação ao uso e ocupação do solo (figura 25) atualizadas em campo para determinara as áreas críticas dentro da microbacia.

Segundo BERTONI \& LOMBARDI NETO (1999), para o condicionamento da capacidade de uso da terra, a topografia, na maioria dos casos, constituí um dos fatores de maior importância, e, para o planejamento conservacionista, não há necessidade de discriminar os graus de declividade do terreno em suas mínimas variações, e sim, basta delimitar as zonas em que ocorrem determinadas classes de declividade.

Para obter o mapa da integração 4, agrupou-se as classes de uso e ocupação do solo atualizado em um número menor de classes, tendo como resultado deste agrupamento a tabela 18 .

\begin{tabular}{ll} 
TABELA 18 - AGRUPAMENTO DAS CLASSES DE USO E OCUPAÇÃO DO SOLO \\
ATUALIZADO & CLASSES AGRUPADAS \\
\hline NOVAS CLASSES & Laranja \\
\hline - Cultura Perene & Culturas Temporárias (Algodão, Milho, Soja e Painço) \\
3 - Cana de Açúcar & Cana de Açúcar \\
4 - Área Urbanizada & Área Urbanizada e Parque Ecológico \\
5 - Vegetação Natural & Cerrado Típico, Cerradão e Capoeira \\
6 - Solo Exposto & Mineração, Depósito de Lixo e Área de Empréstimo \\
7 - Reflorestamento & Reflorestamento \\
8 - Pasto & Pasto \\
9 - Hidrografia & Represas, Lagos, Rio e Várzeas \\
10 - Tanques de Psicultura & Tanques de Pscicultura \\
11 - Estradas & Estradas
\end{tabular}


Para o agrupamento das classes de uso e ocupação do solo atualizado, adotouse como critério as características de cada classe, e as semelhanças possíveis de serem identificadas, mantendo-se as classes que representam grandes atividades na área em estudo.

Após determinado o agrupamento das classes de uso e ocupação do solo atualizado, foi determinado um peso para cada classe, de acordo com o potencial de degradação, e na ordem crescente, do menos degradante para o mais degradante, obtendo como resultado desta ponderação a tabela 19.

TABELA 19 - PESO DAS CLASSES DE USO DE OCUPAÇÃO DO SOLO ATUALIZA
\begin{tabular}{ll}
\hline AGRUPADOS & $\begin{array}{l}\text { PESO } \\
\text { CLASSES DE USO E OCUPAÇÃO DO SOLO ATUALIZADO E } \\
1\end{array}$ \\
$\begin{array}{ll}\text { Vegetação Natural e Reflorestamento } \\
2\end{array}$ & $\begin{array}{l}\text { Cultura Perene e Hidrografia } \\
3\end{array}$ \\
4 & Canto \\
5 & Área Urbanizada e Tanques de Psicultura \\
6 & Solo Exposto e Estradas \\
\hline
\end{tabular}

No mapa de classes de declividade adotou-se, também, como critério o potencial de degradação, e na ordem crescente, onde as classes como maior declividade receberam um peso maior (tabela 20).

TABELA 20 - PESO DO MAPA DE CLASSES DE DECLIVIDADE

\begin{tabular}{cc}
\hline PESO & CLASSES DE DECLIVIDADE \\
\hline 1 & 0 a $3 \%$ \\
2 & 3 a $6 \%$ \\
3 & 6 a $12 \%$ \\
4 & 12 a $20 \%$ \\
5 & $>20 \%$ \\
\hline
\end{tabular}


Com os pesos determinados para cada mapa, gerou-se um mapa resultante com dez classes, utilizando a função overlay soma do Idrisi, e assim, com este resultado agrupou-se dois a dois e gerou-se o mapa da integração 4 (figura 44) com cinco classes de áreas críticas, que segundo PRADO (1999) a determinação destas áreas favorece um estudo da intervenção de cada uma no processo de degradação do curso d'água.

$\mathrm{Na}$ figura 43 podemos observar a variação da porcentagem de cada classe do mapa da integração 4 , em relação a área total da microbacia.

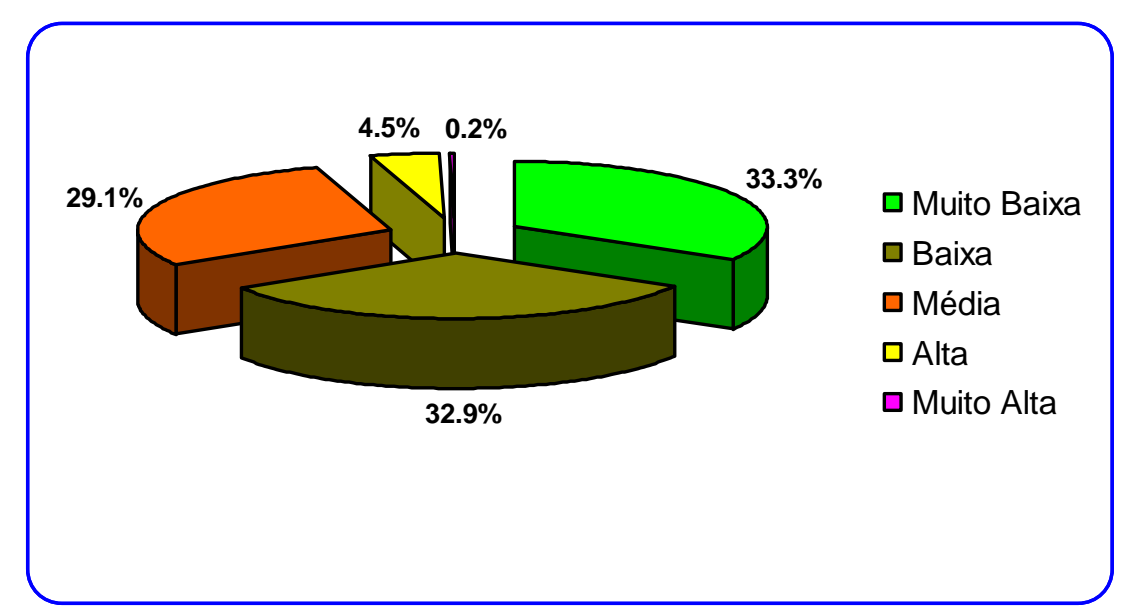

\section{FIGURA 43 - PORCENTAGEM DAS ÁREAS DO MAPA DA INTEGRAÇÃO 4}

Podemos observar que $33.3 \%$ da área total da microbacia encontra-se numa região muito baixa em termos de local crítico, ou seja um terço da área, de acordo com os critérios avaliados nesta análise, tem pouco problema em relação a declividade e uso e ocupação do solo. Nesta área podemos observar de acordo com o mapa de uso e ocupação do solo atualizado (figura 25) que está região tem como principal uso a presença de vegetação natural, e estão localizados em locais com pouca declividade (figura 36), variando de 0 a $3 \%$.

Da área total podemos observar na figura 43, que $32.9 \%$ da região encontrase num local de baixa criticidade, e neste local observa-se maior presença de plantações de cana de açúcar e culturas temporárias, e também, estão em locais de pouca declividade, variando de 0 a $3 \%$. Mas é bom lembrar que a cana de açúcar é uma cultura de alta rotatividade no solo, e que o solo presente nesta região é arenoso o que pode provocar erosões se o manejo não for controlado, e neste caso os defensivos agrícolas utilizados na cana de açúcar podem lixiviar e infiltrar no solo. 


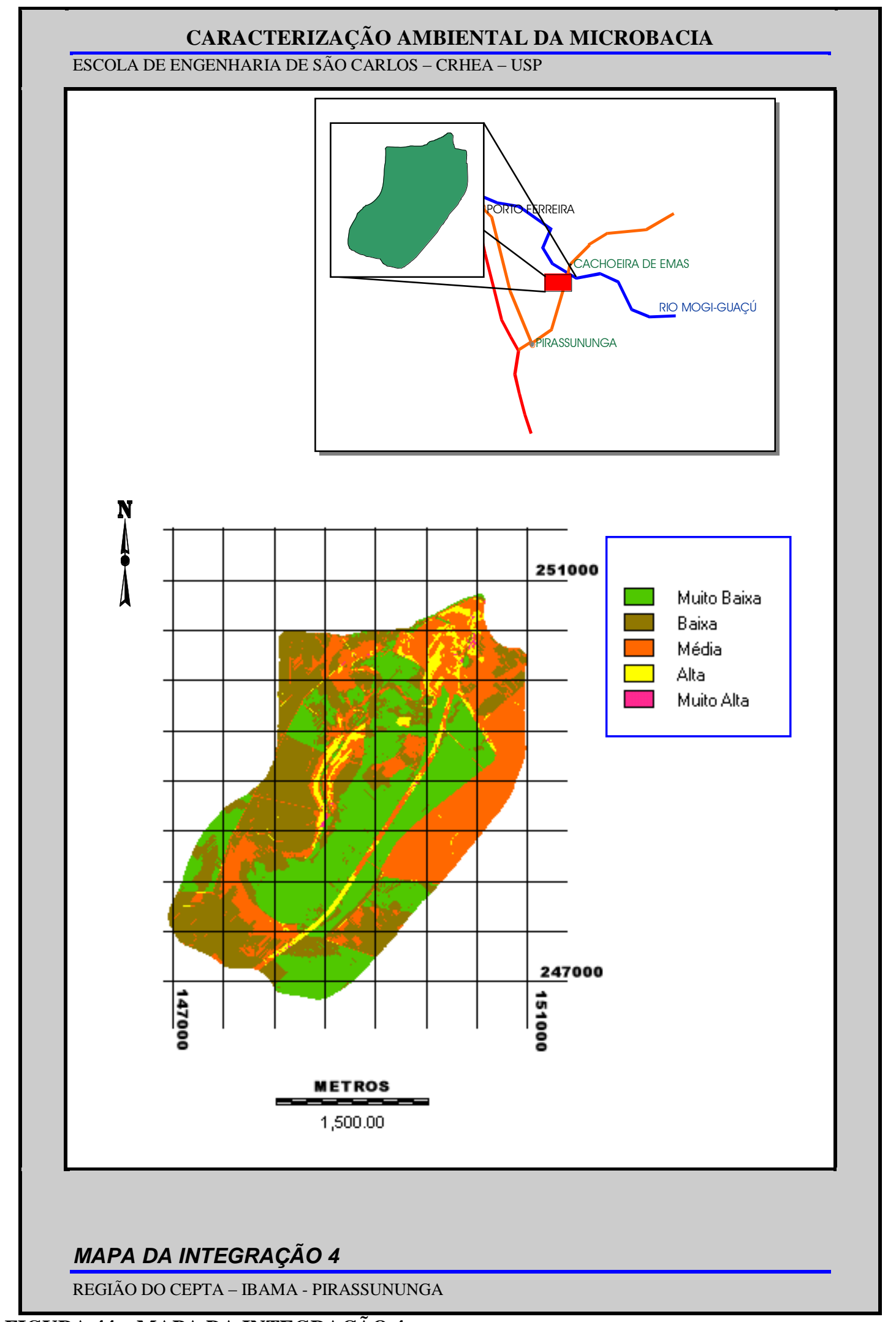

FIGURA 44 - MAPA DA INTEGRAÇÃO 4 
No entanto, $29.1 \%$ da área total encontra-se na região de média criticidade, e neste caso temos locais de área urbanizada, que ocupa a maior parte desta classe de criticidade, mas ao mesmo tempo temos ao longo do córrego e próximo da nascente plantações de cana de açúcar e culturas temporárias, cujas declividades estão nas faixas de 3 a $6 \%$ e 6 a 12\%, e nestes locais temos que ter um manejo bem controlado para não degradar a região da nascente e ao longo do curso d'água, onde pode ocorrer maior lixiviação de materiais devido a variação da declividade.

Podemos observar que $4.2 \%$ da área total está localizado na classe alta, e esta região ocorre ao longo do curso do córrego, onde prevalece declividades com variação entre 12 a $20 \%$ e maior do que $20 \%$, neste local temos pouca vegetação, como o cerradão, que está localizado na faixa do córrego, e maior uso agrícola com plantações de cana de açúcar.

A criticidade muito alta apresenta $0.2 \%$ da área total, e nesta área temos maior degradação ambiental, e mesmo com pouca representação em relação a área total da microbacia, esta região possui como características declividade superior a $20 \%$ e neste local encontra-se um trecho da mineração, que é uma atividade altamente impactante, quando não há um plano de manejo e ações mitigadoras para minimizar o impacto. 


\section{2 - AVALIAÇÃO DO SISTEMA TOPOGRÁFICO LOCAL}

Para avaliação do Sistema Topográfico Local, adotado como sistema de referência na digitalização dos mapas, foram levantados no campo, com GPS de navegação (PIONEER da Magellan com erro estimado de 100 metros), seis pontos bem definidos, que fossem facilmente identificados no mapa e localizados no campo.

As coordenadas da tabela 21 mostram os pontos levantados com o GPS em SAD69, e as mesmas convertidas para o Sistema Topográfico Local, com os respectivos erros em relação a posição correta no mapa (figura 45) em relação ao que foi digitalizado.

TABELA 21 - COORDENADAS LEVANTADAS EM CAMPO E SEUS RESPECTIVOS ERROS

\begin{tabular}{|c|c|c|c|}
\hline PONTOS & $\begin{array}{l}\text { COORDENADAS } \\
\text { GEOGRÁFICAS }\end{array}$ & $\begin{array}{l}\text { COORDENADAS } \\
\text { TOPOGRÁFICO LOCAL }\end{array}$ & $\begin{array}{c}\text { ERRO DO PONTO } \\
\text { (metros) }\end{array}$ \\
\hline 1 & $\begin{array}{l}\text { Latitude: 21G56M27S } \\
\text { Longitude: 47G22M02S } \\
\text { PONTO CORRETO }\end{array}$ & $\begin{array}{l}X=150673,683 \\
Y=249147,570 \\
X=150681,029 \\
Y=249144,918\end{array}$ & 7,8 \\
\hline 2 & $\begin{array}{l}\text { Latitude: 21G57M03S } \\
\text { Longitude: 47G22M44S } \\
\text { PONTO CORRETO }\end{array}$ & $\begin{array}{l}X=149468,383 \\
Y=248040,176 \\
X=149552,404 \\
Y=248026,418\end{array}$ & 85,1 \\
\hline 3 & $\begin{array}{l}\text { Latitude: 21G57M06S } \\
\text { Longitude: 47G23M41S } \\
\text { PONTO CORRETO }\end{array}$ & $\begin{array}{l}X=147832,695 \\
Y=247947,753 \\
X=147883,123 \\
Y=247861,918\end{array}$ & 99,5 \\
\hline 4 & $\begin{array}{l}\text { Latitude: 21G56M19S } \\
\text { Longitude: 47G23M17S } \\
\text { PONTO CORRETO }\end{array}$ & $\begin{array}{l}X=148521,272 \\
Y=249393,604 \\
X=148597,998 \\
Y=249438,918\end{array}$ & 89,1 \\
\hline 5 & $\begin{array}{l}\text { Latitude: 21G56M05S } \\
\text { Longitude: 47G23M09S } \\
\text { PONTO CORRETO }\end{array}$ & $\begin{array}{l}X=148750,830 \\
Y=249824,278 \\
X=148757,701 \\
Y=249742,918\end{array}$ & 81,6 \\
\hline 6 & $\begin{array}{l}\text { Latitude: 21G55M50S } \\
\text { Longitude: 47G22M52S } \\
\text { PONTO CORRETO }\end{array}$ & $\begin{array}{l}X=149238,703 \\
Y=250285,725 \\
X=149263,123 \\
Y=250237,418\end{array}$ & 54,1 \\
\hline
\end{tabular}

OBS: CADA PONTO FOI LEVANTADO COM 5 MINUTOS DE RASTREAMENTO. 
AVALIAÇÃO DO SISTEMA TOPOGRÁFICO LOCAL

ESCOLA DE ENGENHARIA DE SÃO CARLOS - CRHEA - USP

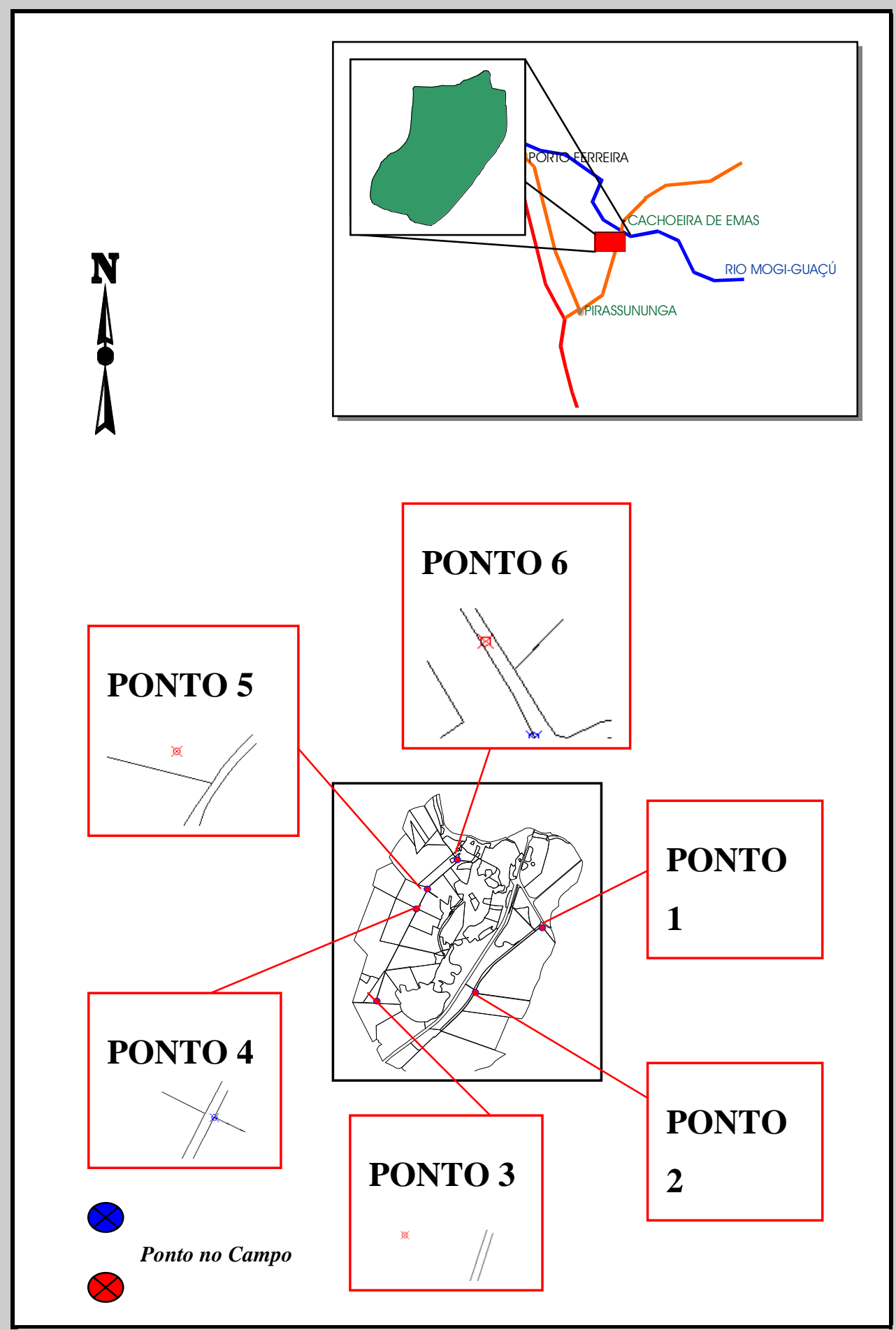

PONTOS UTILIZADOS PARA AVALIAÇÃO

REGIÃO DO CEPTA - IBAMA - PIRASSUNUNGA

FIGURA 45 - PONTOS UTILIZADOS PARA AVALIAÇÃO 
Na figura 46 temos uma foto identificando o ponto 2 levantado em campo, ilustrando a posição correta que o ponto deveria estar no mapa.

AVALIAÇÃO DO SISTEMA TOPOGRÁFICO LOCAL

ESCOLA DE ENGENHARIA DE SÃO CARLOS - CRHEA - USP

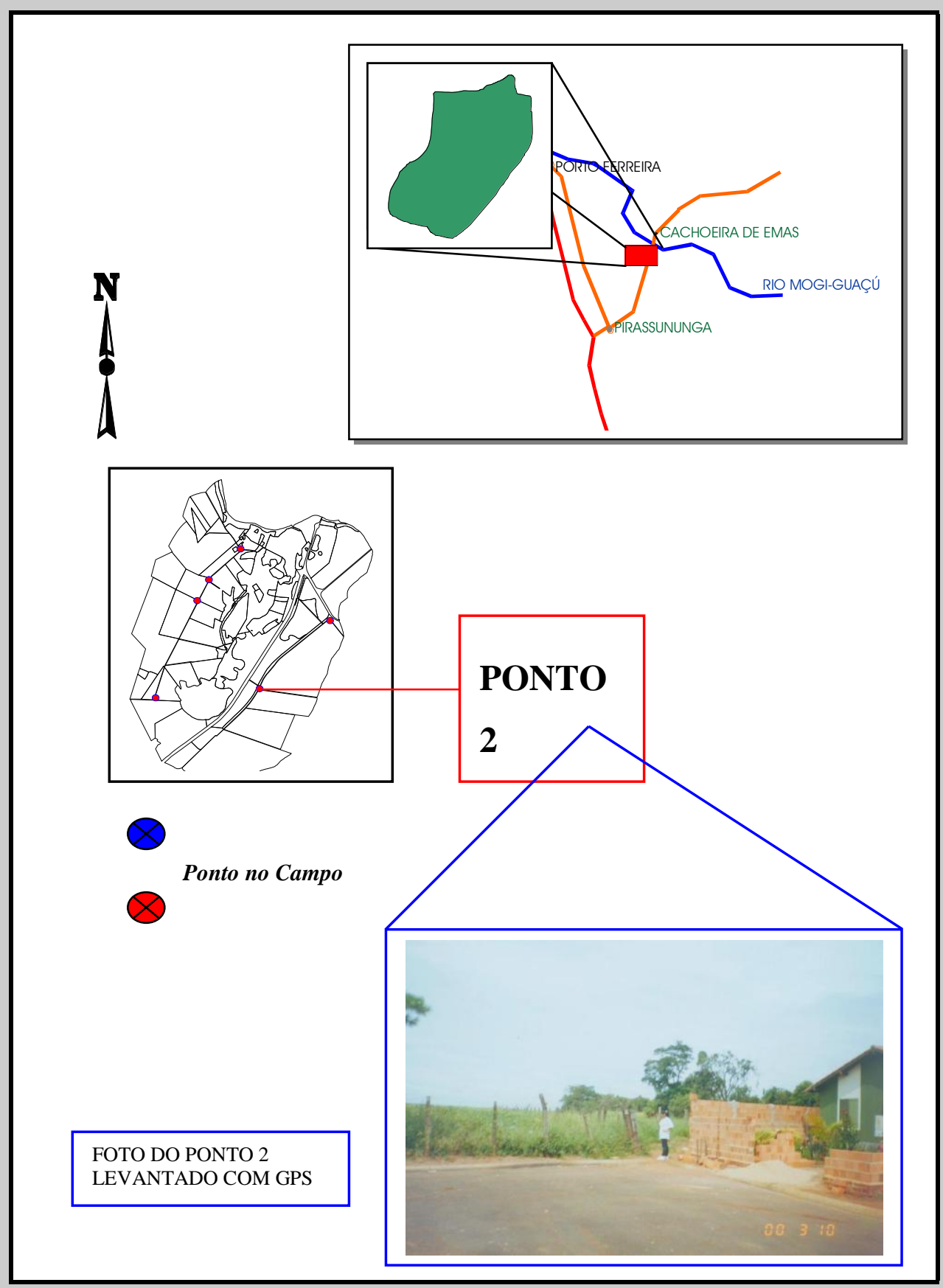

FOTO DA LOCALIZAÇÃO DO PONTO 2

REGIÃO DO CEPTA - IBAMA - PIRASSUNUNGA

FIGURA 46 -FOTO DA LOCALIZAÇÃO DO PONTO 2 
Portanto, com o resultado obtido na tabela chegamos a conclusão de que em alguns pontos o erro foi superior a 80 metros (pontos 2, 3, 4 e 5), porém o equipamento utilizado na avaliação de campo tem um erro relativo de 100 metros, sendo que o resultado obtido está abaixo deste valor.

Temos uma discrepância em relação ao ponto 1 , onde o erro foi de 7,8 metros, e isto pode estar relacionado ao horário do levantamento e a configuração da constelação GPS no momento do rastreamento.

Assim, podemos relatar que o Sistema Topográfico Local pode ser utilizado como uma alternativa em levantamentos de informações ambientais, podendo auxiliar pesquisadores que tenham dificuldades de concatenação de mapas em coordenadas UTM, em regiões de mudança de fuso, que segundo KLEINER \& MENEGUETE (1999) só é permitido o uso de coordenadas no sistema de projeção UTM, quando apenas uma parte da área de estudo, encontra-se no outro fuso, a uma distância de meio grau, o que equivale a aproximadamente $50 \mathrm{~km}$. Mas esta metodologia só poderá ser utilizada, desde que a área de estudo se enquadre nas características do Sistema Topográfico Local (conforme descrito no Capítulo de Materias e Métodos).

Com o anúncio pelo Governo Americano sobre o fim da degradação intencional dos sinais do Sistema de Posicionamento Global - GPS, a Selective Availability (SA). Isso significa que usuários civis do sistema terão acesso a posicionamentos dez vezes mais precisos do que tinham até então (FATORGIS 2000).

Esta decisão é a última medida do esforço para fazer o GPS mais eficiente para usuários civis e comerciais no mundo todo. A decisão de descontinuar a SA foi baseada em recomendação da Secretaria da Defesa em coordenação com os Departamentos de Estado, Transportes, Comércio, com o Diretor da Central de Inteligência e outras agências e departamentos executivos. Essas instituições esperam que a segurança dos transportes, os interesses científicos e comerciais no mundo todo se beneficiem da liberação da degradação intencional.

Assim, as coordenadas obtidas com o GPS de navegação poderão chegar a valores mais próximos com erros bem menores do que foi obtido neste levantamento de campo. 


\section{6 - CONCLUSÕES}

Este trabalho foi desenvolvido com o objetivo de estudar as características ambientais do Córrego da Barrinha, e fazer uma abordagem sistêmica da área, integrando informações físicas como geologia, uso e ocupação do solo, hidrografia e as curvas de nível, utilizando técnicas de geoprocessamento.

Conclui-se portanto, que a área em estudo apresenta problemas em seu entorno relacionado à degradação ambiental, pois ao longo do leito do Córrego da Barrinha ocorrem regiões de exploração de mineração em local que deveria existir uma faixa de mata ciliar, faixa esta determinada pelo Código Florestal e de acordo com as características do curso d'água.

Um outro fator preponderante na região é a atividade agrícola que possui uma grande área (46,5\% da área total - figura 33), com intenso uso do solo relacionado a plantação de cana de açúcar, que pode ser observado no mapa atualizado de uso e ocupação do solo (figura 25), com predomínio de 15,1\% da área total. Esta atividade tem como características o uso de herbicidas, que segundo PRADO (1999) as espécies de cana de açúcar que estão sendo criadas são mais resistentes às pragas devido ao seu melhoramento genético, e portanto, os herbicidas são utilizados para combater ervas daninha. Mas não podemos esquecer que na plantação de cana de açúcar temos o problema das queimadas, que é, também, um fator de degradação do meio ambiente.

Apesar da área ter em sua maior parte uma declividade variando de 0 a 3\%, o que pode ser comprovado pela figura 38 , com $65,2 \%$ da sua área total, mas isto não descaracteriza os problemas, relacionados à erosão, pois há predominância de solos arenosos, o que foi observado na região de culturas temporárias (figura 34), próximo da área de várzea, no entorno da nascente do Córrego da Barrinha, pois estes solos podem estar sujeitos a problemas de erosão, conforme o tipo de manejo utilizado. 
Em relação as atividades no entorno do Córrego da Barrinha, na região de mata ciliar, podemos observar que $24,4 \%$ da área total (tabela 15) da faixa de proteção da mata ciliar está com atividades antrópicas, predominando nesta região a atividade agrícola. E neste caso, é preciso ter planos de recuperação na faixa de mata ciliar, que segundo MEDINILHA (1999) esta faixa pode ser até maior do que o estabelecido no Código Florestal, e assim, garantir maior eficiência na eliminação de poluentes em setores de maior declividade.

Foi observado no mapa de declividades (figura 36) que as regiões de maiores declividades estão localizados ao longo do leito do Córrego da Barrinha, e trabalhos anteriores comprovam que o aumento de fosfato no ecossistema aquático, segundo NASCIMENTO (1994) é devido a atividade agrícola presente na região, cujas concentrações de nitrogênio e fósforo foram detectados na nascente do córrego, e portanto, com a declividade mais acentuada ocorre o favorecimento de lixiviação para o curso d'água, afetando assim, a qualidade da água que abastece os tanques de psicultura do CEPTA/IBAMA.

O sistema topográfico local utilizado como sistema de referência na digitalização dos mapas teve um bom resultado, sendo comprovado através da validação de campo que as coordenadas em outros sistemas de referência podem ser convertidas para este sistema, e com fim da degradação do sinal GPS os receptores de navegação, topográficos e geodésicos terão um desvio padrão cada vez menor, melhorando o posicionamento das coordenadas obtidas em campo.

Neste trabalho, temos que considerar os problemas relacionado a digitalização, que podem influir no resultado final, quando os pontos forem levantados com o GPS, para o georreferenciamento de mapas, pois existem erros sistemáticos, relacionados a experiência do digitalizador e do próprio material (mapa em papel) que está sendo utilizado e que devem ser considerados.

Assim, o sistema topográfico local pode ser uma "nova" alternativa para profissionais que trabalham com informações ambientais e tenham problemas com áreas de estudo localizadas em dois fusos, pois neste caso uma solução é trabalhar com coordenadas no sistema topográfico local. Mas não podemos esquecer, que a área de estudo deve ter características que se enquadrem neste sistema de referência. 
As informações geradas neste trabalho irá propiciar ao Comitê de Bacia do Rio Mogi Guaçú, um entendimento melhor da microbacia do Córrego da Barrinha, pois segundo a Política Nacional de Recursos Hídricos (lei 9433/97) é necessário um diagnóstico da bacia hidrográfica para um gerenciamento adequado, compatibilizando programas setorias para propor ações de recuperação da bacia e garantir uma qualidade de água adequada para o consumo, visando o desenvolvimento sustentável.

Neste aspecto o Comitê de Bacia do Rio Mogi Guaçú, através da Política Estadual de Recursos Hídricos (lei 7663/91), estabelece nos Planos de Bacias Hidrográficas elementos como, por exemplo: programas anuais e plurianuais de recuperação, proteção, conservação e utilização dos recursos hídricos da bacia hidrográfica, mas para isto é necessário um diagnóstico ambiental dos afluentes da bacia, como subsídio na tomada de decisão na atuação de recuperação das bacias hidrográficas.

Portanto, as informações geradas neste trabalho subsidiará o Comitê de Bacia do Rio Mogi Guaçú na tomada de decisão de recuperação da microbacia do Córrego da Barrinha, e servirá também, como referência para estudos em outras microbacias, de qualquer região do Brasil. 


\section{7 - RECOMENDAÇÕES}

Recomendamos para complementação da caracterização ambiental do Córrego da Barrinha, o levantamento do mapa de pedologia na escala de 1:5.000 para gerar mapas de áreas susceptíveis à erosão, de acordo com o tipo de solo da região, e a determinação ou não de áreas potenciais para aterro sanitário.

Com o objetivo futuro de gerar um mapa de zoneamento ambiental da área de estudo, com os dados gerados nesse trabalho, será necessário um levantamento sócioeconômico, flora e fauna da região, para que assim, seja determinado as zonas de uso.

E com isto, futuramente, poderá ser criada uma área de proteção ambiental na região do Córrego do Barrinha, de acordo com a Política Nacional do Meio Ambiente e as normas que deverão ser estabelecidas pelo IBAMA. 


\section{8 - REFERÊNCIAS BIBLIOGRÁFICAS}

AB'SABER, A. N. (1989) - Zoneamento Ecológico Econômico da Amazônia -

Questões de Escala e Método. Estudos Avançados, vol. 3, n. 5, p.4-19.

ADAMI, A. (1999) - Sub-Sistemas de um Software SIG - Entrada de Dados http://www.geocities.com/WallStreat/Exchange/3012/Aula1.html $\quad(11 \mathrm{dez}$ 1999).

AGENDA 21 (1992) - Capítulo 3 - Combate à Pobreza.

AGENDA 21 (1992a) - Capítulo 34 - Transferência de Tecnologia Ambientalmente Saudável, Cooperação e Fortalecimento Institucional.

AlvarengA, S. R. (1997) - A Análise das Áreas de Proteção Ambiental Enquanto Instrumento da Política Nacional do Meio Ambiente: O Caso da APA Corumbataí - SP - São Carlos. 216p. Dissertação (Mestrado) - Escola de Engenharia de São Carlos, Universidade de São Paulo.

ASSAD, E. D. et al (1993) - Estruturação de Dados Geoambientais no Contexto de Microbacia Hidrográfica. In: ASSAD, E.D.\& SANO, E.E. (Coord.). Sistema de Informações Geográficas: Aplicações na Agricultura. Planaltina: EMBRAPA, CPAC. p.89-108.

ASSOCIAÇÃO BRASILEIRA DE NORMAS TÉCNICAS(1998). NBR 14.166 Rede de Referência Cadastral Municipal - Procedimento - São Paulo - SP. $23 \mathrm{p}$.

BERTONI, J.; LOMBARDI NETO, F. (1999) - Conservação do Solo - São Paulo. Ícone, $4^{\mathrm{a}}$ edição. 355p.

BOTELHO, R. G. M. (1999) - Planejamento Ambiental em Microbacia Hidrográfica - In: GERRA, A. J. T. et al (1999) Erosão e Conservação dos Solos: Conceitos, Temas e Aplicações - Rio de Janeiro: Bertrand Brasil. p.269-300.

BRASIL, Leis. (1981) - Lei 6.938 de 31 de agosto de 1981 - Política Nacional do Meio Ambiente. 
BRASIL, Leis (1985) - Ministério do Desenvolvimento Urbano e Meio Ambiente. Conselho Nacional do Meio Ambiente. Resolução n004 de 18 de setembro de 1985. Diário Oficial da União, Brasília, DF.

BRASIL, Leis. (1988) - Ministério do Desenvolvimento Urbano e Meio Ambiente. Conselho Nacional do Meio Ambiente. Resolução n⿳010 de 14 de dezembro de 1988. Diário Oficial da União, Brasília, DF.

BRASIL, Leis. (1989) - Lei 4.771 de 15 de setembro de 1965, alterado pelas leis 7.803/89 e 7.875/89 - Código Florestal Brasileiro.

BRASIL, Leis. (1990) - Decreto 99.274 de 6 de junho de 1990. Regulamenta a Lei 6.902 e a Lei 6.938.

BRASIL, Leis. (1991) - Lei 7.663 de 30 de dezembro de 1991 - Política Estadual de Recursos Hídricos e o Sistema Integrado de Gerenciamento de Recursos Hídricos.

BRASIL, Leis. (1997) - Lei 9.433 de 8 de janeiro de 1997 - Política Nacional de Recursos Hídricos.

BRASIL. IBGE (Fundação Instituto Brasileiro de Geografia e Estatística) (1994) Mapa de Unidades de Conservação Federais do Brasil - Rio de Janeiro, RJ. Escala 1:5.000.000. Colorida.

BUFON, A. G. M. (1999) - Variação Temporal da Taxa de Sedimentação na Represa Velha (CEPTA/IBAMA/SP) e sua Influência sobre as Características Limnológicas do Sistema. Um Estudo de Impacto Ambiental. Pirassununga. Faculdade de Engenharia de Agrimensura de Pirassununga. 85p. (Monografia).

BURROUGH, P. A. (1986) - Principles of Geographic Information Systems for Land Resources Assessment - Oxford, Oxford University Press, 193p.

CALIJURI, M. L. \& ROHM, S. A. (1994) - Sistemas de Informações Geográficas - Viçosa, Minas Gerais. Imprensa Universitária, Universidade Federal de Viçosa UFV, 34p.

CALIJURI, M. L. (1995) - Sistemas de Informações Geográficas II - Viçosa, Minas Gerais. Imprensa Universitária, Universidade Federal de Viçosa - UFV, 40p.

CALIJURI, M. L. (1997) - Apostila de Sistemas de Informações Geográficas Aplicado ao Programa de Pós Graduação em Engenharia Civil. Viçosa, Minas Gerais. Universidade Federal de Viçosa - UFV, 102p.

CÂMARA, G.; MEDEIROS, J. S. (1996) - Geoprocessamento Para Projetos Ambientais - Instituto Nacional de Pesquisas Espaciais (INPE). São José dos Campos, SP. 139p. 
CARVAlHO, I. C. M. (1992) - Educação, Meio Ambiente e Ação Política. In: ACSELRAD, H. (1992) - Meio Ambiente e Democracia - Editora IBASE (Instituto Brasileiro de Análises Sociais e Econômicas). Botafogo, Rio de Janeiro. $127 \mathrm{p}$.

CERUCCI, M. (1998) - A Análise da Eficácia do EPIA Quanto a Aplicação de Metodologias para a Localização de Empreendimentos. São Carlos. 128p. Dissertação (Mestrado) - Escola de Engenharia de São Carlos, Universidade de São Paulo.

CHAVES, E. E. D. (1998) - Análise da Qualidade de Dados Georeferenciados Utilizando a Tecnologia GPS. São Carlos.174p. Dissertação (Mestrado) - Escola de Engenharia de São Carlos, Universidade de São Paulo.

CHAVES, E. E. D.; SEGANTINE, P. C. L. (1997) - Aplicações do GPS em SIG In XVIII Congresso Brasileiro de Cartografia. Rio de Janeiro - RJ.

CHRISMAN, N. (1997) - Exploring Geographic Information Systems - John Wiley \& Sons, New York, 298p.

CORDINI, J. et al (1999) - Transformações de Referenciais Geodésicos - In: V Congresso e Feira para Usuários de Geoprocessamento da América Latina (GIS Brasil 99) - Salvador, BA, 1999. Anais.

COWEN, D. J. (1988) - GIS Versus CAD Versus DBMS: What are the Differences. Photogrammetric Engineering and Remote Sensing. 54: 1551-4.

D’ALGE, J. C. L. (1999) - Coordenadas Geodésicas e Sistemas de Informações Geográfica - In: V Congresso e Feira para Usuários de Geoprocessamento da América Latina (GIS Brasil 99) - Salvador, BA, 1999. Anais.

DANA, P. H. (1994) - The Geographer's Craft Project Department of Geography The University of Texas at Austin. http://www.utexas.edu/depts/grg/gcraft/notes/gps/gps.html. (5 ago 1999).

DAVIS JR, C. (1999) - Introdução ao GIS: Conceitos e Aplicações - Apostila Curso - ExpoGEO Brasil 99. 185p.

DAVIS JR, C. A. \& FONSECA, F. T. (1994) - Geração de Dados em CAD para Uso em GIS: Precauções - In: GIS BRASIL 94. Curitiba, PR. Anais. p.43-47.

DIEGUES, A. C. S. (1993) - Populações Tradicionais em Unidades de Conservação: o Mito Moderno da Natureza Intocada - Série Documentos e Relatórios de Pesquisa n. 21. NUPAUB/CEMAR/USP, São Paulo, SP. 281p.

DONZELI, P. P. et al (1992) - Técnicas de Sensoriamento Remoto Aplicadas ao Diagnóstico Básico para Planejamento e Monitoramento de Microbacias Hidrográficas - Campinas, IAC, set. 1992. p.91-119 (PRE). 
EASTMAN, J. R. (1998) - IDRISI For Windows v 2.0: Manual do Usuário Introdução e Exercícios Tutoriais. Editores da Versão em Português, Heinrinch Hasenack e Eliseu Weber. Porto Alegre - RS, UFRGS Centro de Recursos Idrisi. $235 \mathrm{p}$.

ESRI (1999) - Como Funciona um SIG - Octopus - Sistema e Informação Geográfica Ltda http://www.octopus.pt/sig/index.html. (11 dez 1999).

FATORGIS (2000) - EUA Anunciam Fim da Degradação Intencional do Sinal GPS. http://www.fatorgis.com.br/noticias/exibe.cgi?fNoticia=545\&grupo=1 $(2$ maio 2000).

FELDMANN, F. (1997) - A Caminho da Sustentabilidade: Gestão Ambiental e Cidadania. Anais - I Encontro para Conservação da Natureza. Viçosa, Minas Gerais. Universidade Federal de Viçosa - UFV - 21 a 24 de setembro de 1997, p.221 a 249 .

FERRARI, R. (1996) - Cenários Alternativos para o Uso de GIS em Municípios In: GIS BRASIL 96, 1996. Anais. Curitiba, Sagres, p17-24.

FREICHO, D. M. B. (1996) - Métodos de Posicionamento GPS - Viçosa: Setor de Engenharia de Agrimensura. Departamento de Engenharia Civil, Universidade Federal de Viçosa.

FUCHS, R. B. H.(1986) - Avaliação do Uso da Terra, por Classe de Declividade, na Sub-bacia Hidrográfica do Rio Vacacaí-Mirim - RS. Santa Maria - RS. Monografia (Curso de Especialização - CEIIOSO). Universidade Federal de Santa Maria. 56p.

GANZELI, J. P. (1995) - Aspectos Ambientais do Planejamento dos Recursos Hidrícos: A Bacia do Rio Piracicaba. In: TAUK, S. M. (Organizadora). Análise Ambiental: Uma Visão Multidisciplinar - Editora UNESP. p.134-140.

GRIFFITH, J.J. et al. (1995) - Roteiro Metodológico para Zoneamento de Áreas de Proteção Ambiental. Viçosa, Universidade Federal de Viçosa/IBAMA/Programa Nacional de Meio Ambiente, 37p. (Projeto BRA/90/010, Documento Final).

GRIGG, N. S. (1997) - Systemic Analysis of Urban Water Supply and Growth Management. - Journal of Urban Planning and Development. v. 123, n 2. p.2333.

GUERRA, A. J. T. (1999) - Planejamento Ambiental em Microbacia Hidrográfica In: GERRA, A. J. T. et al (1999) Erosão e Conservação dos Solos: Conceitos, Temas e Aplicações - Rio de Janeiro: Bertrand Brasil. p.17-50.

GUIMARÃES FILHO, H.A. \& CRÓSTA, A.P. (1993) - Digitalização de Mapas. In Simpósio Brasileiro de Sensoriamento Remoto, VII., 1993. Anais. SBSR, p.351-358. 
HOFMANN-WELLENHOF, B. et al (1997) - GPS Theory and Practice Springer-Verlag, Fourth, revised edition. Vienna. 389p.

IBGE (Instituto Brasileiro de Geografia e Estatística) (1996) - Contagem da População - Rio de Janeiro - RJ.

IBGE (Instituto Brasileiro de Geografia e Estatística) (1997) - Sistema de Referência Geocêntrico para a América do Sul: Relatório Final - Grupos de Trabalho I e II. Departamento de Geodésica. Rio de Janeiro, RJ. 99p.

JONES, C. B. (1997) - Geographical Information Systems and Computer Cartography - Longman. 319p.

KENNEDY, M. (1996) - The Global Positioning System and GIS: An Introduction - Ann Arbor Press. Chelsea, Michigan, 268p.

KLEINER, R. M.; MENEGUETE, A. A. C. (1999) - Geração de Base de Dados Espaciais para SIG Empregando Fotolitos ou Cartas em Papel - In: V Congresso e Feira para Usuários de Geoprocessamento da América Latina (GIS Brasil 99) - Salvador, BA, 1999. Anais.

KURTZ, F. C. et al (1999) - Aplicação do SIG no Zoneamento Ambiental da Estação Ecológica da Taim - In: V Congresso e Feira para Usuários de Geoprocessamento da América Latina (GIS Brasil 99) - Salvador, BA, 1999. Anais.

LEICK, A. (1991) - La Interrelácion GPS/GIS. Revista Cartográfica do Instituto Panamericano de Geografia e História, n. 59, p.89-92.

MACHLIS, G. E. \& TICHNELL, D. L. (1985) - The State of the World's Parks $\mathrm{Na}$ International Assentement for Resource Manegement, Policy and Research. Westview Press, USA, 131p.

MADRUGA, P. R. de A.; PEREIRA, R. S. (1991) - Sistema de Informação Geográfica Aplicada à Área Florestal - Uma Proposta Metodológica. Tópico Especial Apresentado ao Curso de Pós-Graduação em Engenharia Florestal. UFPR. Curitiba. 145p.

MATTOS, C. O. (1996) - Contribuição ao Planejamento e Gestão da Área de Proteção Ambiental de Sousas e Joaquim Egídio, Campinas/SP - São Paulo. 235p. Dissertação (Mestrado) - Instituto de Biociências, Universidade de São Paulo.

MEDINILHA, A. (1999) - A Degradação da Mata Ciliar e os Impactos nos Recursos Hídricos Desencadeados pela Expansão Urbana de Rio Claro-SP no Entorno do Rio Corumbataí. - São Carlos. 181p. Dissertação (Mestrado) Escola de Engenharia de São Carlos, Universidade de São Paulo. 
MELLO, H. M. C. F. \& CINTRA, J. P. (1993) - Erros Associados à Digitalização de Mapas - In: II Simpósio Brasileiro de Geoprocessamento. São Paulo, SP. Anais. p.30-46.

MERICO, L. F. K. (1996) - Introdução à Economia Ecológica - Editora da FURB. Blumenau, Santa Catarina. 160p.

NAGAMI, T. (1993) Oportunidades de Inversion en Áreas Protegidas. In: BARZETT, V. (ed.) Parques y Progresso: Áreas Protegidas y Desarrollo Econômico en América Latina y el Caribe. UICN, Washington, USA: 202-232.

NASCIMENTO, V. M. C. (1994) - Caracterização Limnológica e Efeito dos Vários Usos do Solo na Qualidade da Água do Córrego da Barrinha, Pirassununga/SP. - Brasília. 115p. Dissertação (Mestrado) - Universidade de Brasília, Instituto de Ciências Biológicas, Departamento de Ecologia.

NETO, N. P. (1997) - Apostila de Sistema Topográfico Local - Aplicada na Disciplina PTR 761 (Tópicos Avançados de Geodésia e Projeção Cartográfica). São Paulo, SP. Escola Politécnica da Universidade de São Paulo - USP, 71p.

OLIVEIRA, C. (1983). In: Dicionário Cartográfico (1983). - Rio de Janeiro. IBGE (Fundação Instituto Brasileiro de Geografia e Estatística) 164p.

OSW (1994) - Leica - Open Survey World

PAVESI, A. (1998) - Poderação dos Fatores Ambientais na Localização de Áreas Irrigáveis e na Cobrança do Uso da Água para Irrigação. São Carlos. 125p. Dissertação (Mestrado) - Escola de Engenharia de São Carlos, Universidade de São Paulo.

PRADO, R. B. (1999) - Influência do Uso e Ocupação do Solo na Qualidade da Água: Estudo no Médio Pardo - SP (período de 1985 a 1997). - São Carlos. 209p. Dissertação (Mestrado) - - Escola de Engenharia de São Carlos, Universidade de São Paulo.

RAMALHO FILHO, A. \& BEEK, K. J. (1994) - Sistema de Avaliação de Aptidão Agrícola das Terras - 3 ed. ver. - Rio de Janeiro: EMBRAPA-CNPS. 65p.

RANIERI, S. B.L. (1996) - Avaliação de Métodos e Escalas de Trabalho para Determinação de Risco de Erosão em Bacia Hidrográfica Utilizando Sistema de Informações Geográficas (SIG). São Carlos. 128p. Dissertação (Mestrado) Escola de Engenharia de São Carlos, Universidade de São Paulo.

REZENDE, A. V. (1998) - In: RIBEIRO, J. F. ed. Cerrado: Matas de Galeria Planaltina: Embrapa-CPAC, DF. p.3-15. 
ROSA, S. S. et al (1981) - Mapeamento, Quantificação e Análise do Uso da Terra por Classes de Declividade, nas Microbacias do Arroio Catanduva e Sanga da Taquara no Município de São Pedro do Sul - RS. - Departamento de Engenharia Rural (UFSM - Universidade Federal de Santa Maria - RS). 41p.

SANTOS, N. A. dos \& SOUSA-SILVA, J. C. (1998) - In: RIBEIRO, J. F. ed. Cerrado: Matas de Galeria - Planaltina: Embrapa-CPAC, DF. p.157-162.

SCHIAVETTI, A. (1997) - Proposta de Zoneamento Recreativo para o Parque Estadual dos Mananciais de Campos do Jordão: Subsídios para o Plano de Manejo. São Carlos. 81p. Dissertação (Mestrado) - Escola de Engenharia de São Carlos, Universidade de São Paulo.

SEGANTINE, P. C. L. (1998) -GPS Sistema de Posicionamento Global - Apostila. São Carlos. STT/EESC/USP, 177p.

SEMA (1988) - Coordenadoria de Áreas de Proteção Ambiental (2 ed.) Caracterização e Diretrizes Gerais de Uso da APA do Rio São Bartolomeu Escala de 1:100.000. Brasília. V. 1, 53p.

SILVA, A. S. (1997) - Apostila de GPS (Global Positioning System) - Aplicada ao Curso de Engenharia de Agrimensura. Viçosa, Minas Gerais. Universidade Federal de Viçosa - UFV, 117 p.

SILVA, R. M. da (1997) - Processos de Vetorização para uso em SIG (Sistemas de Informações Geográfica) - Monografia apresentada ao Curso de Graduação em Engenharia de Agrimensura. Viçosa, Minas Gerais - Universidade Federal de Viçosa - UFV, 31p.

SILVA, R. M. da et al (1998) - Planejamento de Recursos Hídricos: Um Enfoque Regional. Trabalho Apresentado à Disciplina Tópicos Especiais em Ciências Ambientais. EESC/CRHEA/USP.

SMA (Secretaria do Meio Ambiente do Estado de São Paulo) (1998) - Atlas das Unidades de Conservação Ambiental do Estado de São Paulo, parte II: Interior. São Paulo: Metalivros.

SOUZA, P. H. (1998) - O Uso do SIG na Ponderação de Fatores Ambientais para a Proposição de Zoneamento para Distritos Industriais. São Carlos. 183p. Dissertação (Mestrado) - Escola de Engenharia de São Carlos, Universidade de São Paulo.

STRANG, H. E. (1977) - Conservação do Meio Ambiente. Rio de Janeiro. IBGE. $63 p$.

TEIXEIRA, A. L. \& A., CHRISTOFOLETTI (1997) - Sistemas de Informação Geográfica (Dicionário Ilustrado) - Editora Hucitec, 244p. 
THUM, A. B. (1997) - Uso de Sistema de Informações Geográficas (SIG) na Determinação das Potencialidades de Zonas Propícias a Criação de Áreas de Proteção Ambiental (APA's) - Monografia Apresentada ao Curso de Especialização em Interpretação de Imagens Orbitais e Suborbitais. Santa Maria, R.G.S. - Universidade Federal de Santa Maria - UFSM, 54p.

TOLBA, M. K. (1987) - Sustainable Development Constraints and Oportunities. London, Butterworth.

UNIÃO INTERNACIONAL PARA A CONSERVAÇÃO DA NATUREZA E DOS RECURSOS NATURAIS (UICN) (1984). Estratégia Mundial para a Conservação: a conservação dos recursos vivos para um desenvolvimento sustentado. II SP, CESP, 20 seções.

UNIÃO INTERNACIONAL PARA A CONSERVAÇÃO DA NATUREZA E DOS RECURSOS NATURAIS (UICN) (1986) - Managing Protected Areas in the Tropics. Gland, Switzerland. 295p.

VERONEZ, M. R. (1998) - Proposta de Parâmetros de Transformação entre os Sistemas WGS-84 e o SAD-69 para Região de São Carlos-SP. -São Carlos. 113p. Dissertação (Mestrado) - Escola de Engenharia de São Carlos, Universidade de São Paulo.

VILlELA, S. M. \& MATTOS, A. (1975) - Hidrologia Aplicada - São Paulo. McGraw-Hill do Brasil. 245p.

WEBER, E.; HASENACK, H. (1998) - Análise de Alternativas de Traçado de um Gasoduto Utilizando Rotinas de Apoio à Decisão em GIS. http//www.fatorgis.com.br. (17 out 1998).

YOUNG, A. F.; ROCHA, J. V. (1999) - Análise das Condições Ambientais de Microbacias Utilizando SIG - Sistemas de Informações Geográficas - In: V Congresso e Feira para Usuários de Geoprocessamento da América Latina (GIS Brasil 99) - Salvador, BA, 1999. Anais.

ZAKIA, M. J. B. (1998) - Identificação e Caracterização da Zona Ripária em uma Microbacia Experimental: Implicações no Manejo de Bacias Hidrográficas e na Recomposição de Florestas. São Carlos. 98p. Tese (Doutorado) - Escola de Engenharia de São Carlos, Universidade de São Paulo. 


\section{9 - ANEXOS}

FÓRMULAS DE TRANSFORMAÇÃO DE COORDENADAS GEOGRÁFICAS GEODÉSICAS EM COORDENADAS PLANORETANGULARES NO SISTEMA TOPOGRÁFICO LOCAL

É importante mencionar que, na aplicação das fórmulas, considerar a latitude negativa no hemisfério sul e a longitude crescendo positivamente para o oeste.

Os coeficientes $C$ e $D$ são negativos no hemisfério sul.

$O$ eixo das ordenadas é o eixo dos $Y$ e o das abscissas é o $X$.

O formulário a ser apresentado é baseado segundo a NBR 14166:

$$
\begin{aligned}
& X_{p}=150.000+x_{p} \\
& Y_{p}=250.000+y_{p} \\
& x_{p}=-\Delta \lambda_{1} \cdot \cos \phi_{p} \cdot N_{p} \cdot \operatorname{sen} 1^{\prime \prime} \cdot c \\
& y_{p}=\frac{1}{B} \cdot\left[\Delta \phi_{1}+C \cdot x_{p}^{2}+D \cdot\left(\Delta \phi_{1}\right)^{2}+E \cdot\left(\Delta \phi_{1}\right) \cdot x_{p}^{2}+E \cdot C \cdot x_{p}^{4}\right] \cdot c \\
& \Delta \lambda=\lambda_{p}-\lambda_{0} \\
& \Delta \phi=\phi_{p}-\phi_{0} \\
& \Delta \lambda_{1}=\Delta \lambda^{\prime \prime} \cdot\left[1-3,9173 \cdot 10^{-12} \cdot\left(\Delta \lambda^{\prime \prime}\right)^{2}\right] \\
& \Delta \phi_{1}=\Delta \phi^{\prime \prime} \cdot\left[1-3,9173 \cdot 10^{-12} \cdot\left(\Delta \phi^{\prime \prime}\right)^{2}\right] \\
& B=\frac{1}{M_{0} \cdot \operatorname{sen} 1 "}
\end{aligned}
$$




$$
\begin{aligned}
C & =\frac{\operatorname{tg} \phi_{0}}{2 \cdot M_{0} \cdot N_{0} \cdot \operatorname{sen} 1 "} \\
D & =\frac{3 \cdot e^{2} \cdot \operatorname{sen} \phi_{0} \cdot \cos \phi_{0} \cdot \operatorname{sen} 1 "}{2 \cdot\left(1-e^{2} \cdot \operatorname{sen}^{2} \phi_{0}\right)} \\
E & =\frac{1+3 \cdot \operatorname{tg} \phi_{0}}{6 \cdot N_{0}^{2}} \\
C & =\frac{R_{0}+H_{t}}{R_{0}} \\
R_{0}=\sqrt{M_{0} \cdot N_{0}} & a \cdot\left(1-e^{2}\right) \\
M_{0}= & \frac{a}{\left(1-e^{2} \cdot \operatorname{sen}^{2} \phi_{0}\right)^{3 / 2}} \\
N_{0}= & \frac{a}{\left(1-e^{2} \cdot \operatorname{sen}^{2} \phi_{0}\right)^{0,5}} \\
N_{p}= & \frac{a}{\left(1-e^{2} \cdot \operatorname{sen}^{2} \phi_{p}\right)^{0,5}} \\
& =\left(\frac{a^{2}-b^{2}}{a^{2}}\right)^{0,5}=[f \cdot(2-f)]^{0,5}
\end{aligned}
$$

onde:

$\checkmark \quad M_{0}$ corresponde ao raio de curvatura da seção meridiana do elipsóide de referência em $P_{0}$ (origem do sistema);

$\checkmark \quad N_{0}$ corresponde ao raio de curvatura da seção normal ao plano meridiano do elipsóide de referência em $P_{0}$;

$\checkmark \quad N_{\mathrm{p}}$ corresponde ao raio de curvatura da seção normal ao plano meridiano do elipsóide de referência em $P$;

$\checkmark \quad c$ corresponde ao fator de elevação;

$\checkmark " a "$ corresponde ao semi-eixo maior do elipsóide de referência;

$\checkmark " b "$ corresponde ao semi-eixo menor do elipsóide de referência;

$\checkmark$ "e" corresponde a primeira excentricidade do elipsóide de referência; 
$\checkmark " f "$ corresponde ao achatamento do elipsóide de referência;

$\checkmark \quad H_{\mathrm{t}}$ corresponde a altitude ortométrica média do terreno ou altitude do plano topográfico local. 


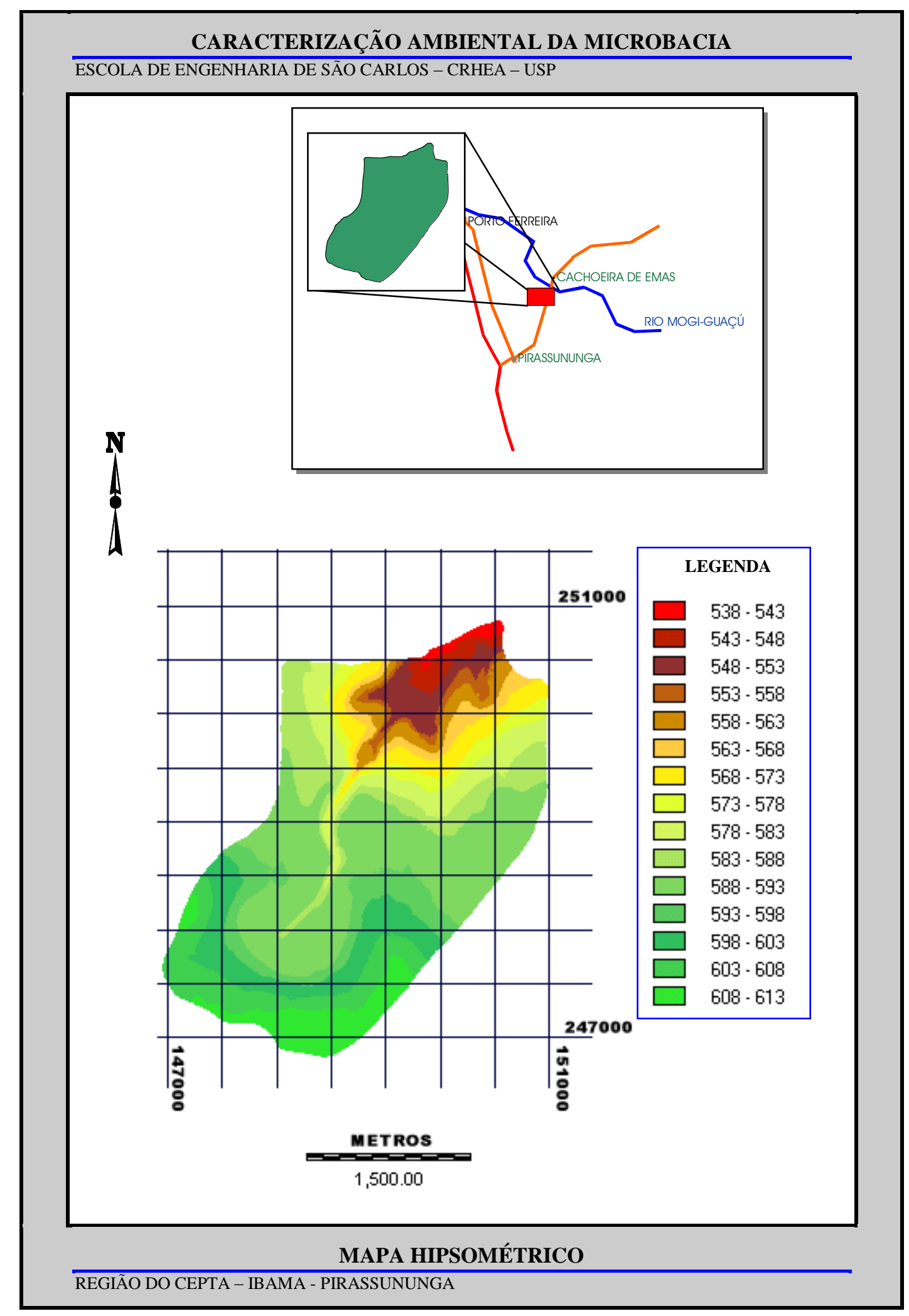




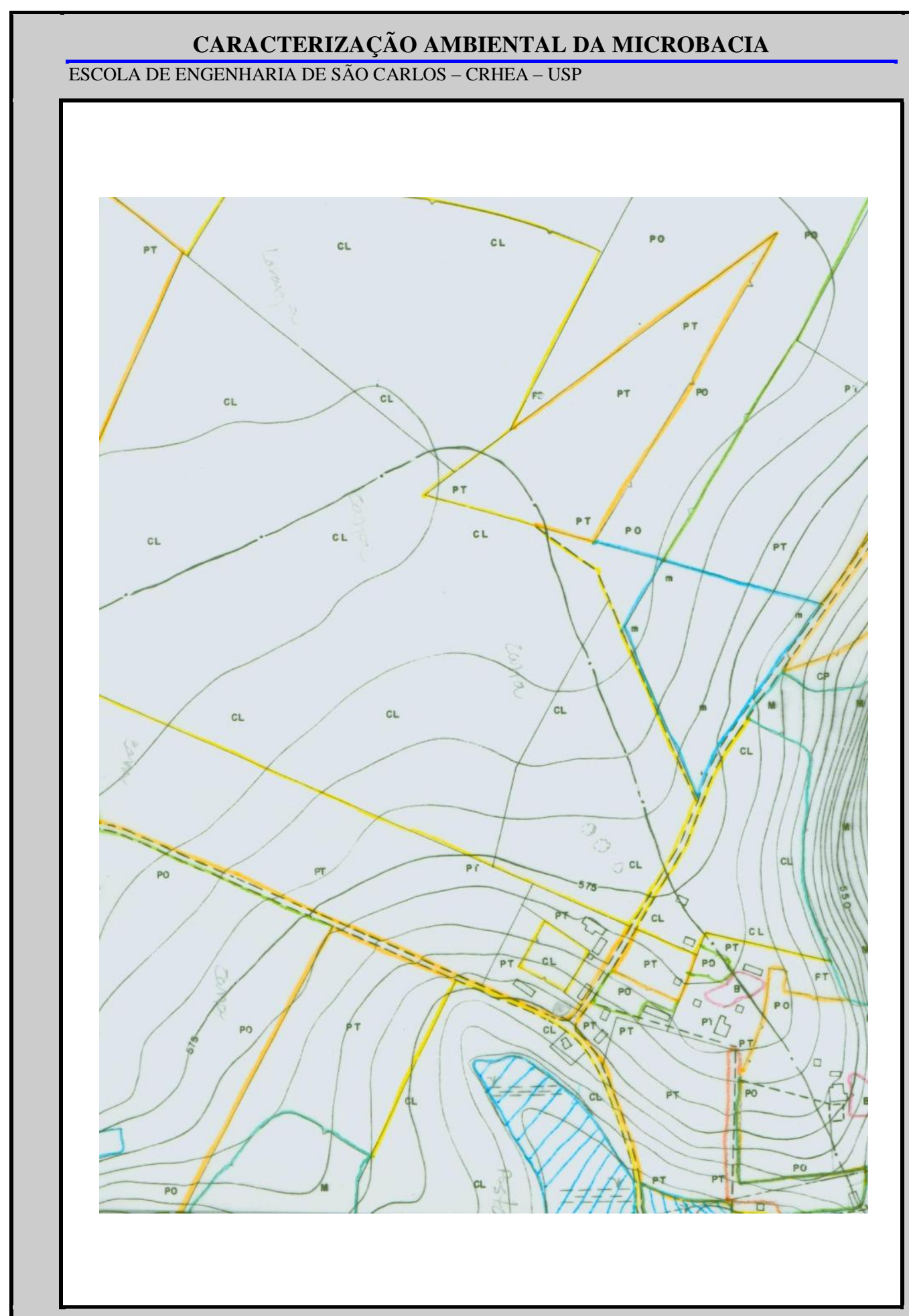

PARTE DO MAPA DA ÁREA DE ESTUDO UTILIZADO NA DIGITALIZAÇÃO REGIÃO DO CEPTA - IBAMA - PIRASSUNUNGA 